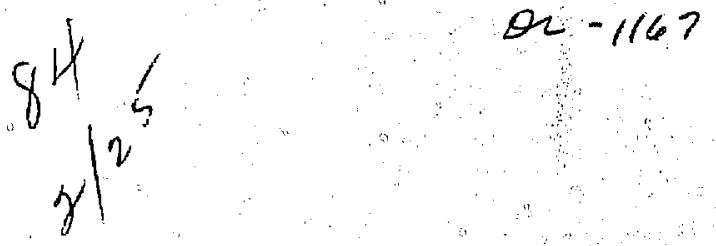

UCRL-51710

\title{
BNERGETIC ELECTRONS IN THE NNER BELT IN 1968: FITS TO LAWRENCE LUERMORE LABORATORY'S MAGNETIC ELECTRON SPECTROMETER DATA OBTAINED ON OGO-5
}

\author{
R. M. Buck
}

H, I. West, Jr.

December 2, 1974

\section{Prepared for U.S. Atomic Energy Commissionunder contract No. W-7405-Eng-48}
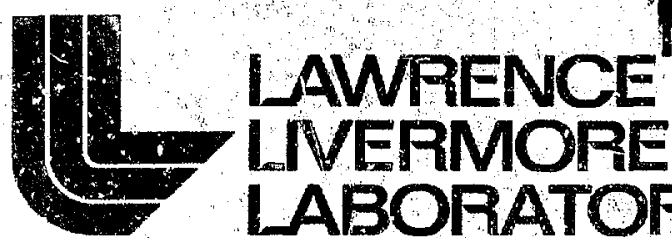

LABORATORY

University of Califomia/Livermore
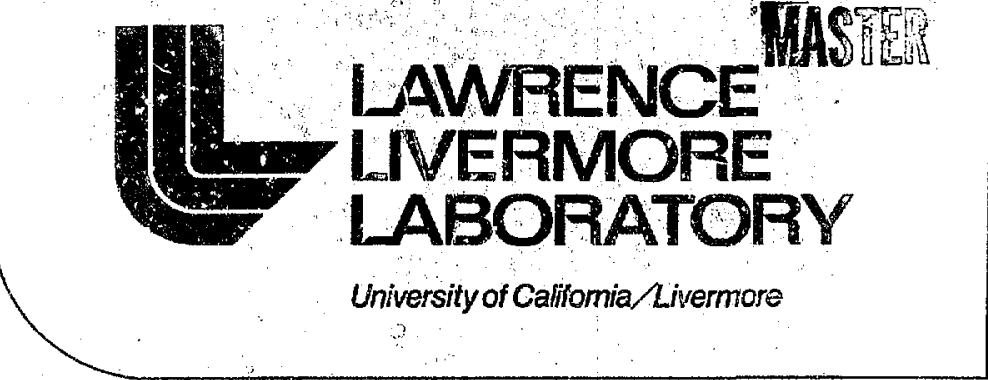


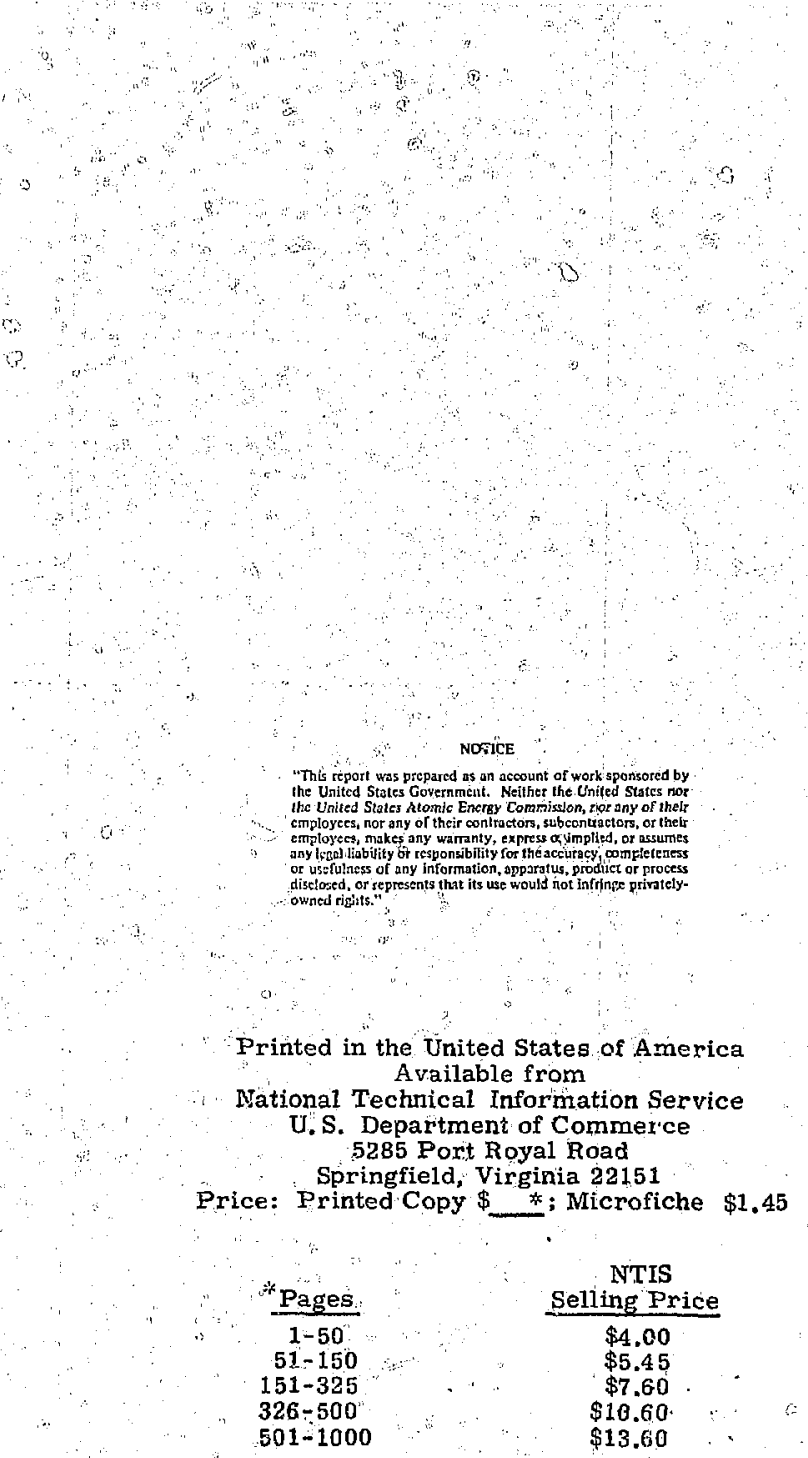


TLD-4500, $\mathrm{LC}-34 \mathrm{~b}$

Physics - Cosmic and

Terrestrial

\title{
迎 \\ LAWRENCE LNERMORE LABORATOAY

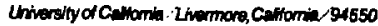

\author{
UCRL- 51710
}

\section{ENERGETIC ELECTRONS IN THE INER BELT IN 1968: FITS TO LAWRENCE LIVERMORE LABORATORY'S MAGNETIC ELECTRON SPECTROMETER DATA OBTAINED ON OGO-5}

R. M, Buck

H. 1. West, Jr.

MS date: December 2, 1974

This teport was prepatice oponeored by the Uniled Status Gover nment. Neither the Utuled States nor the Utuled States Energy Research and Development Adtrinisiration, nof any of thelr employes, nor any of their contractors, subcontretor, of their cmployecs, nakes any subcontractors, of thei cmployecs, nokes any

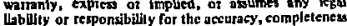
or ukfulnes of any information, apparatus, product as process dicclosed, of represents that its use would nol Infinge privately owned ights.

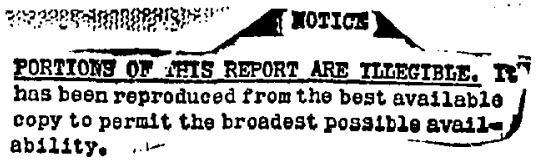




\section{Contents}

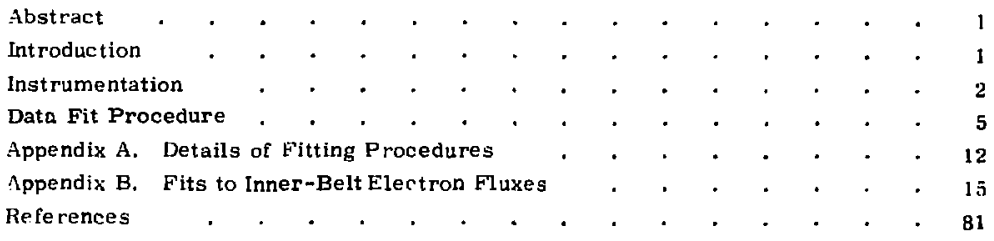




\title{
ENERGETIC ELECTRONS IN THE INNER BELT IN 1968: FITS TO LAWRENCE LIVERMORE LABORATORY'S MAGNETIC ELECTRON SPECTROMETER DATA OBTAINED ON? OGO-5
}

\begin{abstract}
Pitch-angle data were sbtained by the Jawrence Livernmre l,aboratory's lowest-energs chamels, 79-822 keV, were analyzed in terms of time decay magnetic olectron spertuneter on OGO-5 during its traversats of the J vs invariant latitude at constant $L$. This document contain the details of inner radiation belt Mlarch $196 \mathrm{G}$ lurough January 1465. Data Crom the five ritting the data at $L=1.3 .1 .35,1.4$, 1.5 , etc. to 2.4 .
\end{abstract}

\section{Introduction}

Prior to the starlish higli-altitude nuclear detonation on July 9, 1962 our knowledge of the eicctron Ruxes in the inner belt was rither incomplete. Mast of our knowledge is sonlained in studies done by Pizzellu at al. ${ }^{1,2}$ and Plzzella. 3 Unfortunately, the'Bo data suffered from problems inherent to this early exploratory period; backgrounds from per etrating, highenergy protons mate neasurements oi electrons inaccurate; calibrations were all too often performed after the fast; and a proper system of coordinates $(B, L)$ had not been developied. The Starfish detonation of July 9, 1962 over Johnson Island injected large amounts of high-t?nergy flssiondecay electrons into the radiation belts. Because the decay mean-lives varied rapidly with location (from times on the order of a year in the inner belt to days for $L>2.5$ ) the residual from the Starfish injection was confined largely to the inner belt after 1962. Some of the carly Starfish measurements were reported in the collected works int roduced by Brown el al.

Only one post siarlish experiment really dies the tine varlations together (1963-1968), the experinient of Beall et al. ${ }^{5}$ and Hostrom et al. ${ }^{6}$ on satellite 1963-38C. This experiment. consisting of solid-stute detectors. provided thresholds at 0.28, 1.2, and $2.4 \mathrm{Mlel}$. In Fig. 1, we show their data obtained for energies $>0.28 \mathrm{MeV}$.

The most complete prior study of the equatorial nuxes in the inner belt is that of the University of Minnesota group (Pfitzer, Kane, and Winkler). ${ }^{7-10}$ They made measurements on $\mathrm{OGO}^{\prime} \mathrm{s} 1$ and 3 covering the time period from September t964 to December 1967. Their measurements were made with magnetic electron spect rometers ( 5 channels) cove ring the 


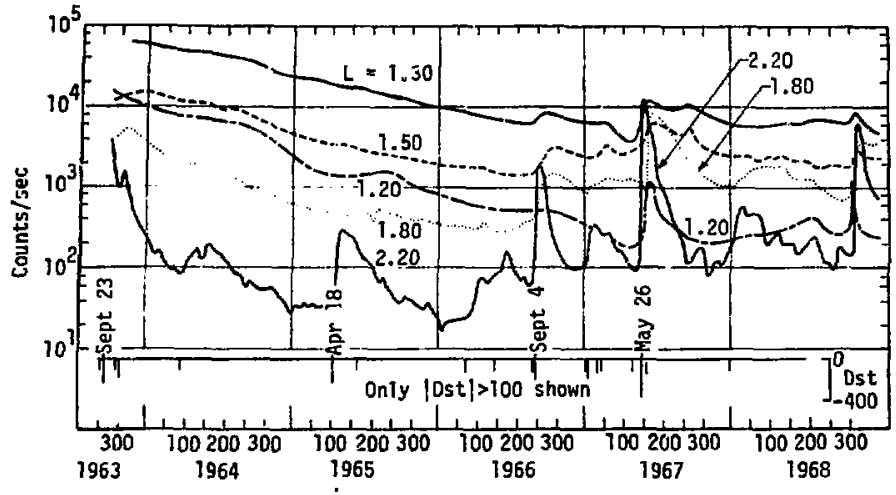

Fig. 1. lnner-belt electrons $>0.28 \mathrm{MeV}$ obtanned on satellite $1963-38 \mathrm{C}$ in the period $1963-1968$, after Bostrom et al. 6 The geometrical factor is $2.8 \times 10^{-3} \mathrm{~cm}^{2}-\mathrm{sr}$. These data provide a useful overview of the period covering our 0GO- 5 data and earlier times.

range from 50 to 4000 keV. They organlzed their data in terms of equatorial pitch angle since they had found that for a glven $\mathrm{L}$-shell $(\mathrm{L}<2.4$ ), the pitch-angle distribution was largely independent of energy. Once the equatorial pitch-angle distribution is obtained one can transform to the equator, and henceforth, talk only about the equatorial nuxes. We adopt this procedure in the present work. However, there are some finite energydependent effects, as we shell see.

We have obtainad inner-belt data on the OGO-5 satellite cove ring the lime perlod from launch, March 4, 1968, into early 1969. At launch, OGO-5 had a perigee of a few hundred kilometer's. 13y May 1960, perigee had risen to an equatorial L-shell of 2.5; hence, our coverage was largely limited to 1968 . A fairly quiet period, in te rms of inne r-belt dynamics, existed up to the times of the major inner-belt injection during the magnetic storms of October 31 and November 1, which has allowed us to conside $r$ the electron decay (for $L<2$ ) as exponential for this period. A mild storm occurred June 11 that caused injection effects for the higher-energs channels on the higher L-shells; this caused some minor complteations in the analysis. The results of our studies and their comparison with other data, pre- and post-Starfish, are reported in detail by West and Buck.: It is the purpose of this report to document the details of the reduction of the 0GO- 5 data.

\section{Instrumentation}

The instrument is described in detail by West et al. 12 Brieny the instrument consisted of two small magnetic electron spectrometers located on a boom on the 
Table 1. Spectromete $\mathbf{r}$ characte ristics.

\begin{tabular}{cccc}
\hline Channel & $\begin{array}{c}\text { Electron } \\
\text { energy range } \\
(\mathrm{keV})\end{array}$ & $\begin{array}{c}\text { Geametry } \\
\left(\mathrm{cm}^{2}-\mathrm{keV}-\mathrm{sr}\right)\end{array}$ & $\begin{array}{c}\text { Acceptance } \\
\text { angle } \\
(\text { deg) }\end{array}$ \\
\hline $\mathrm{E}_{1}$ & $79 \pm 23$ & 0.180 & 7.6 \\
$\mathrm{E}_{2}$ & $158 \pm 36$ & 0.277 & 5.9 \\
$\mathrm{E}_{3}$ & $265 \pm 36$ & 0.390 & 4.7 \\
$\mathrm{E}_{4}$ & $479 \pm 52$ & 0.605 & 3.5 \\
$\mathrm{E}_{5}$ & $822 \pm 185$ & 4.43 & 5.3 \\
$\mathrm{E}_{6}$ & $1530 \pm 260$ & 8.57 & 4.1 \\
$\mathrm{E}_{7}$ & $2820 \pm 270$ & 3.88 & 2.5 \\
\hline
\end{tabular}

${ }^{\mathrm{a}}$ Effective full width at $50 \%$ acceptance in the scan plane.

OGO- 5 spacecraft. The energy channels $\left(E_{1}-E_{7}\right)$ are listed in Table 1 along wth their respective geometrical factors. Backgrounds we re very carefully evaluated and subtracted from the data. For channels $\mathrm{E}_{3}-\mathrm{E}_{7}$, individual background detectors were provided; the channels $E_{1}-E_{7}$, shared a common background detector. Typical electronto-background ratios in the heart of the inner belt were 100/1, 100/1, 100/1, 40/J, $20 / 1,2 / 1$, and $1.2 / 1$, respective: $y$.

The experiment was scanned relative to the sun-eartlz stabilized spacec rait at $3^{\circ}$; sec through excursions of $\pm 115^{\circ}$ wo obtain pitch-angle information. The experiment scanned so as to view directions perpendicular to the earthsatellite radius vector. An example of the scan-modulated fluxes is shown in Fig. 2. Data were obtained at accumulation times of $4.608,0.576$, and $0.072 \mathrm{sec}$ depending upon the satellite bit rates in use $-1,8$, or $64 \mathrm{kbit} / / \mathrm{sec}$. Although the intrinsic resolution of the spectrometer was less than $10^{\circ}$, the finite data accumulation times caused additional loss of resolution. At the longest accumulation times, the resolution was about $25^{\circ}$. The effect of the finite aperture was to lower the apparent $j$ values and saise the values for lower pitch angles $(\leq 80 \%$. In the interest of consistency, data acquired at higher bit rates we re ave raged to the lower rates (unfortunately the lower-bitrate data formed too large a body of data to be ignored). Corrections" could have been applied to the data at a later time but the scatter of the data in the affected regions at high latitude did not warrant it.

The data were organized in terms of j. values vs $\lambda_{1}$, at constant $L$. The invariant latitude, $\lambda_{I}$. is related to the local magnetic field $B$ by

\footnotetext{
"The procedure is first to fit the data as $j_{1}-v s-\lambda$ on a given L-shell, Then, using the fi: equation, transform to the local pitch-angle distribution. The resolution is then folded inte the pitchangle distribution and the reduction in $j$ gives a good measure of the error in the original $j_{\text {_ measurement. }}$
} 


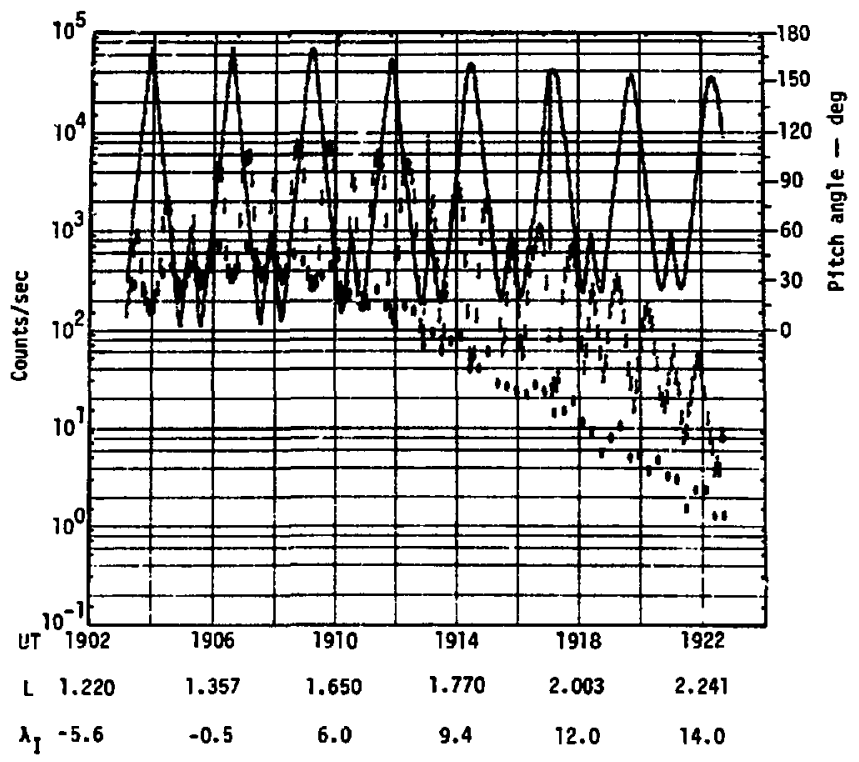

Fig. 2. Scan modulated $E_{5}$ and $E B_{5}$ nuxes obtained on a typical pass through the inner belt. The I's indicate the $E_{5}$ nuxes $(4.6-\mathrm{sec}$ averages) and the $O$ 's indicate $\mathrm{EH}_{\mathrm{j}}$, the backgruund. The pitch angle is given to the right of the plot and was determined using VCLA magnetometer data.

$$
\frac{B}{B_{0}}=\frac{1}{\cos ^{6} \lambda_{I}} \sqrt{4-3 \cos ^{2} \lambda_{I}} \text {. }
$$

where $\mathrm{B}_{0}$ is the equatorial field on the local field line. As such, plotting in terms of $j_{1}-v s-\lambda_{I}$ is equivalent to $\mathrm{j}-\mathrm{vs}-\mathrm{B}$ or $\mathrm{j}-\mathrm{vs}-\mathrm{B} / \mathrm{B}_{0}$, or to $\mathrm{j}(\theta)-v s-$ equatorial pltch angie. We have chosen to use $j_{1}-v s-\lambda_{I}$ because of its immediate physical significance. The $j_{1}$ values we re obtained by interpolating between the peaks in the scan-modulated fluxes such as those of Fig. 2.
The orbital period of OGO-5 was about 2-1/2 days. However, an additional experiment shared our scan platform and at the behest of the experimenters the platform was configured, on alte rnate orbits inside $4 \mathbf{R}_{E}$. into the "gy ro mode" the experiment looked forward into the plane of the orbit. Usually we ignored these data, since all too often the spectrometer was not measuring $j_{-}$fluxes. and used only the scan data. This then gave us two data points per L-shell, one inbound and one outbound, every 5 days. 


\section{Data Fit Procedure}

The mirror-point fluxes on each Lshell were approximated in a least-squares sense by a model which contained both time and space dependence. The model assumed that for a given electron energy,

1) The Iluxes along an L-shell could be represented by a power series in $\lambda_{1}$ at any time;

2) The flux along an L-shell exhibited a simple exponential time decay over the time interval studied.

Because the data we re collected over a period of time which was of the same orde $r$ as the observed decay mean-lives of some belt electrons, it was necessary to include explic it time-dependence in the model.

iT he model used was

$$
\begin{aligned}
\hat{y}= & \exp \left[-\left(t-t_{0}\right) / b_{1}\right] \\
& \times b_{2} \exp \left[\sum_{j} b_{j} \lambda^{2(j-2)}\right], j=3 \text { to } 10,
\end{aligned}
$$

where $\hat{y}$ = perpendicular electron $\boldsymbol{n}_{u x}$ at $\lambda$ (particles $/ \mathrm{cm}^{2}-\mathrm{keV}-\mathrm{sr}-\mathrm{s}$ ).

$t$ = time of year 1968 (days),

$t_{0}=$ initial time, taken as day 69 ,

$\lambda$ = scaled invariant latitude, he reinafter called simply "latitude,"

$\lambda=\lambda_{\mathrm{J}} / 50^{\circ} ; \lambda_{I}$ in degrees.

The b's are coefficlents which we re determined by the least-squares process.

$b_{1}=$ mean-decay life (days) for the epoch day $69-293,1968$.

$b_{2}=$ nux amplitude at $t=t_{0}, \lambda=0$.

$b_{3}-b_{10}=$ latitude coefficients.

A fit was computed for each of the 5 channels over data from each of $13 \mathrm{~L}$ shells. The backward elimination proce- dure was used to determine the optimum number of coefficients in eac: ase. First, a 10-coeficient fit was calculated and a tlest performed on each coefficient to deter mine whether it was significantly different from zero. The least significant coeificient was discarded, and the fit was recalculated using nine coeficients. This process was continued until the smaliest set of coefficients remained that gave a good fit to the data. Details of the fitting procedures and fit statistics and an explanation of printout headings a re given in Appendix $A$.

The simple exponential time-decay of the model is strictly appropriate only for particle populations maintained by steady state sources and sinks. For timevarying conditions, $b_{1}$ represents an average exponential decay life-time for the epoch day 69-293,1968, The lower L-shells $(\mathrm{L}=1.3-1.9)$ were sufficiently quiet during this epoch for the complete model to be independently applied to all channels. It was not possible to determine both time and latitude coefficients concurrently for the higher energy channels (E2-F5) at the tigher L-shells $(L=2,0-2.4)$ be:ause of the disturbarces caused by the October-November magnetic storms. As so, a mild storm (Dst $=-94 \gamma$ ) occurring on day 163 caused major fluctuations in channels E3-E5, and lesser effects in F2. However, F1 showed essentially the same decay lifetime after day 163 as before. The average decay llfetime for the highe $r$ energy channels we re calculated by setting their latitude coefficients equal to the corresponding coefficients for Channel $\mathrm{El}$, 
and allowing only $b_{1}$ and $b_{2}$ to be determined for each channel. This "fit over time only" procedure was successful since the shape of the $j_{-}-v s-\lambda_{I}$ curve is not markedly energy dependent on these higher shells.

In Appendix B, we give plots of (I) the raw $j_{1}-v s-\lambda_{1}$ data, (2) the $j_{\perp}-v s-\lambda_{1}$ data fitted and time-transformed to day 69 , (3) the fluxes transformed to the equator and plotted vs time, and (4) tables covering the fit statistics. The aymbols used on the plots are:

$x^{\prime}=$ input data points accepted for fitting. days 69-293, $f=$ input data points $w$ ith $\lambda>\lambda_{\text {max }}$ and not included in lit,

$0=$ input data points at high $\lambda$,

$T=$ input data points for days greater than 293 ,

$\ldots .$. = calculated fit points.

Note that for the higher $r$-shells the time-independent flux plot shows a fair degree of scatter of the time-transformed data ahout the calculated curve. This means unat the simple exponential decay used in the $E_{1}-f i t$ to determine the latitude coefficients is not adequate for the higher-energy channels on the higher
L-chells. The effect of thi shows in the standard error of the $b_{1}$ and $b_{2}$ coefficients. However, the time-plot curve ( $j$ _equatorial vs days) is properly given subject only to the errors in determining the latitude coefficients in $E_{1}$ and the smull differences that exist in the $j_{-}-v s^{-} \lambda_{I}$ curves as a function of ene rgy \{like $10 \%$ e rrors?. Note that in the time plots, the poins plotted as 0's occasionally show a large scatter: by reforence to the time-independent flux plors, the 0 's can be identified as fallings in the high-latitude skirts of the diatribution and should be ignored.

To give an overview of the data fits we have ove rlaid the time-independent flux plots for each energy as given in Figs. 3 (a), (b), (c), (d), and (e) for energy channels $E_{1}$ through $E_{5}$. In putting togethe $r$ the overlays, small artifacts resulting from limitation in the fitting were removed. The plots show the general consistency in the analysis procedure. Nevertheless, the re are obvious ismall; discrepane ies in the region wi the flux falloff: at high latitudes that symmetry tells us probably are not real. A more complete discussion of these results is given by West and Buck. 


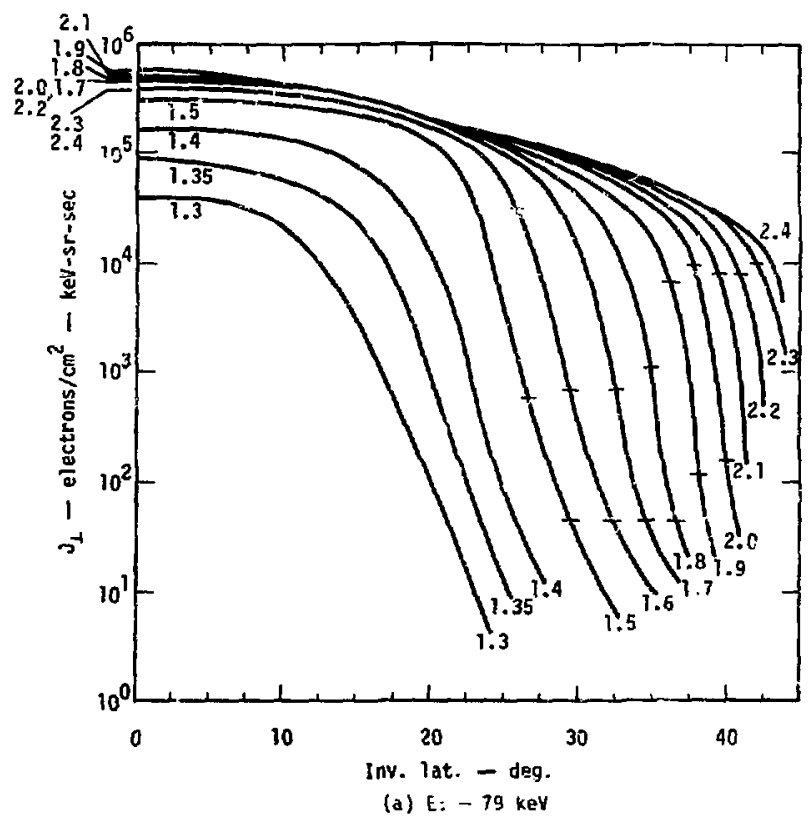

Fig. 3. Plots of $j_{1}-v s-\lambda_{1}$ profiles time-transformed to day 69,1968 . These data provide a summation of the data plots given in Appendix $B$. 


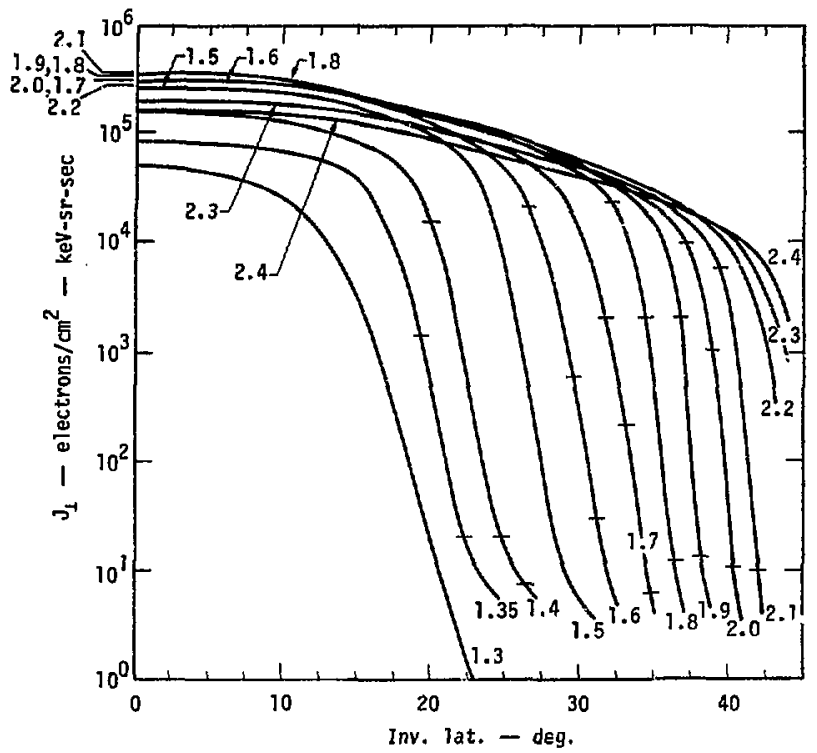

(b) E2 - $158 \mathrm{keV}$

Fig. 3. Plots of $j_{1}-v s-\lambda_{I}$ protiles time-transformed to day 69,1968 . These data provide a summation of the data plots given in Appendix $B$ (continued). 


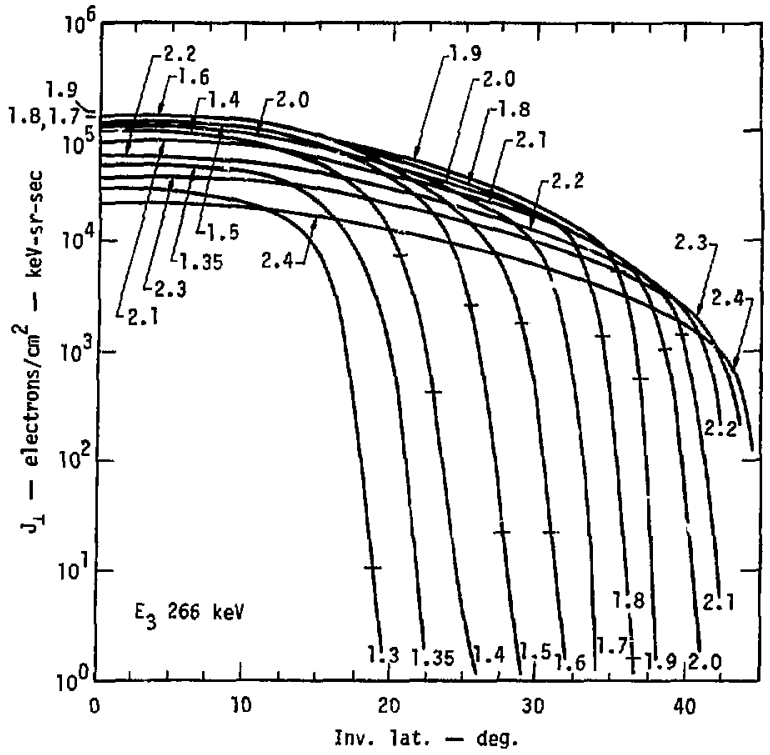

(c) $\mathrm{E}_{3}-266 \mathrm{keV}$

Fig. 3. Plots of $j_{1}-v s-\lambda_{1}$ profiles time-transformed to day 69,1968 . These data provide a summation of the data plots given in Appendix $B$ (continued). 


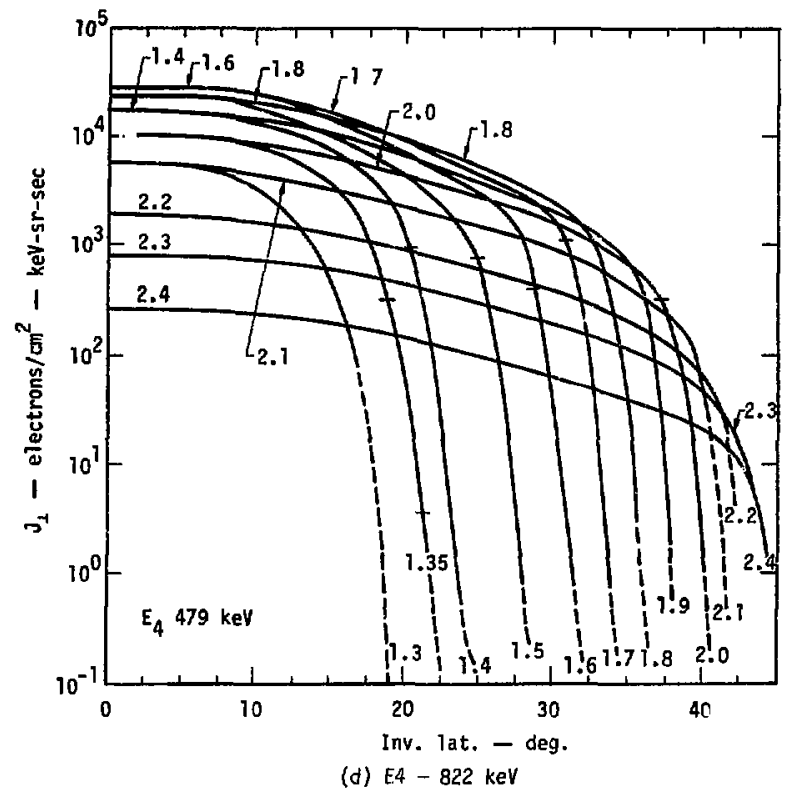

Fig. 3. Plots of $j_{1}-v s-\lambda_{1}$ profiles time-transformed to day 69,1968 . These data provide a summation of the data plots given in Appendix B (continued). 


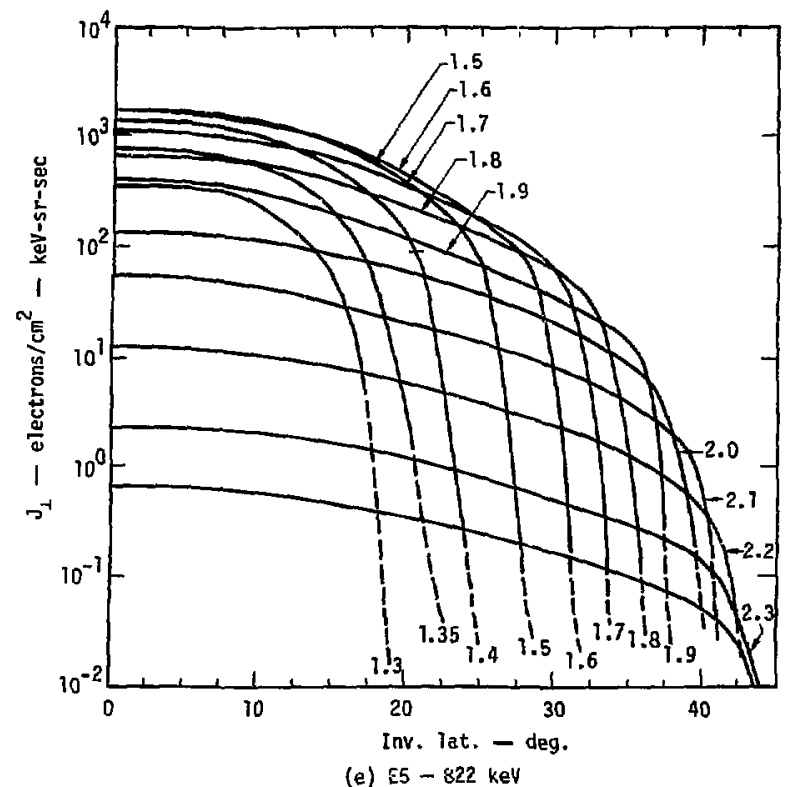

Fig. 3, Plots of $j_{\perp}-v s-\lambda_{1}$ profiles time-transformed to day $69,196 U_{\text {, These data }}$ provide a summation of the data plats given in Appendix $B$ (continued). 


\section{Appendix A.}

\section{Details of Fitting Procedures}

The following terms are used in the description of the fit and the statistics. For an elementary treatment of the least-squares method, see Draper and Smith. ${ }^{13}$

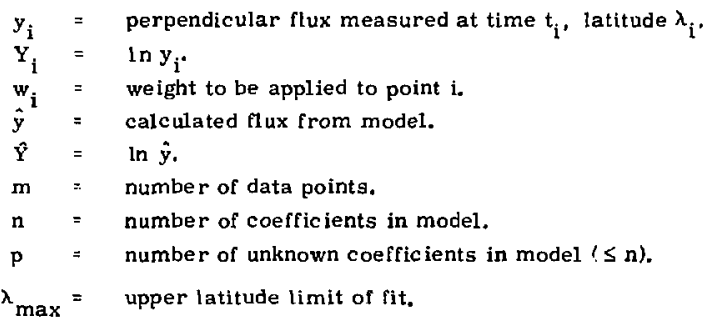

The nonlinear model [ Eq. (1)] was linearized by taking the logarithm of both sides, yielding

$$
\hat{Y}=-\left(t-t_{0}\right) / b_{1}+b_{2}+\sum_{j} b_{j} \lambda^{2(j-2)}, j=3, \ldots .
$$

The unknown coefficients $b_{j}$ we re then determined by the usual least-squares criterion that $Q^{2} \equiv \sum_{i=1}^{m} w_{i}\left(\hat{Y}_{i}-\hat{Y}_{i}\right)^{2}$ be a minimum. In matrix terms, the set of equations to be solved is

$$
\underline{Z}=\underline{\mathrm{X}} \underline{\mathrm{B}} .
$$

where

$$
\begin{array}{ll}
z_{i}=\sqrt{w_{i}}\left(Y_{i}\right) . & i=1,2, \ldots m . \\
x_{i 1}=-\sqrt{w_{i}}\left(t_{i}-t_{0}\right), & i=1,2, \ldots m, \\
x_{i 2}=\sqrt{w_{i}} & \\
x_{i j}=\sqrt{w_{i}} \lambda_{i}^{2(j-2)} & j \cdot 3,4, \ldots p . \\
B_{1}=1 b_{1}, & j \cdot 2,3 \ldots p . \\
B_{j}=b_{j} &
\end{array}
$$


Formally the solution is given by

$$
\underline{B}=\underline{C} \underline{x}^{T} \underline{z}
$$

where $\underline{C} \equiv\left(\mathrm{X}^{\mathrm{T}} \mathrm{X}\right)^{-1}$ is the covariance matrix. Rather than finding $\underline{B}$ by first calculating C. which involves the inversion of the ill-conditioned $\left(\mathrm{X}^{\mathrm{T}} \mathrm{x}\right)^{-1}$ matrix, we have used a

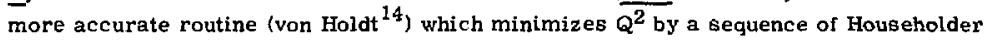
reflections.

It was often desirable to adopt non-uniform weights to compensate for the natural fluctuations in counting rate as a function of latitude. In particular, a weighting function was devised which gave less weight to smaller fluxes, thus reducing the effects of the low level, more highly variable hlgh-latitude fluxes on the fit at low latitude. The type of weighting is indicated on the plots in Appendix B.

$$
\begin{aligned}
K W T & =0, w_{i}=1 \text { (uniform weight), } \\
& =2,\left\{\begin{array}{l}
w_{i}=1+\log \left(y_{i} / y_{\max }\right)\left[\frac{1-W M L N}{W D E C}\right], y_{\max } \geq y_{i} \geq y_{\max } \times 10^{-W D E C} \\
w_{i}=w \text { MIN, } y_{i}<y_{\max } \times 10^{-W D E C}
\end{array}\right.
\end{aligned}
$$

WMIN = minimum weight, $0<$ WMIN $\leq 1$.

WDEC = number of decades over which $w_{i}$ decreases from $i$ to WMIN.

The following terms are useful in interpreting the fit statictics:

$$
\begin{aligned}
\text { DOF } & \text { stakistical degrees of treedom, } \\
\text { DOF } & =m-p . \\
s^{2} & \text { mean square residual, } \\
s^{2} & =\frac{1}{\text { DOFF }} \sum_{i=i}^{m}\left(\hat{y}_{i}-y_{i}\right)^{2} .
\end{aligned}
$$

A amall $\mathrm{S}^{2}$ denolos a good agreement between model and data.

$n^{2}$ a the equare of the muttiple correlation coeffictent, $\times 100$. This is the percent of the total varialion about the mean which te accounted for by the fit.

$$
u^{2} \cdot\left[\sum_{i=1}^{m}\left(\dot{x}_{1}-m\right)^{2} / \sum_{i=1}^{m}\left(x_{i}-p\right)^{2}\right] \times 100 .
$$

Tho rinter $\mathrm{n}^{2}$ eppronches $100 \%$ the better the fit.

$$
\begin{aligned}
& b_{j} \text { outhmated stendard error in coeifietent } b_{j} \text {. } \\
& \hat{y}_{1}=\sqrt{s^{2}\left(x^{2} x\right)^{-1}}
\end{aligned}
$$


$t_{j} \equiv$ the ratio $b_{j} / \hat{\sigma}_{j}$, which follows a $t$-distribution with DOF degrees of freedom if $\mathrm{b}_{\mathrm{j}}$ is not significantly different from zero. The coefficient with the smallest $t_{j}$ was el iminated in each step of the backwards elimination process desc ribed earlier. 


\section{Appendix B. \\ Fits to Inner Belt-Electron Fluxes}

For each L-value, a group of four 'jlots is presented for each energy channel. These plats are:

1) Measured perpendicular fluxes $j_{\perp}\left(\lambda_{i}, t_{i}\right)$ vs invariant latitude $\lambda$.

2) Measured fluxes fitted and transformed in time to $t=t_{0}$ (day 69). The curve is the fitting function $\hat{y}(\lambda, t)[E q .(2))$ evaluated at $t=t_{0}$, versus $\lambda$. The data points are the measured fluxes transformed in time to $t=t_{0}$ according to

$$
j_{1}\left(\lambda_{i}, t=t_{0}\right)=j_{1}\left(\lambda_{i}, t_{i}\right) e^{\left(t_{i}-t_{0}\right) / b_{1}} .
$$

3) Equivalent equatorial fluxes vs time. The curve is $\hat{y}(\lambda, t)$ evaluated at $\lambda=0$, vs $t$. The data points are the measured fluxes transformed in $\lambda$ to the equator according to

$$
j_{\perp}\left(\lambda=0, t_{i}\right)=j_{1}\left(\lambda_{i}, t_{i}\right) \times \hat{y}\left(\lambda=0, t_{i}\right) / \hat{y}\left(\lambda_{i}, t_{i}\right) .
$$

4) Fit coefficients and fit statistics. 

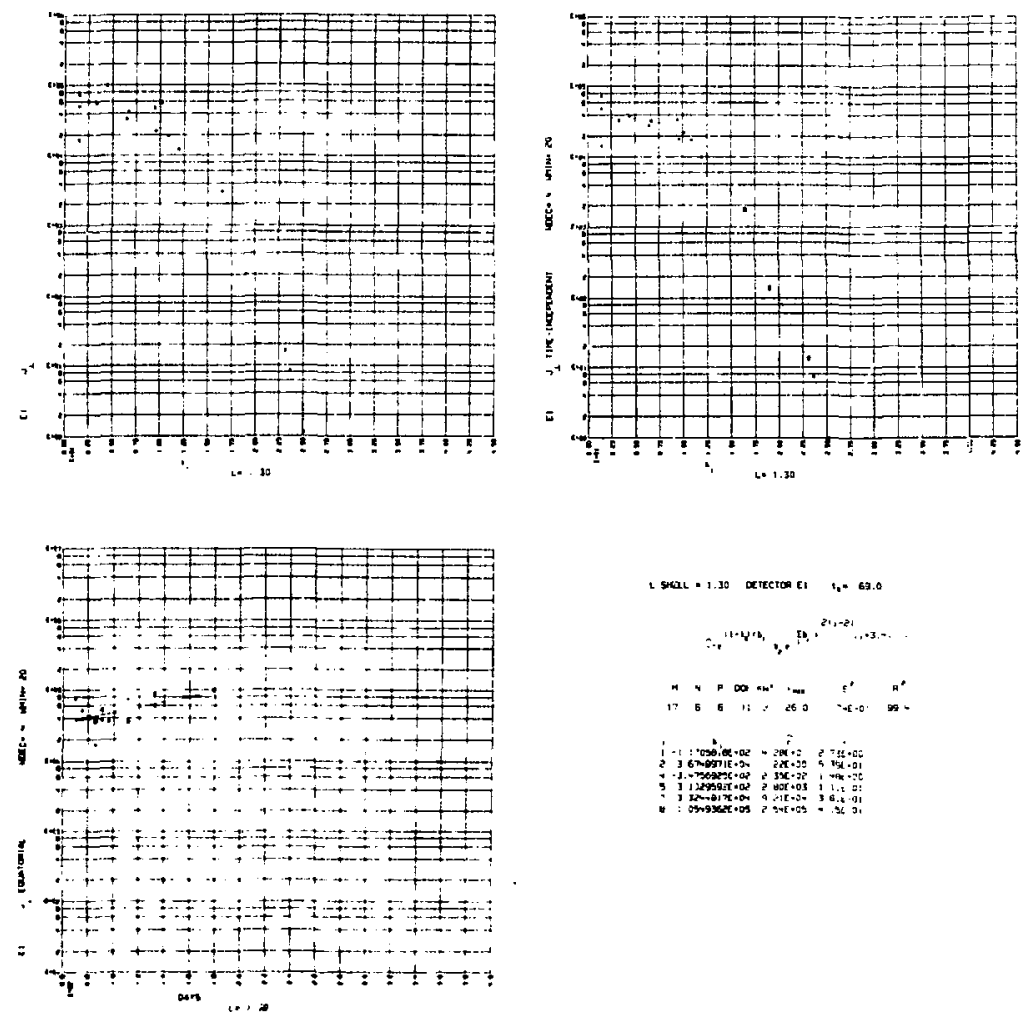

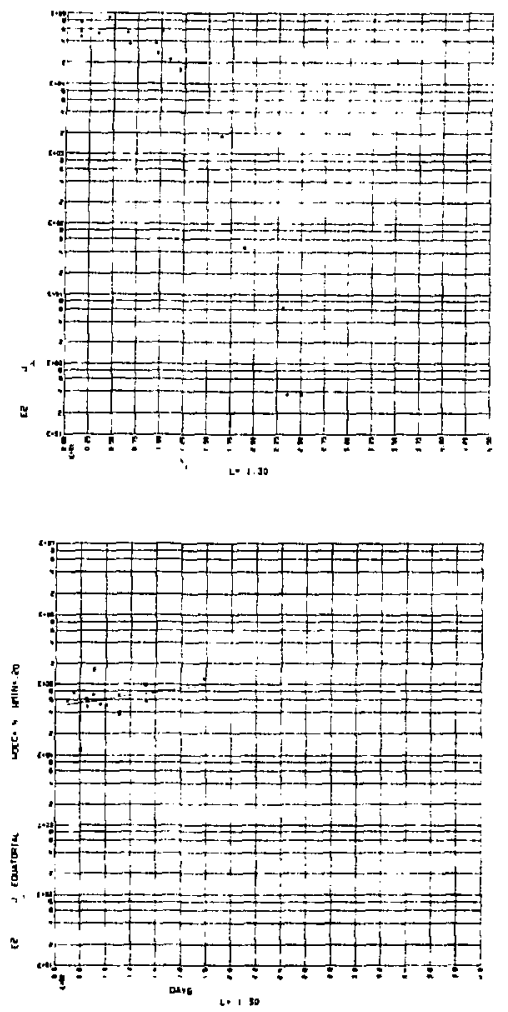
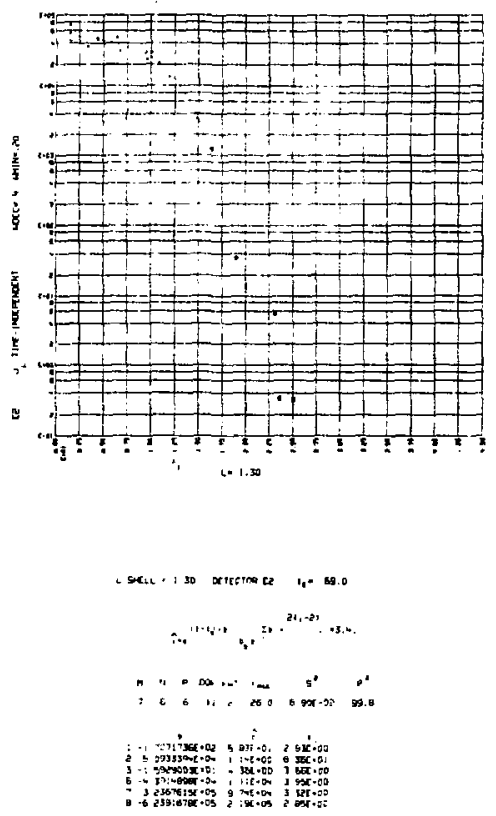

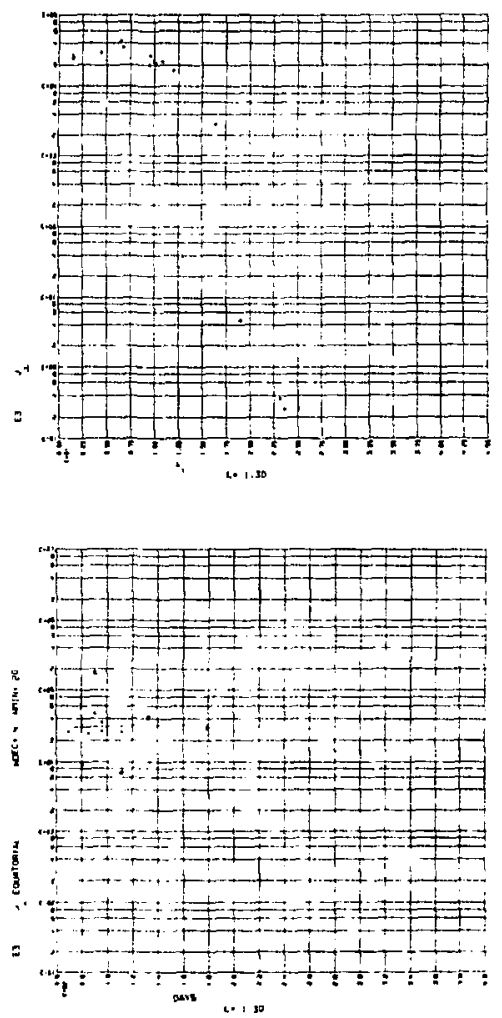
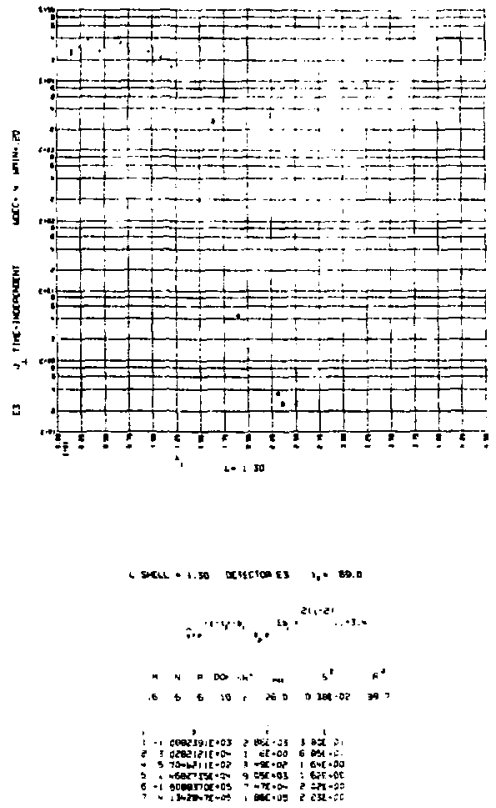

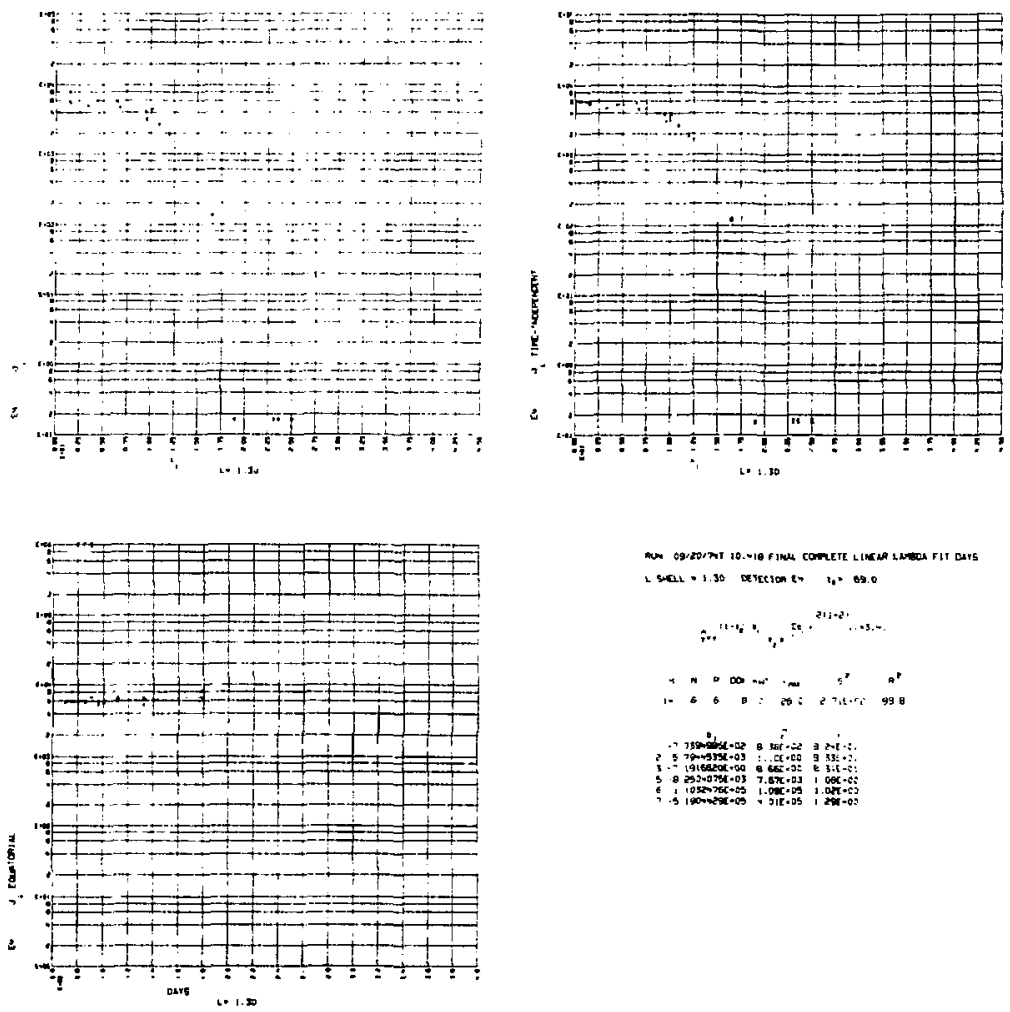

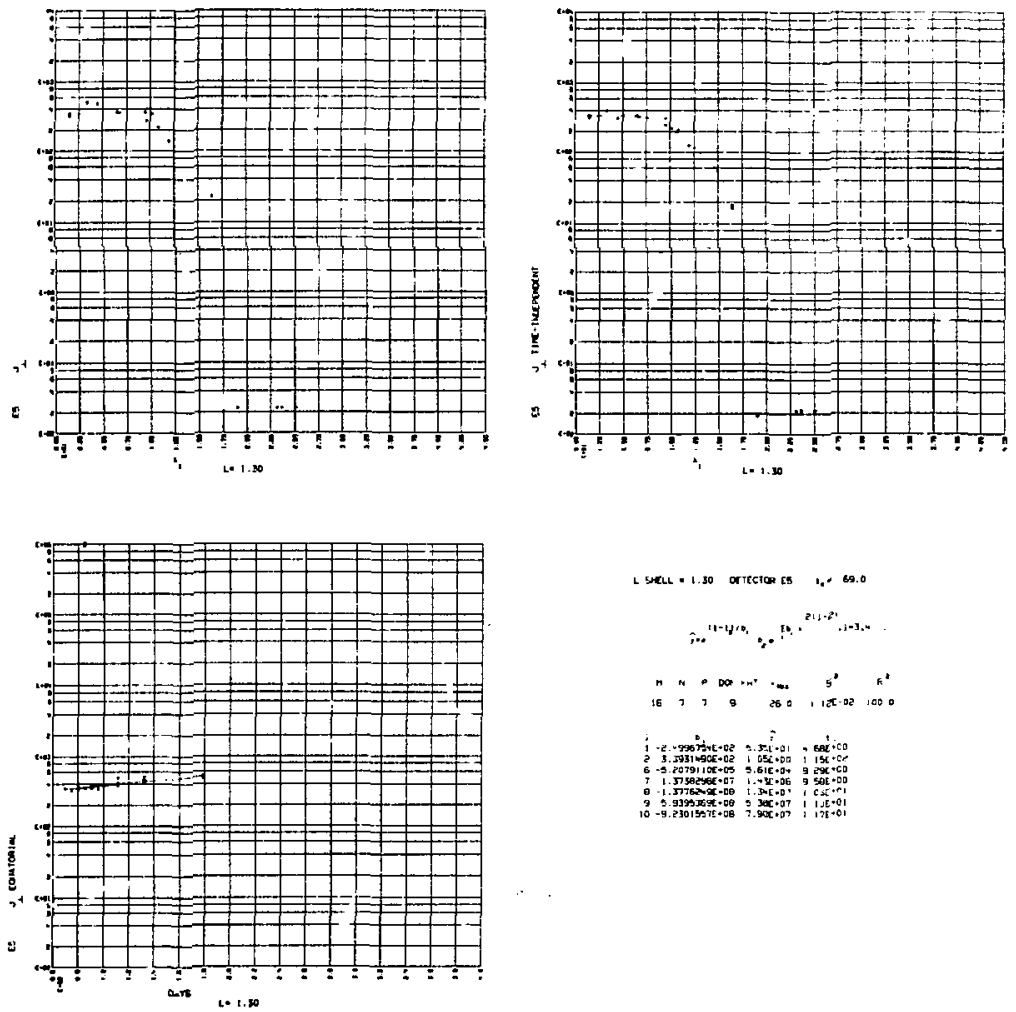

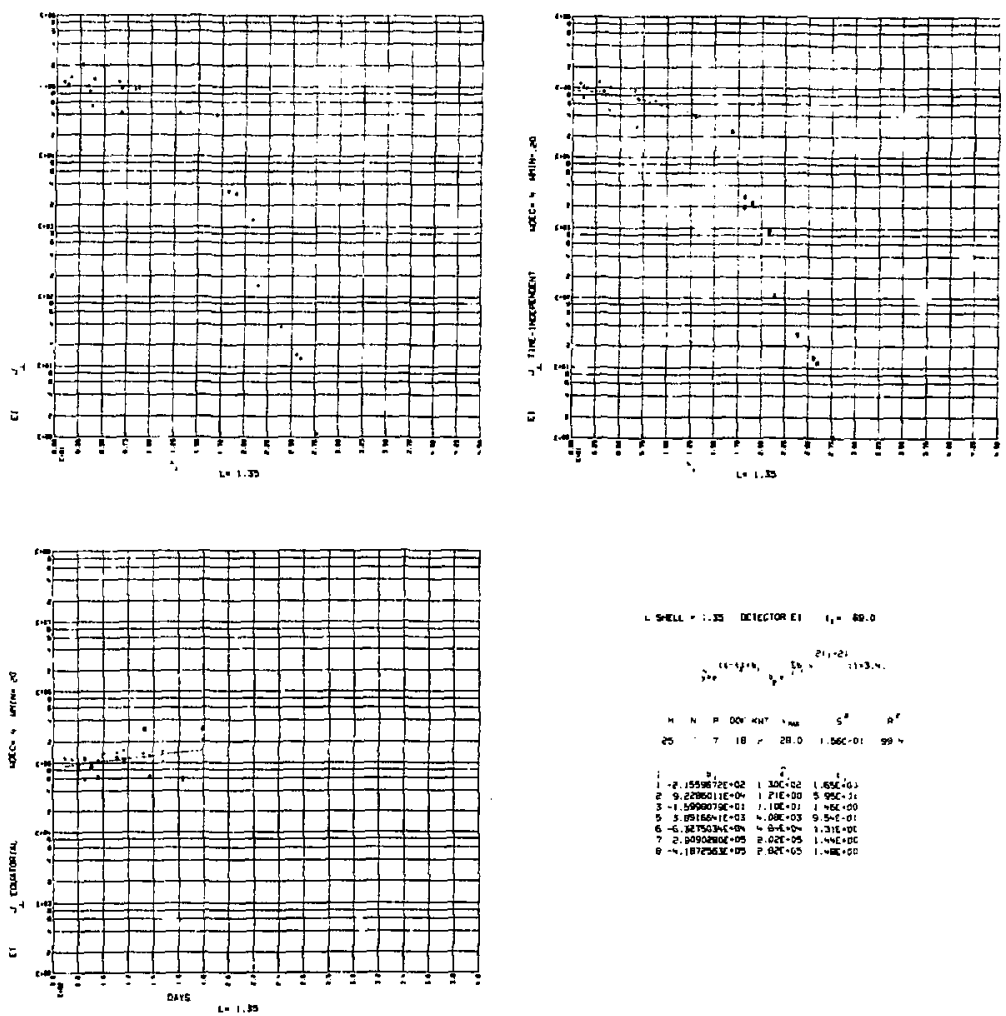

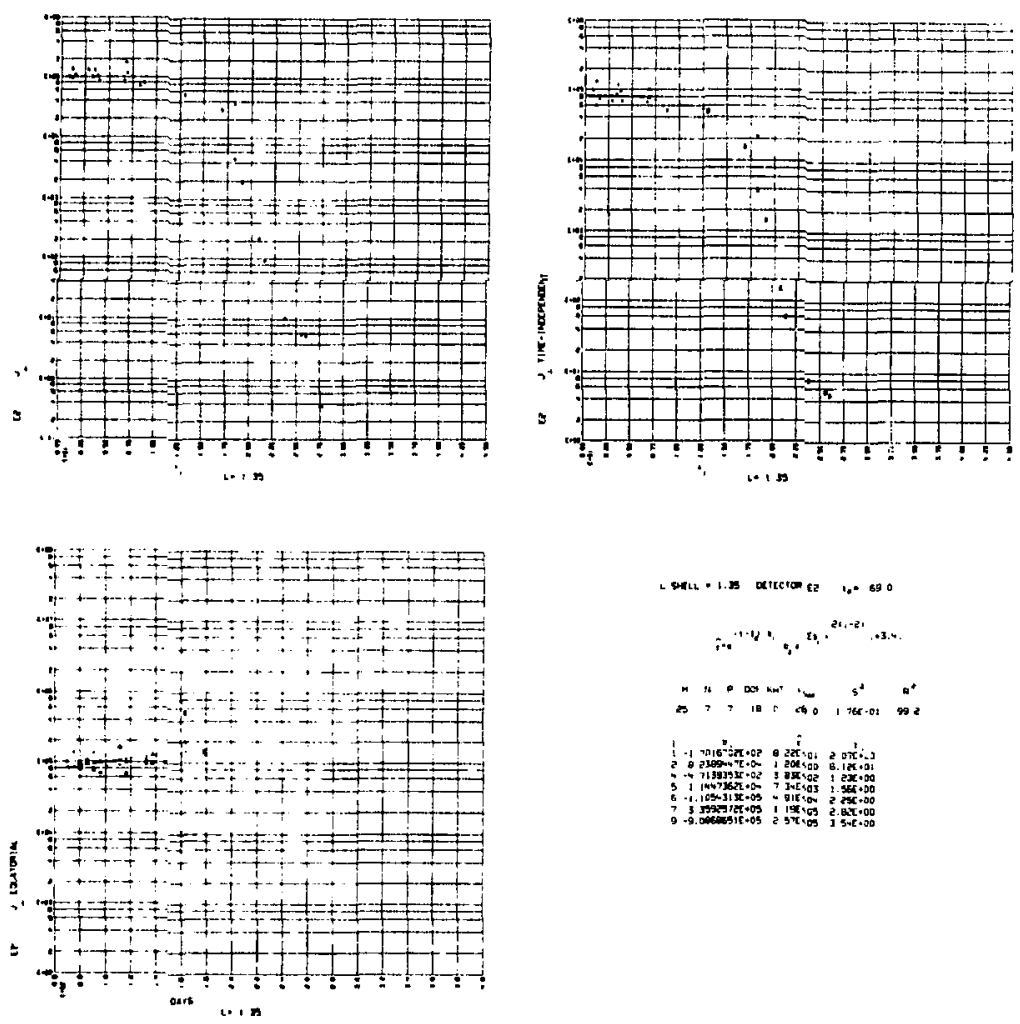


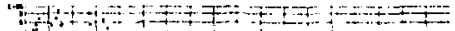
w

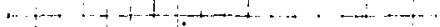

萂

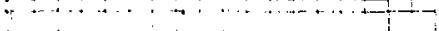
" - . . . + . . . , . + + + m.

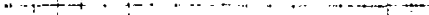

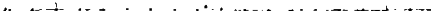

(4)

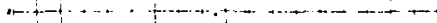
w 구 I T t $+1+1+\cdots+1$

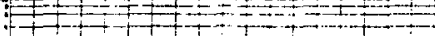

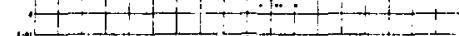

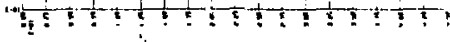
1. 19
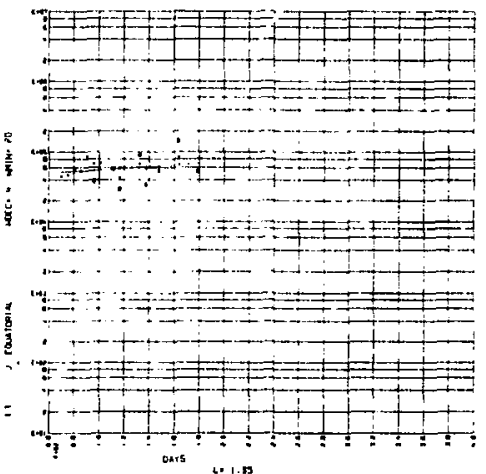
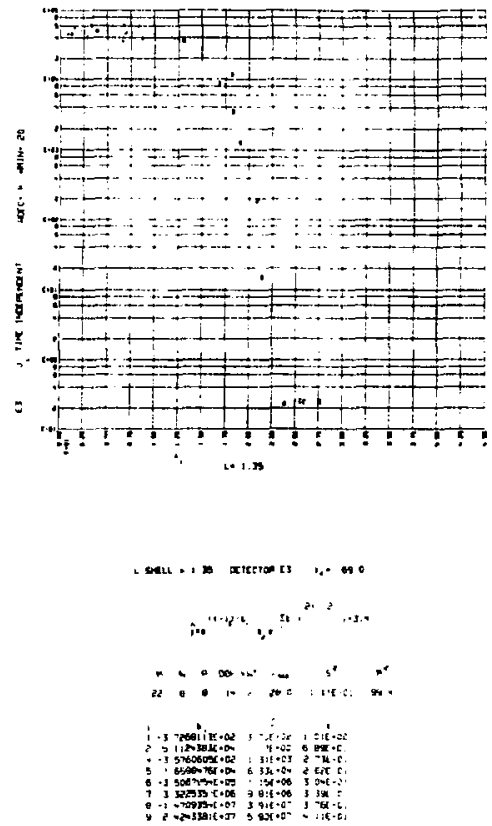

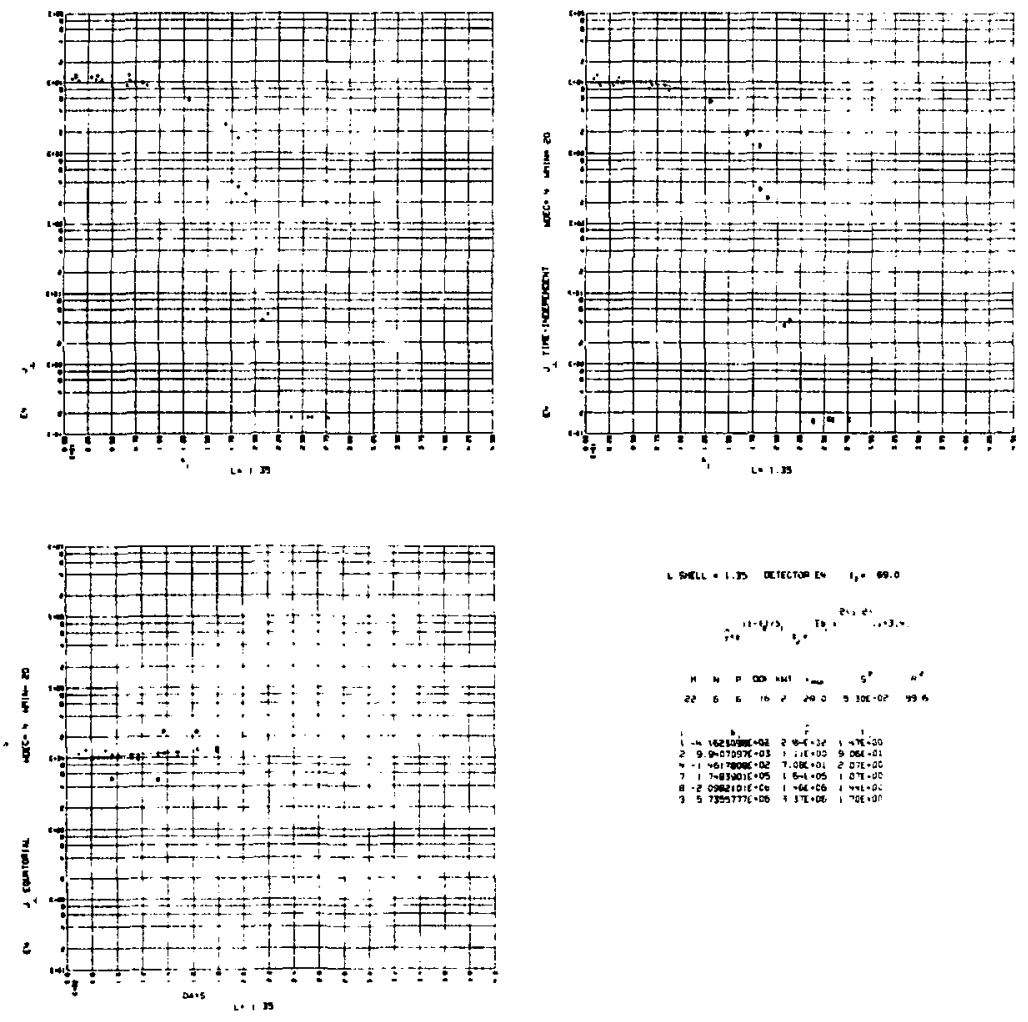

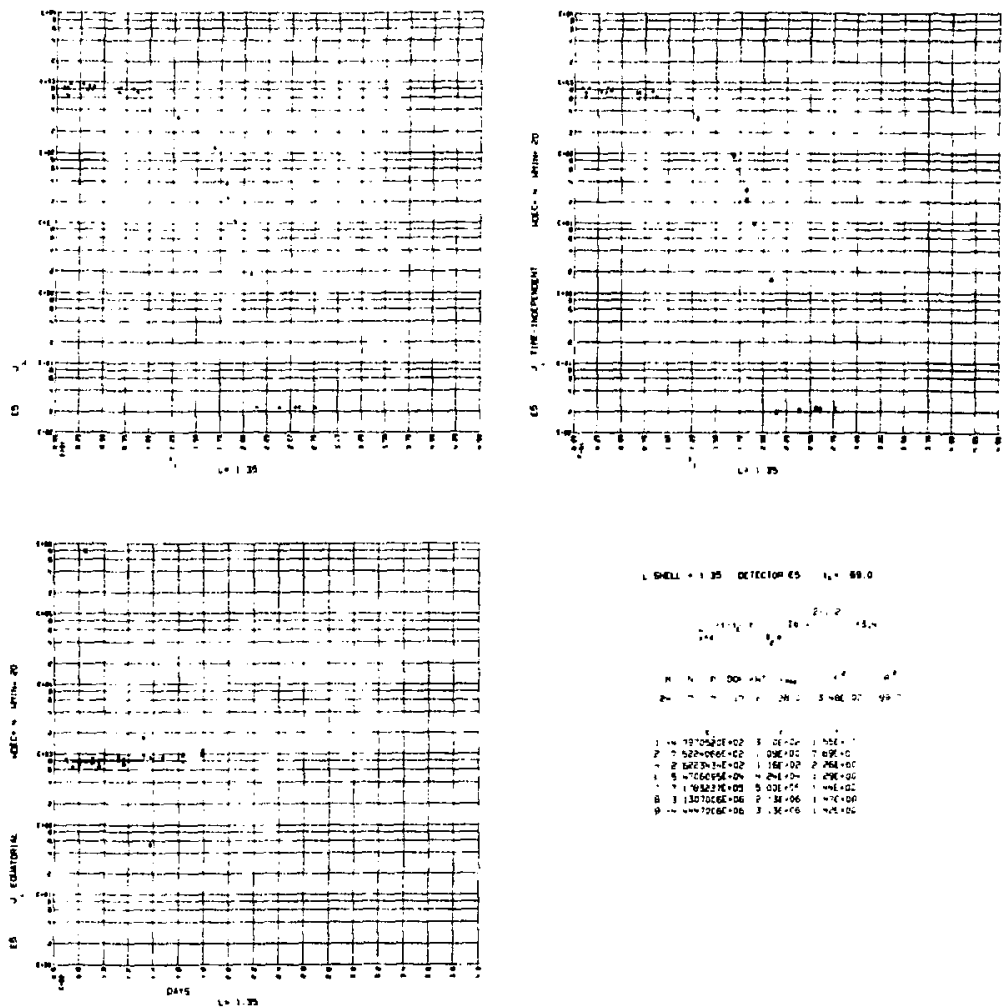


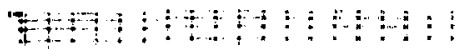
mon

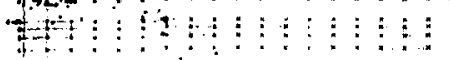

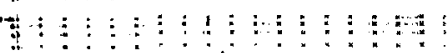

ษง

T. . .

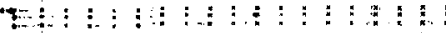

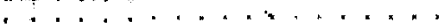

$\vdots$

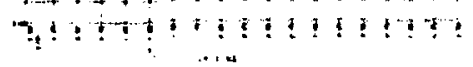

ะด:

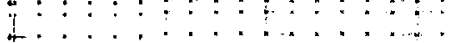

ษ

$\cdots$

ษ + - :

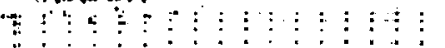

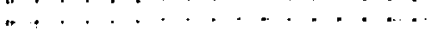

-

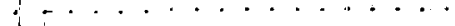

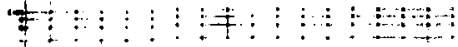

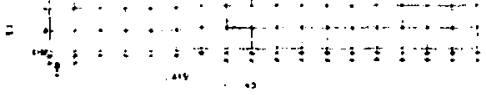

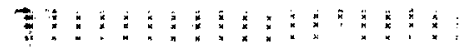

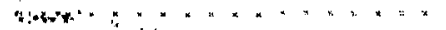

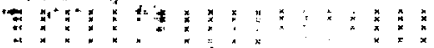
a.....

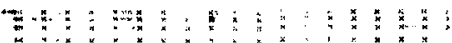
.... 获!

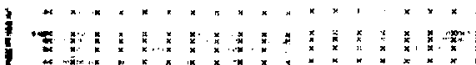
an..........

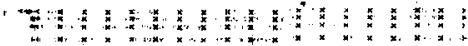

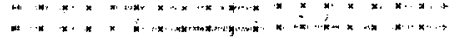
4 $+1 \rightarrow$

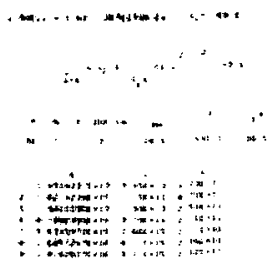




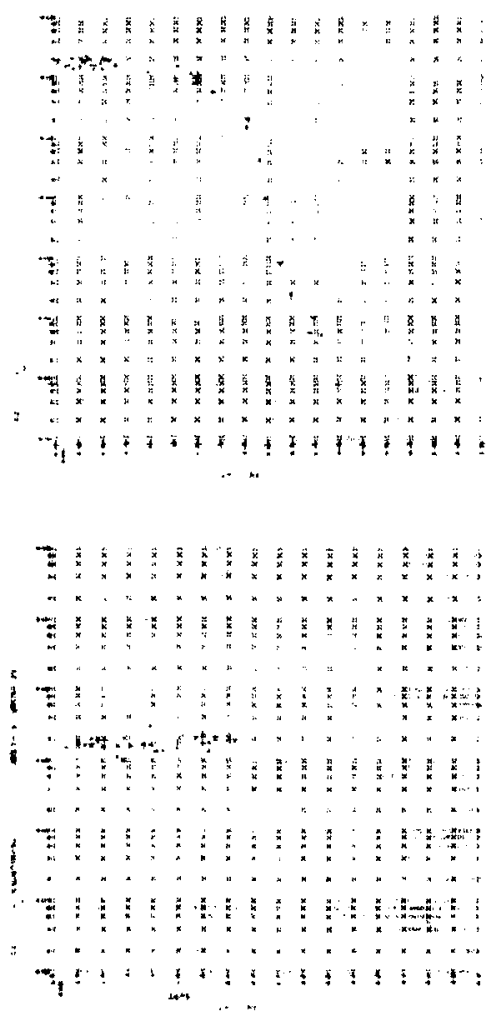

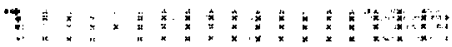

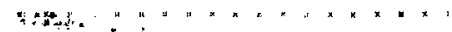

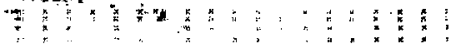

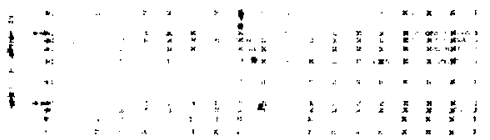

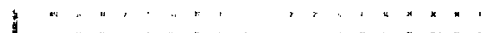

1

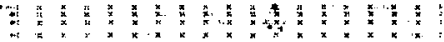

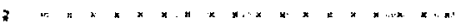

特!

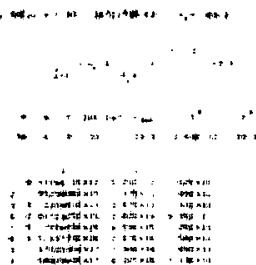

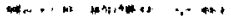

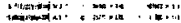



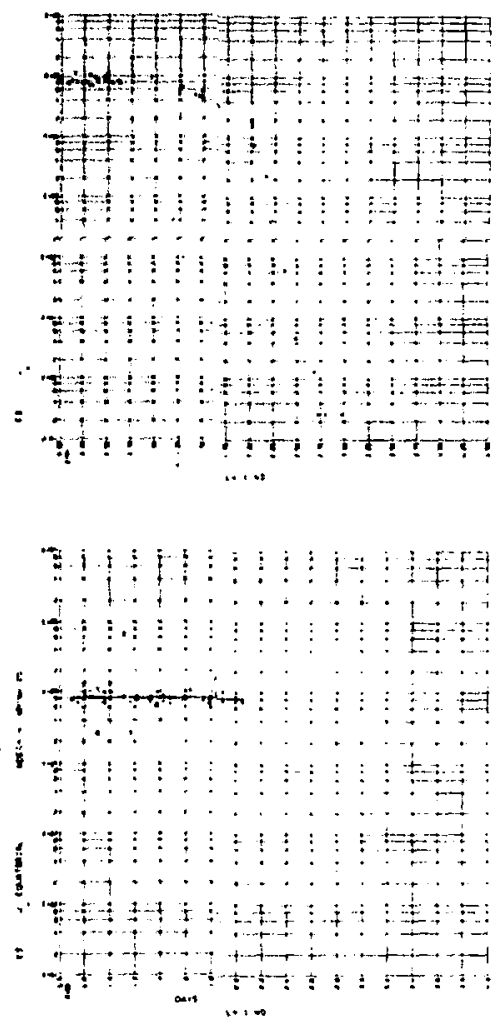
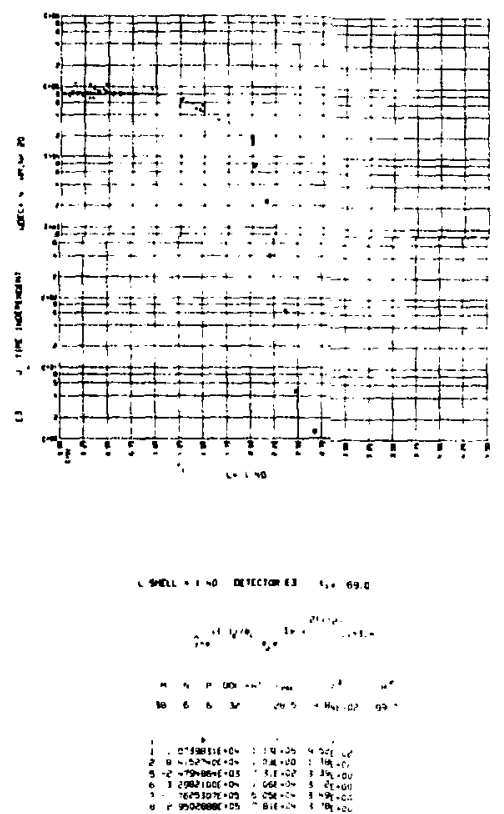

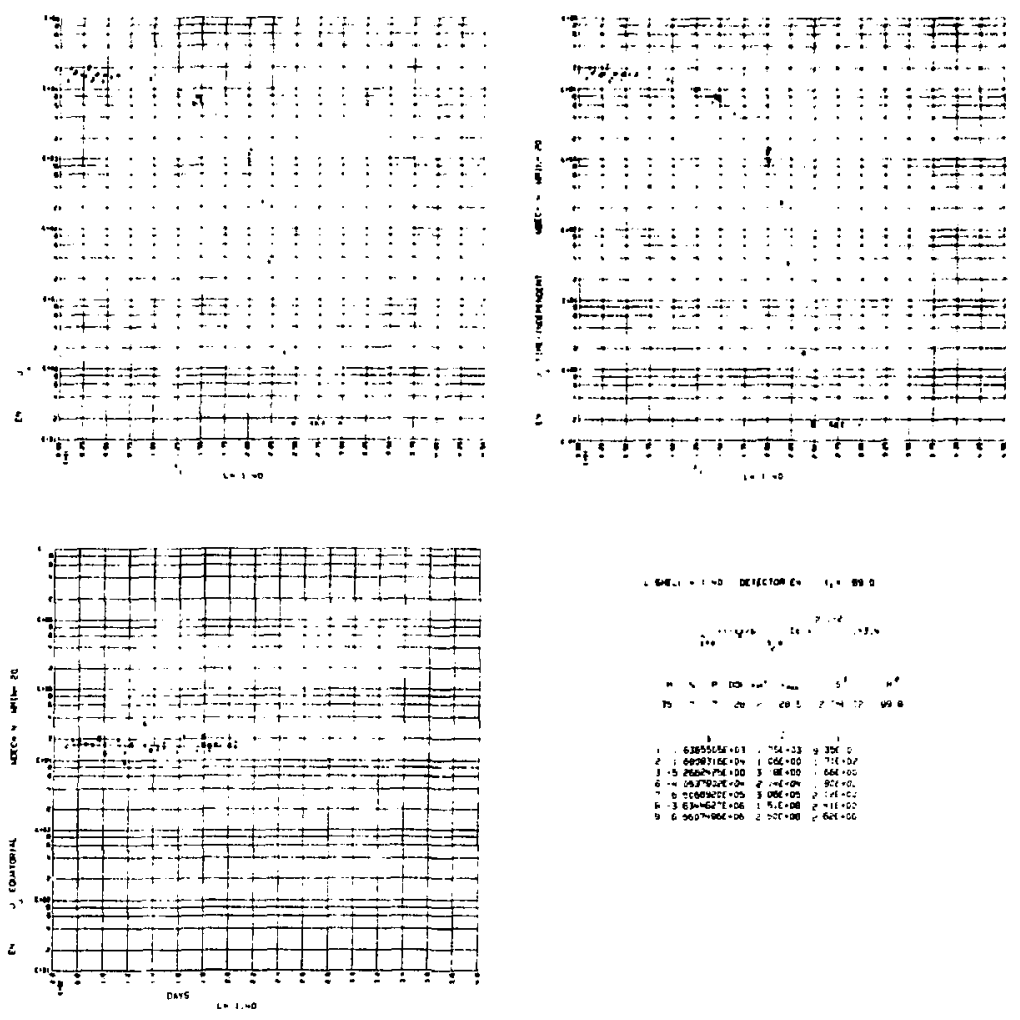
सममामी मी: +1. . . . . . .

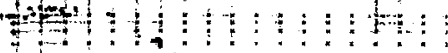

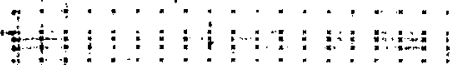
$\cdots \ldots \ldots$ ษ! and

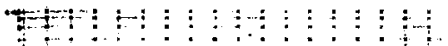
$\div$ + - +

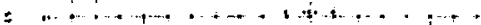
+ $\because+\infty$

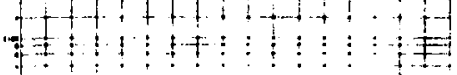

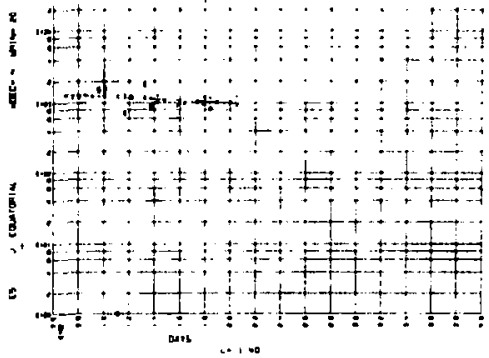

•

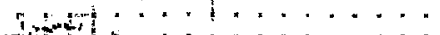

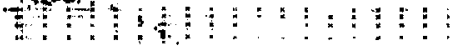

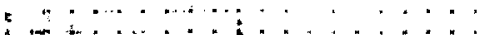

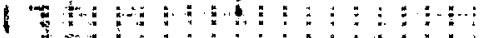

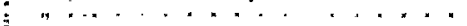
“..

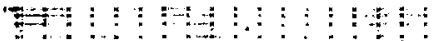

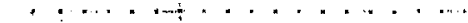

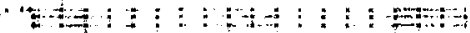

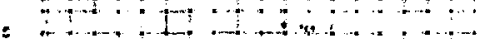
प! ! $\because+4$

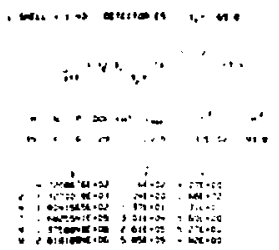



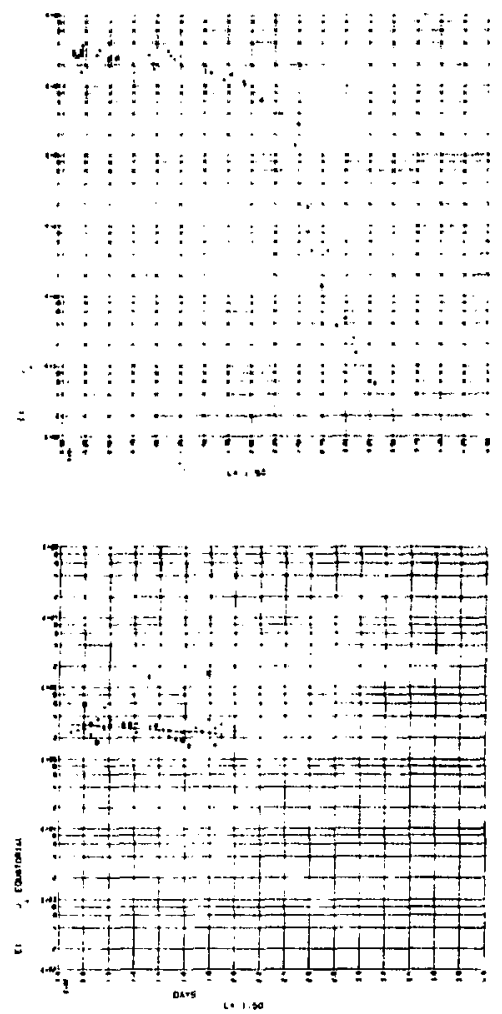
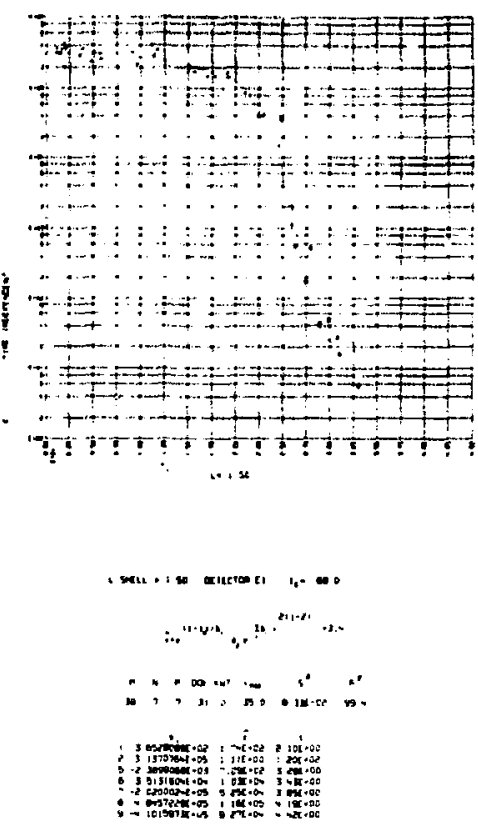

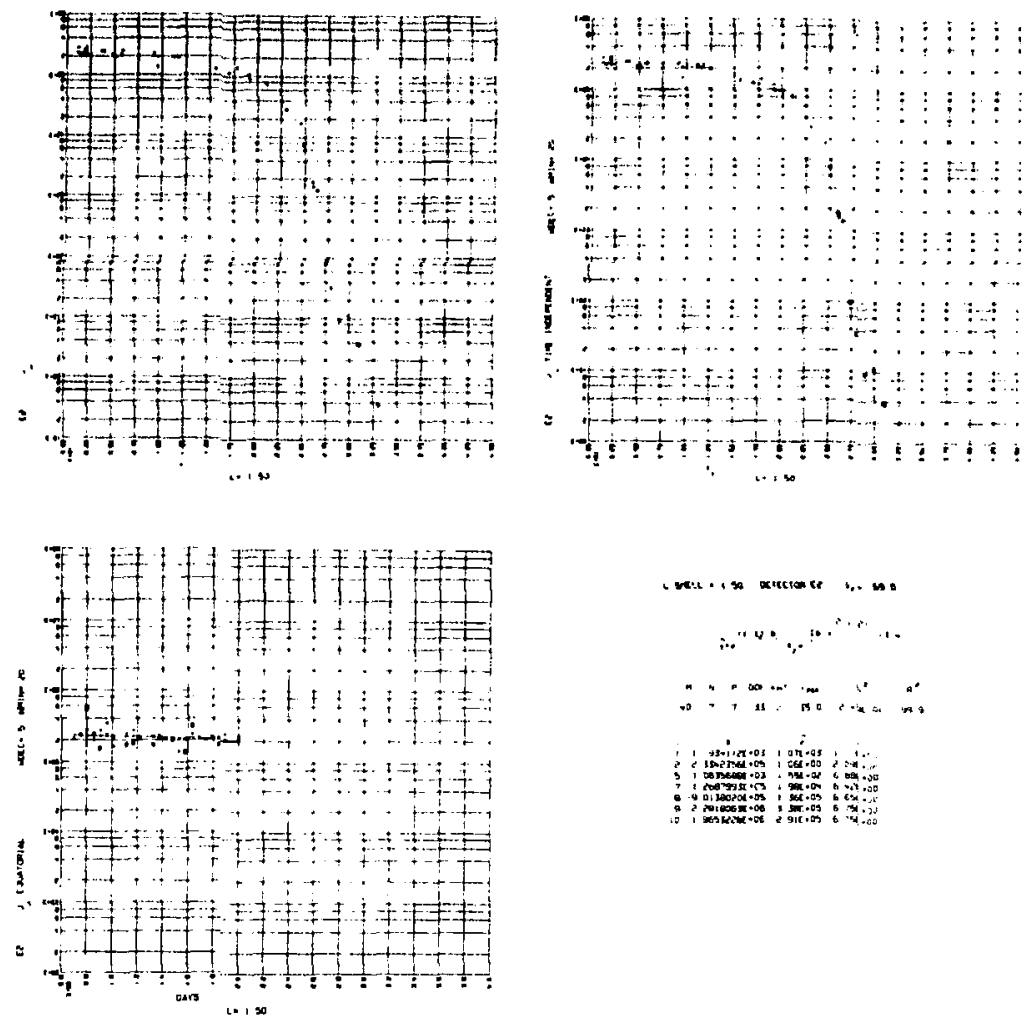
7 10 $+1+1+1+\ldots+\cdots$ of at? : : : : 1

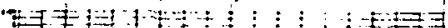
7 $n+\cdots, \cdot \ldots+\ldots, \ldots+\ldots$

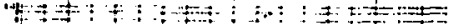
- $\rightarrow$ a

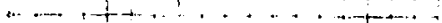

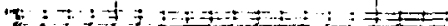

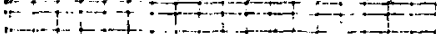
$4 \div \div \div 2 \div$

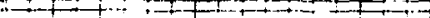
+ ' $=1+1+1+1+1+1+2+1+2$

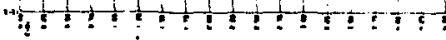
(1) 13

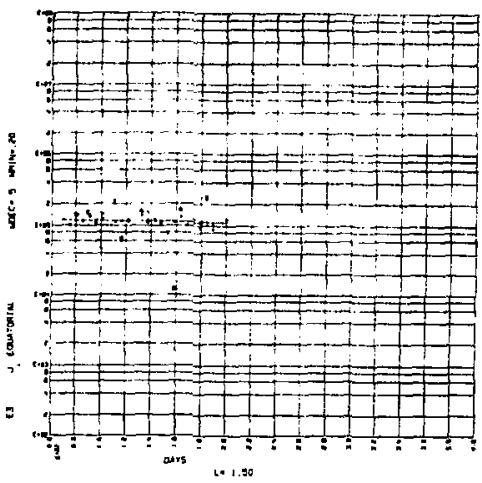

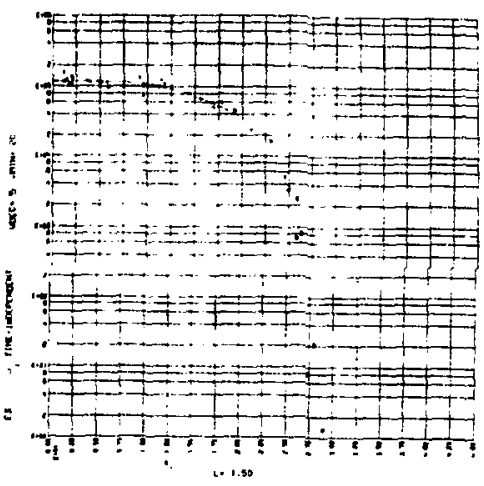

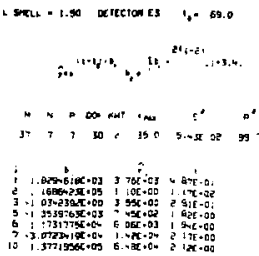



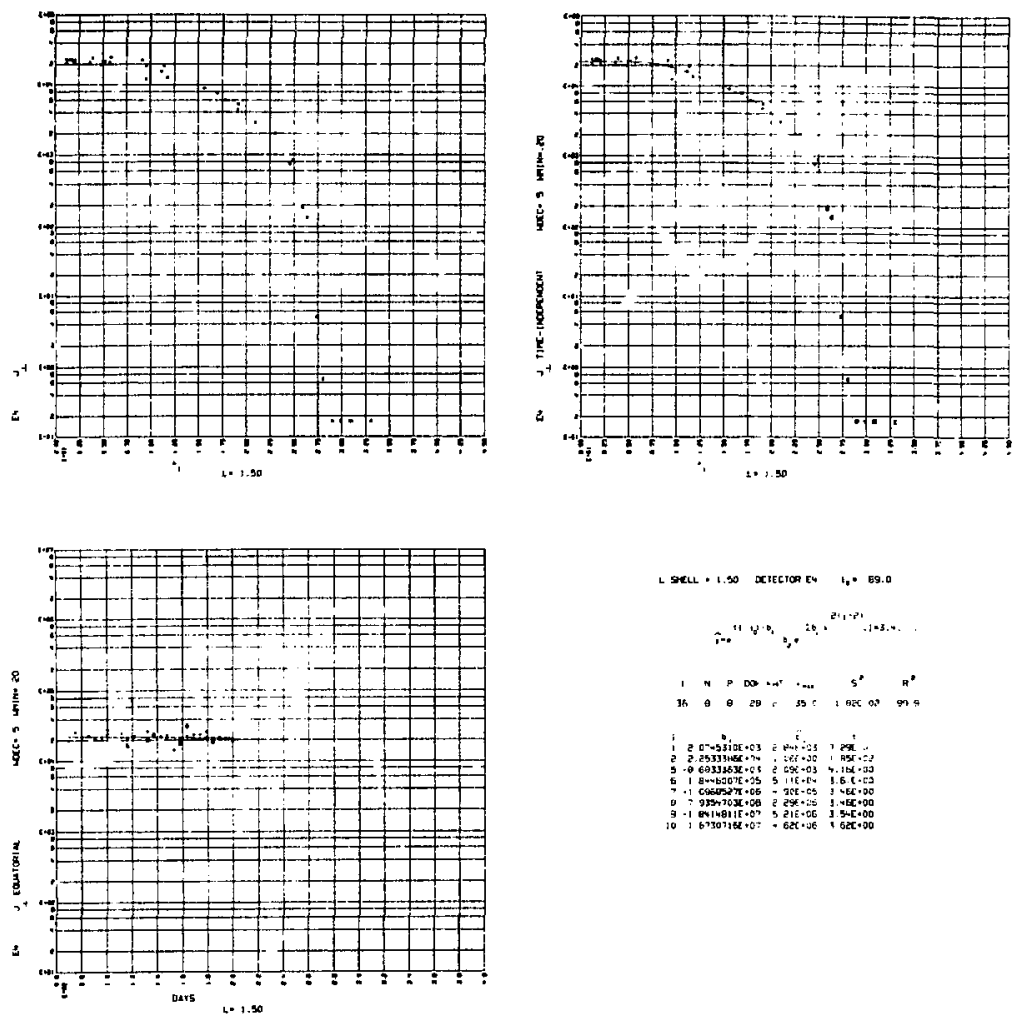

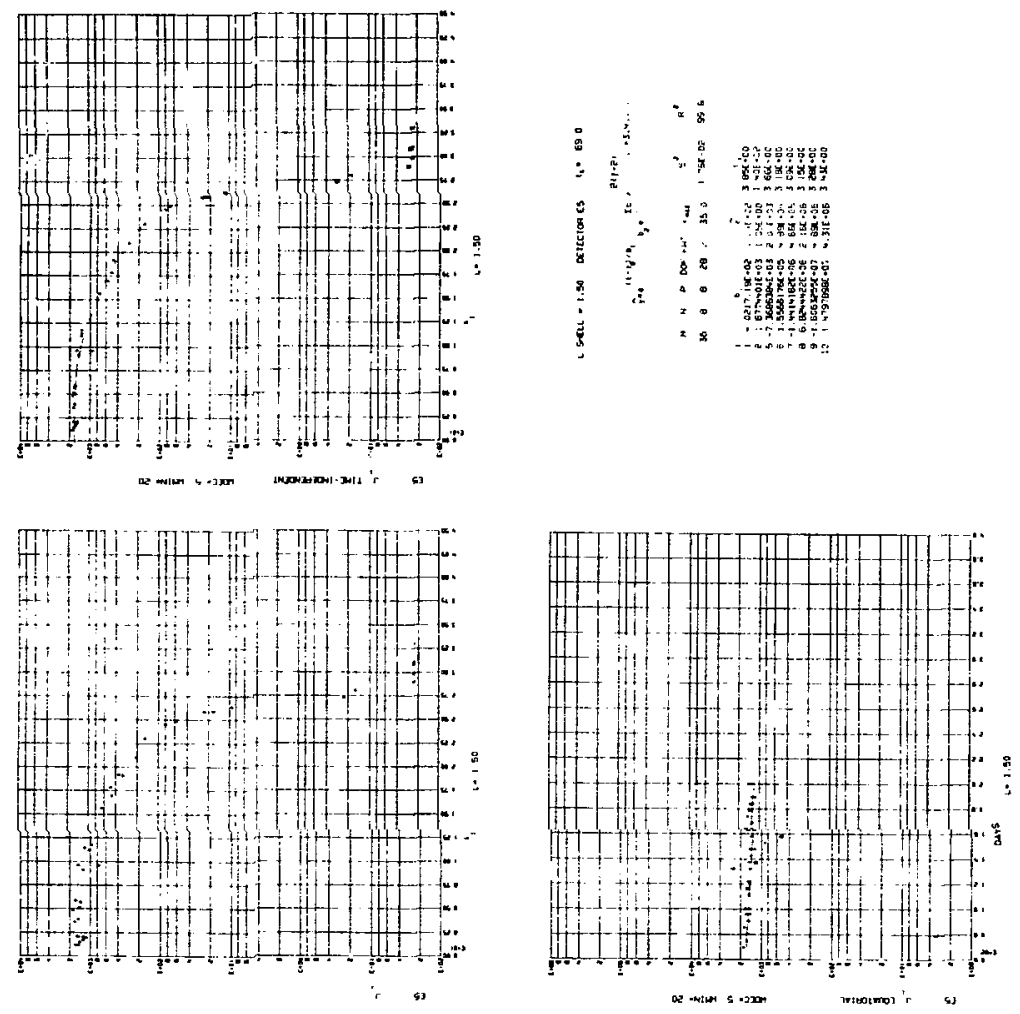

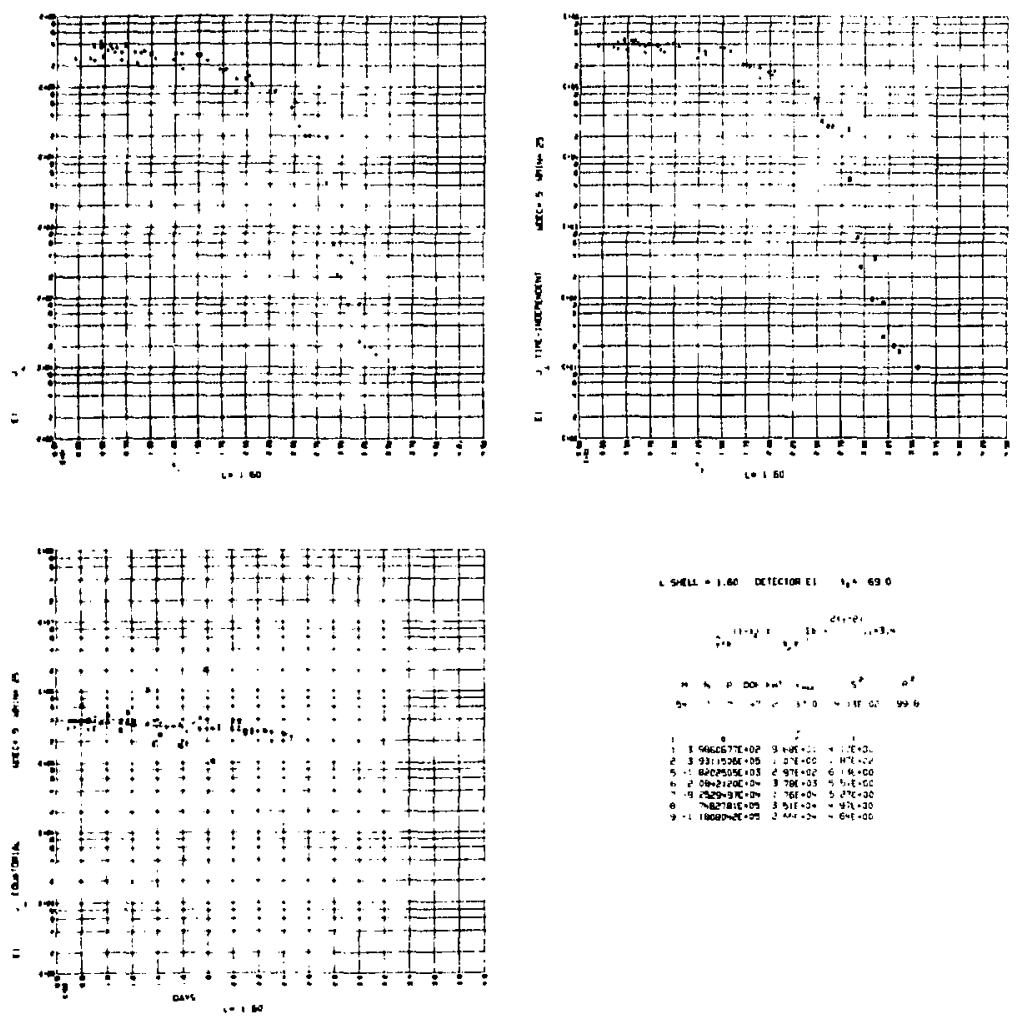

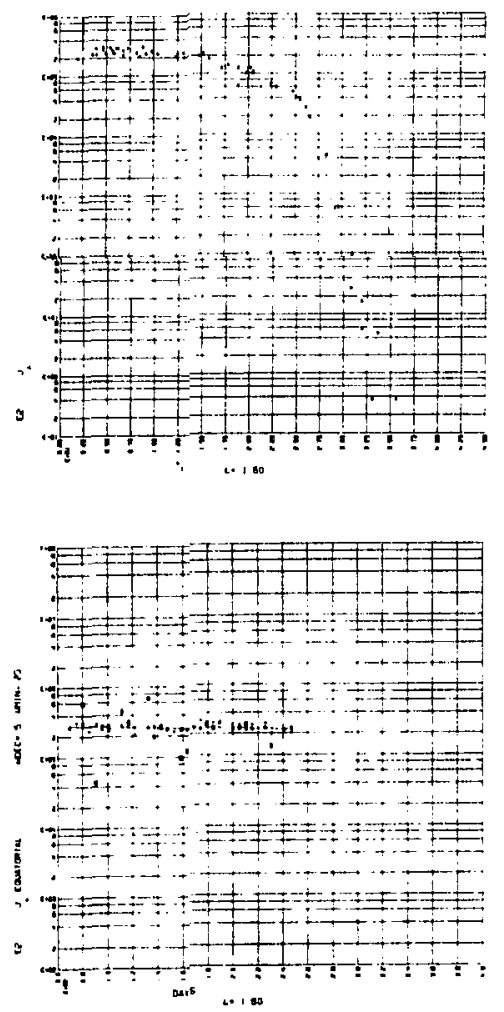

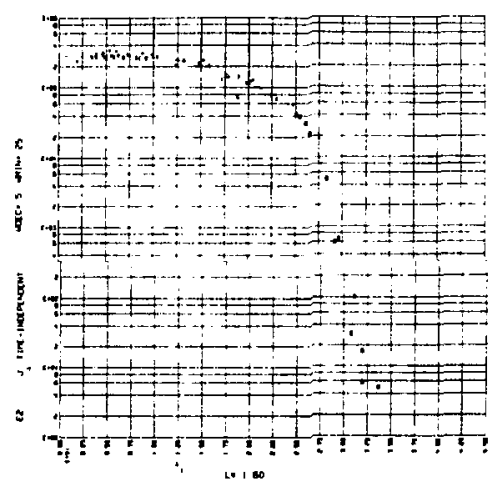

tscll - i so atecian te

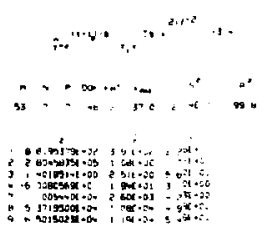



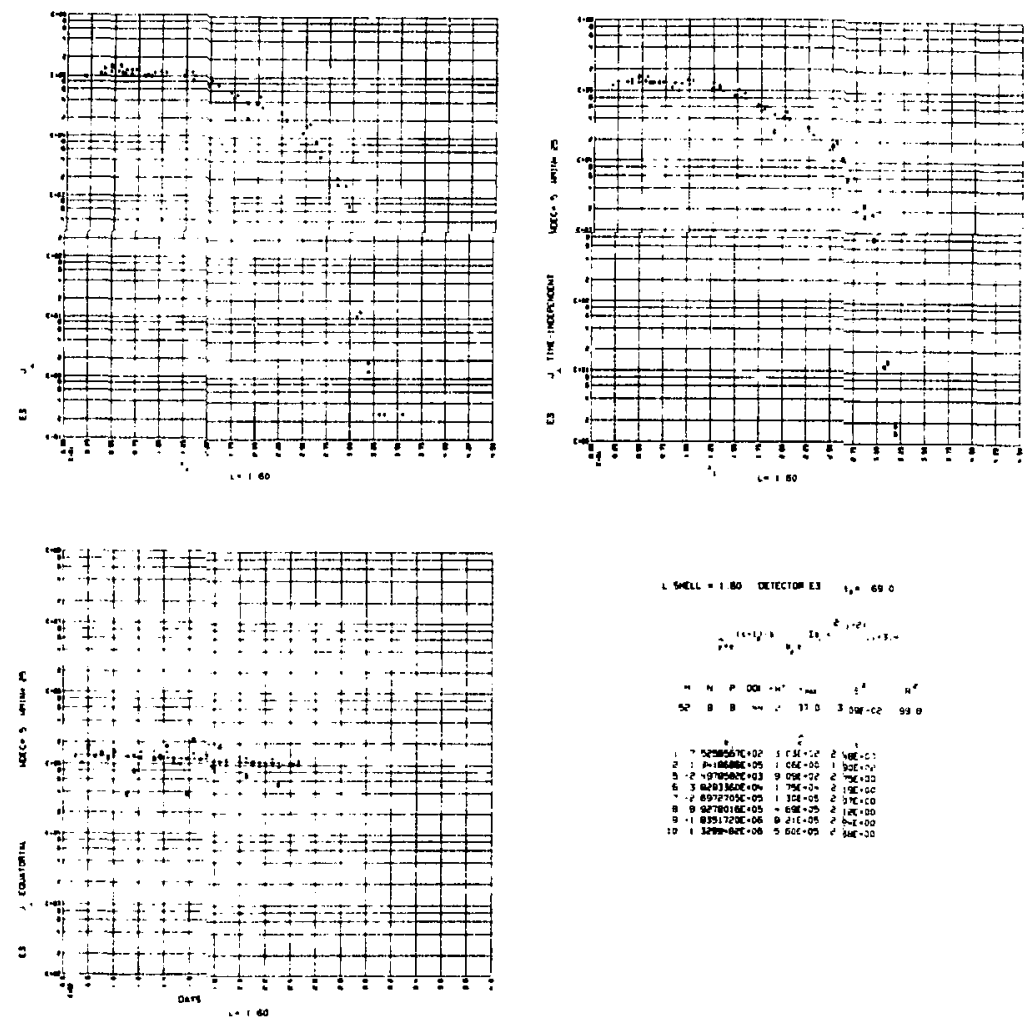

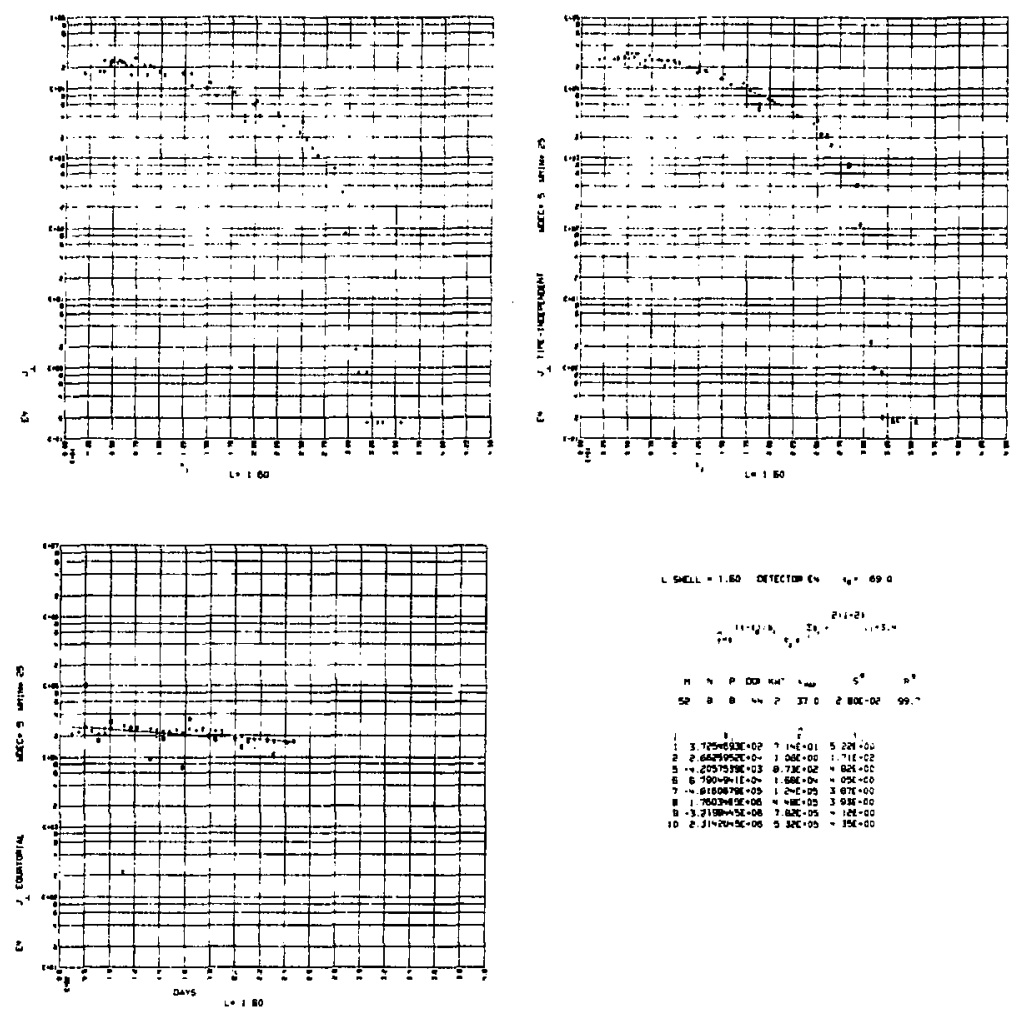

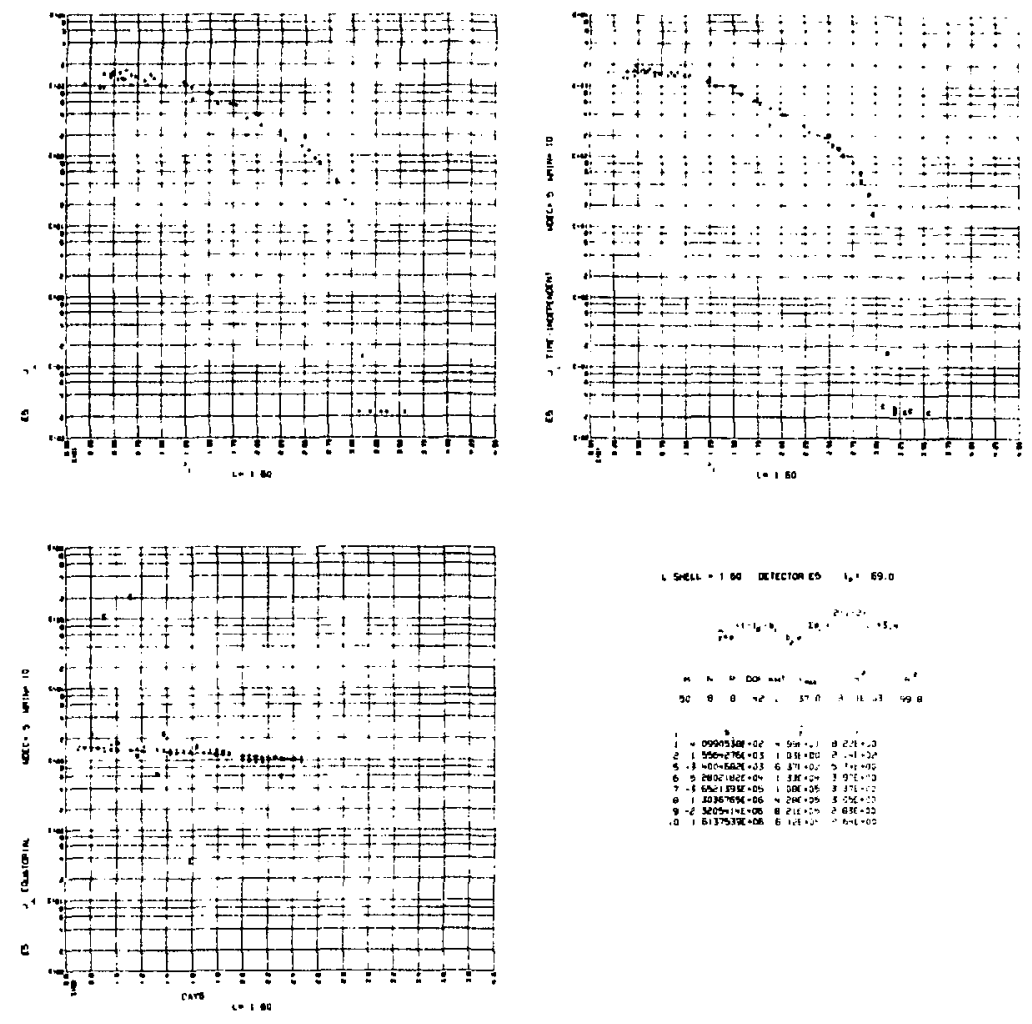

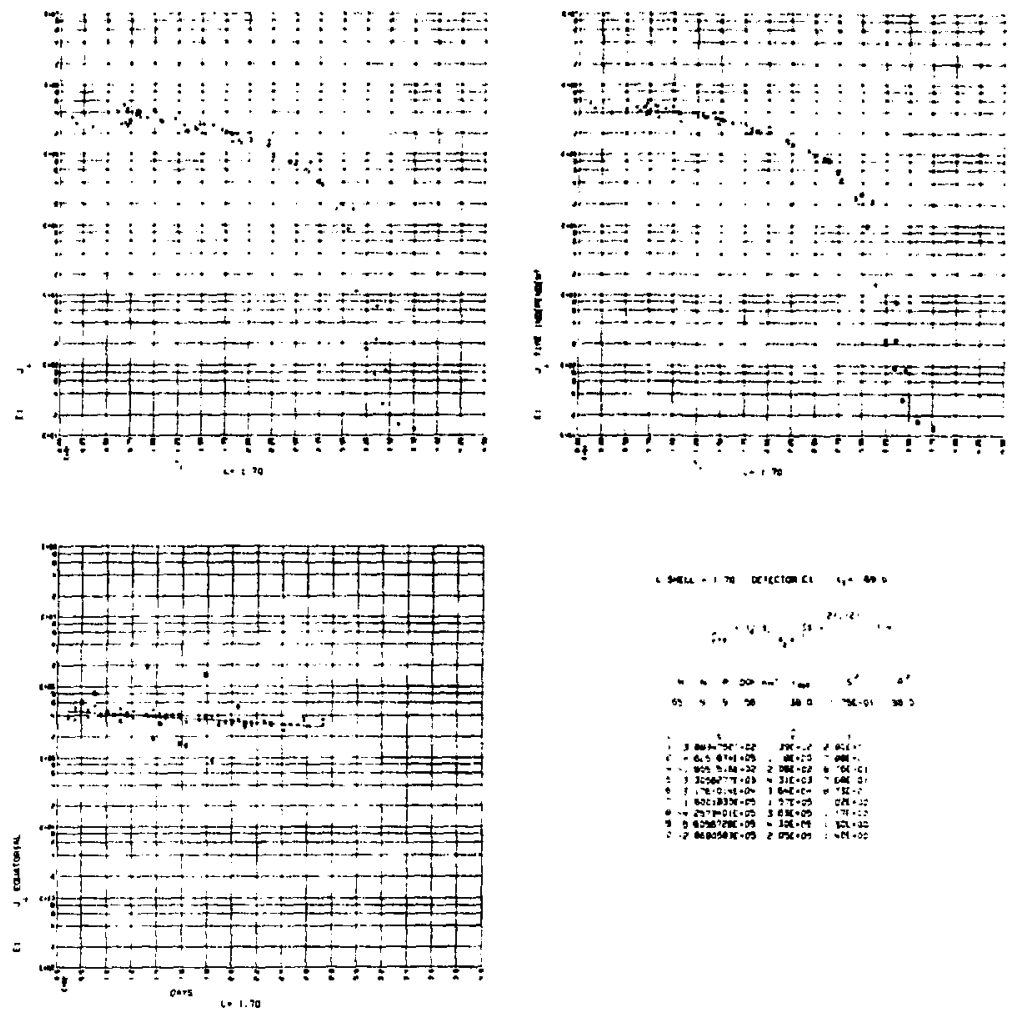

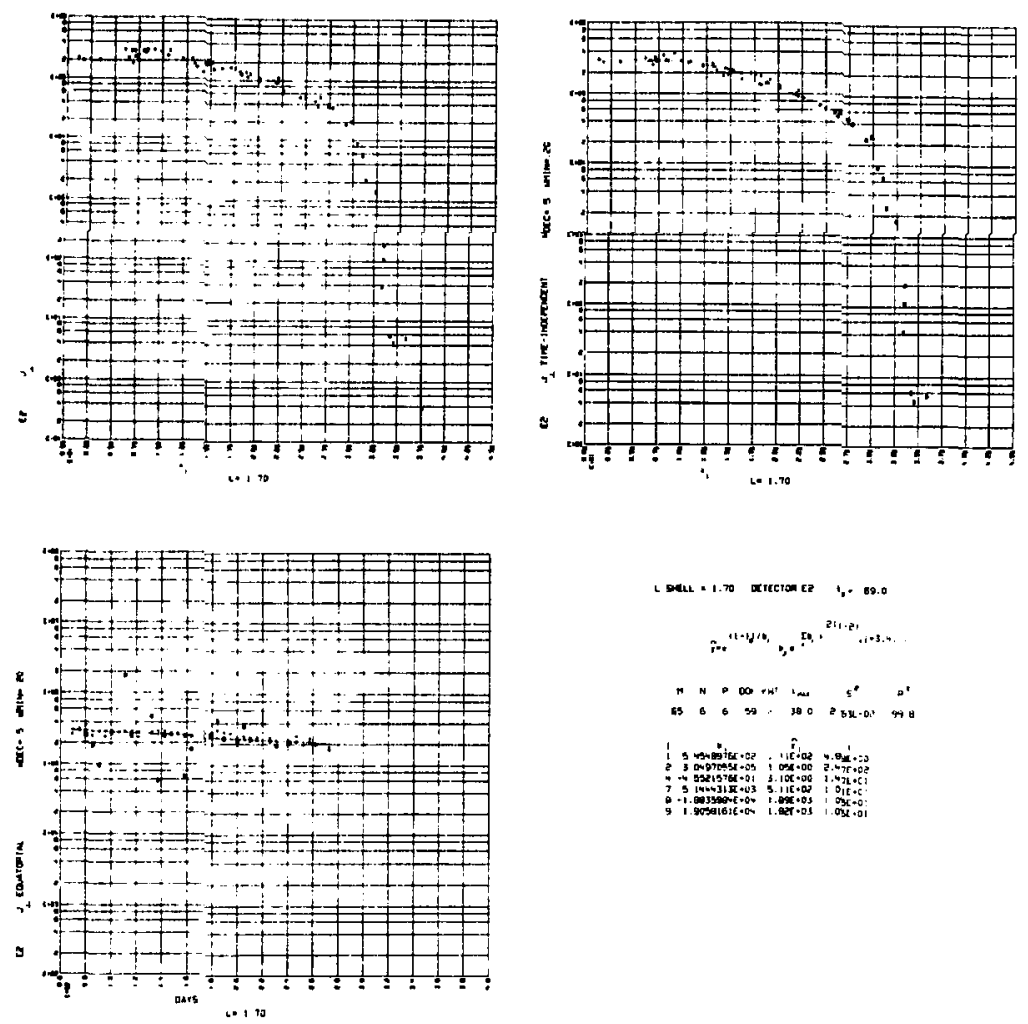

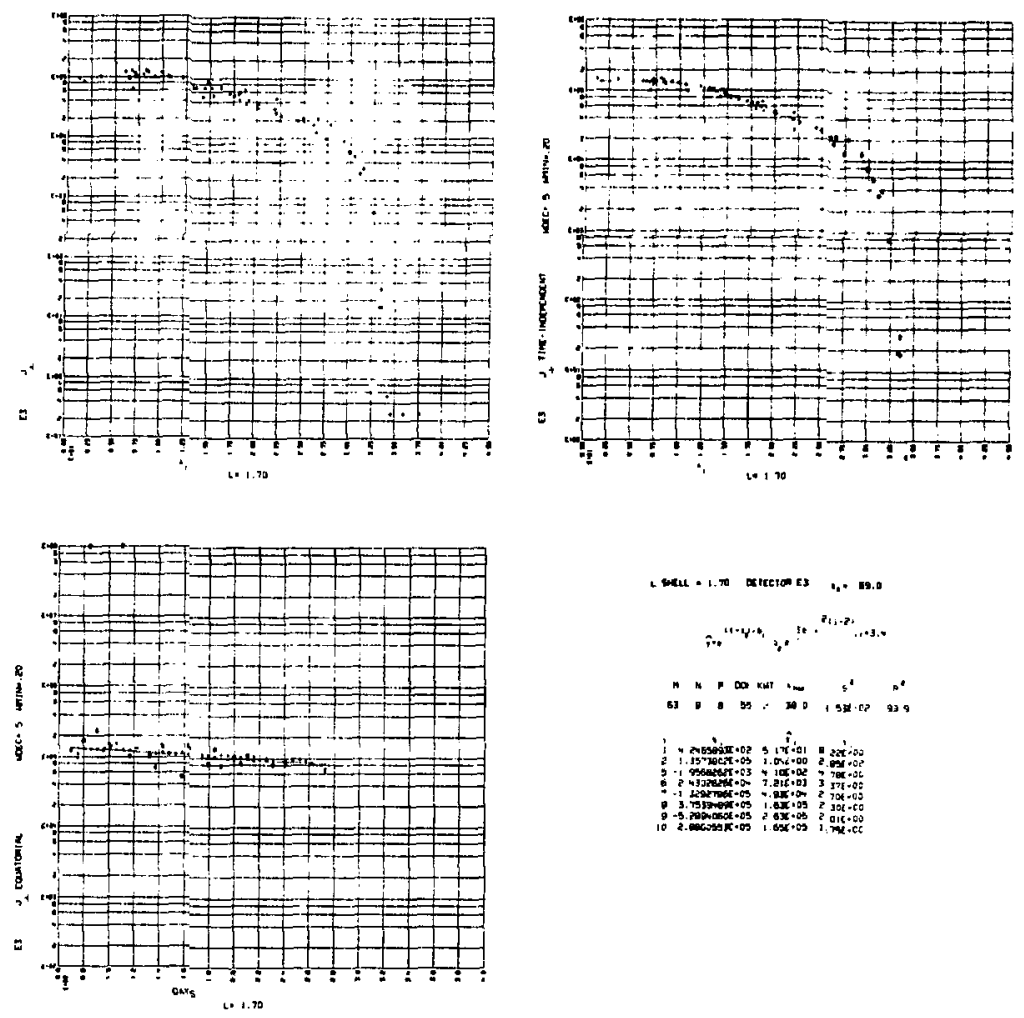

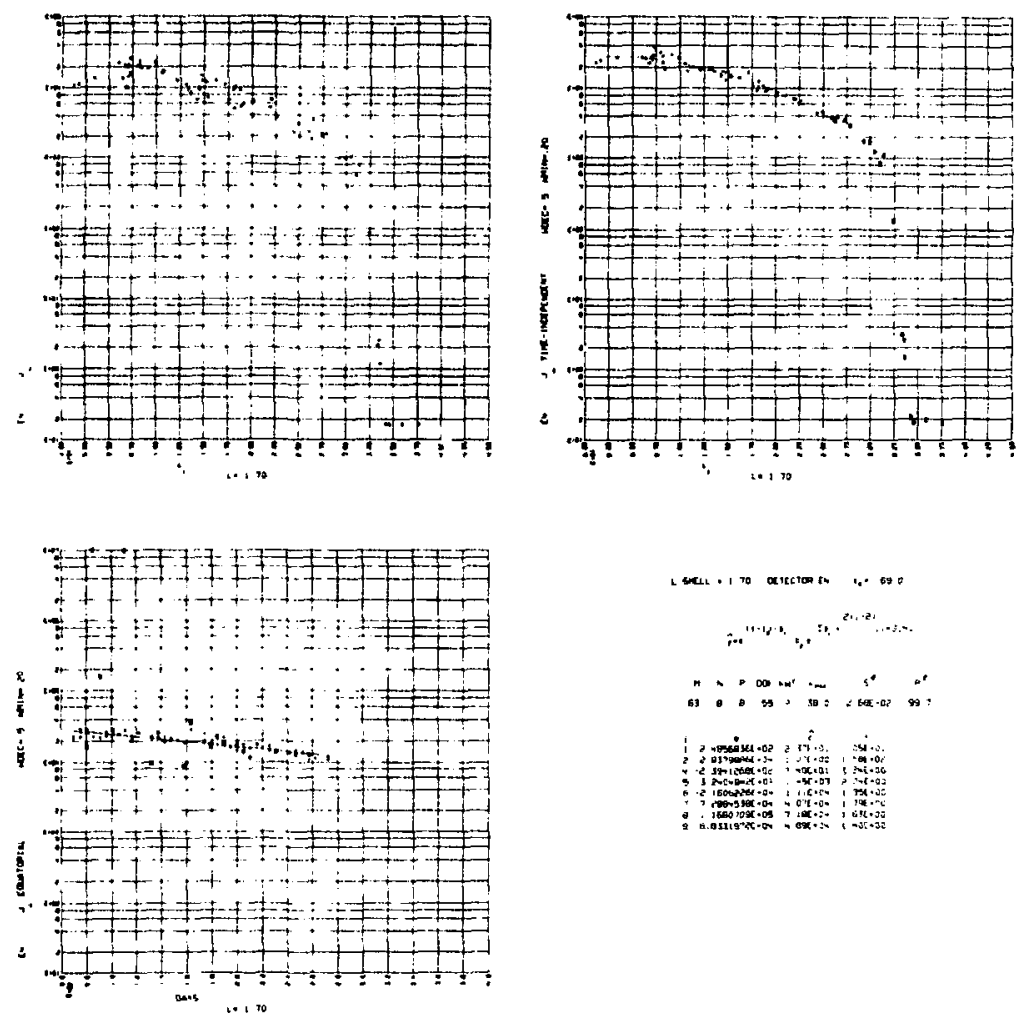

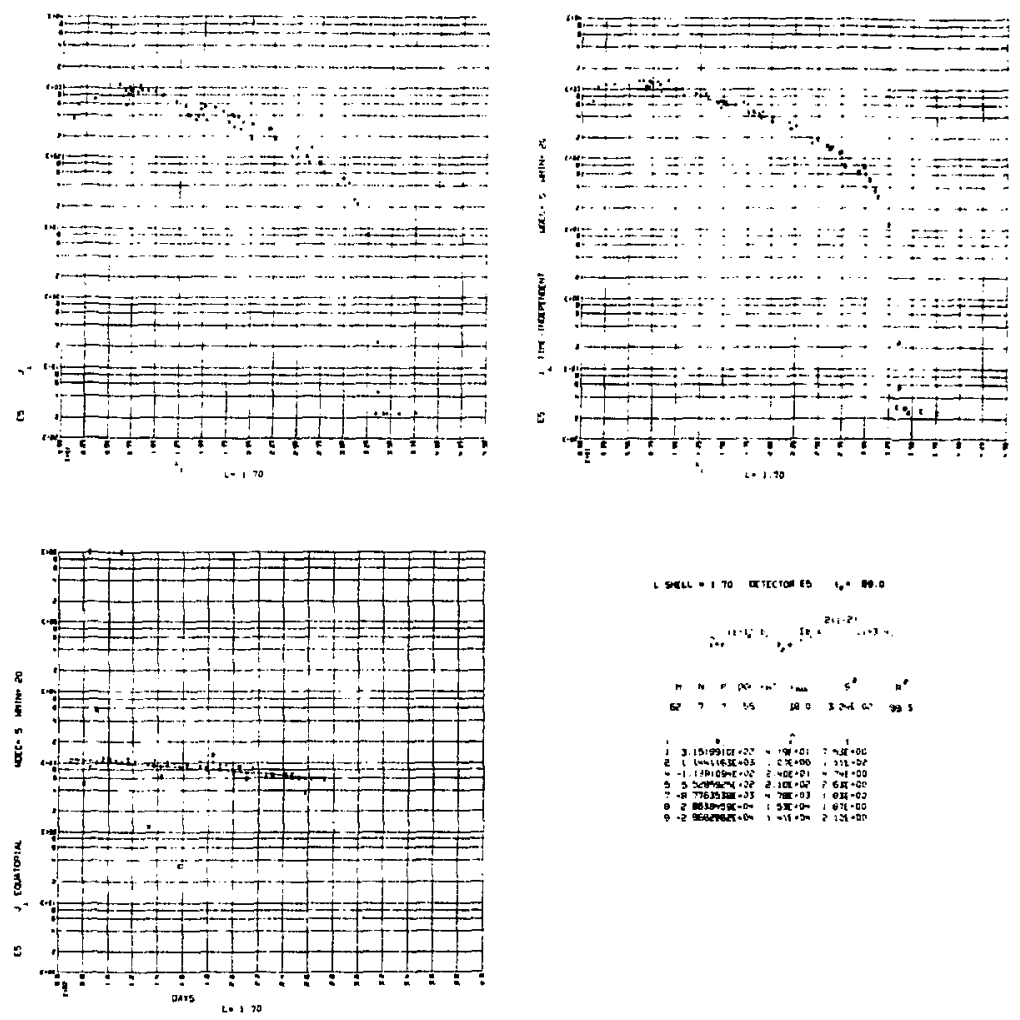

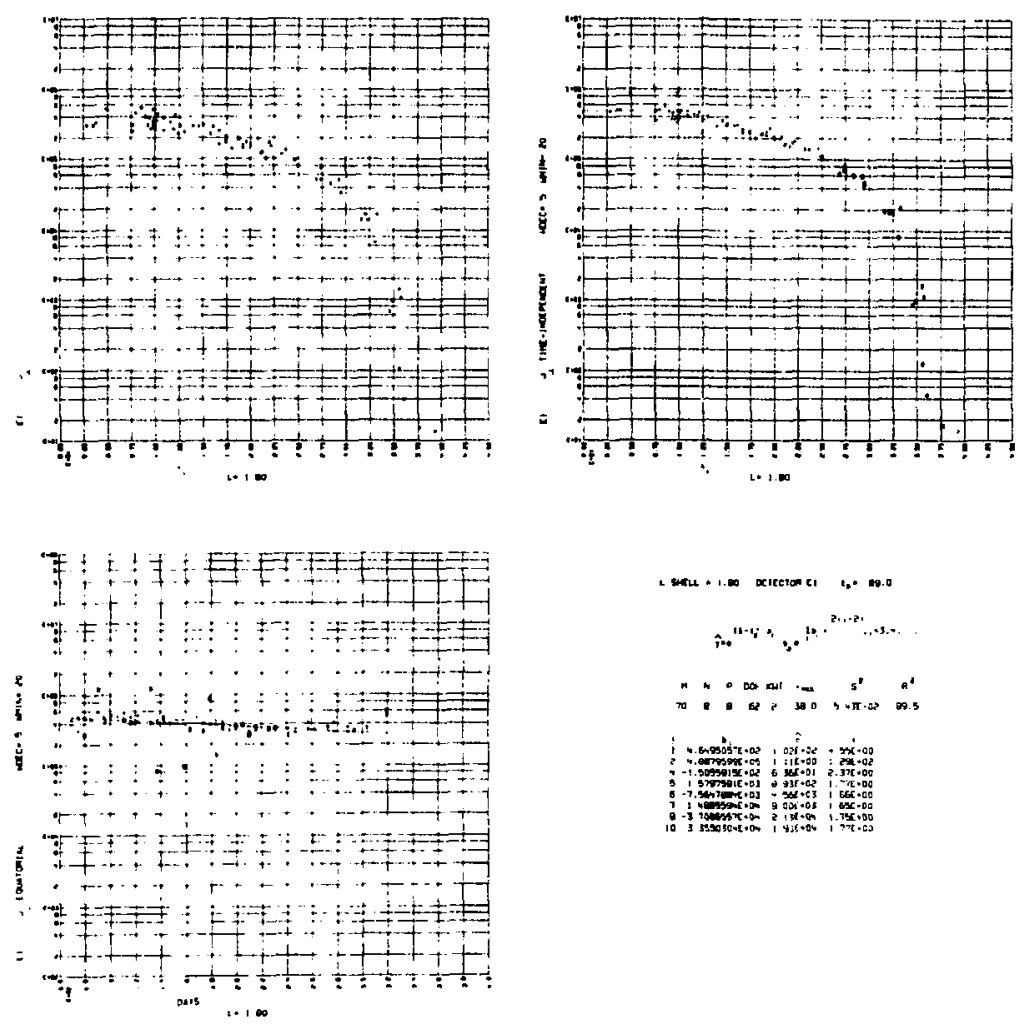

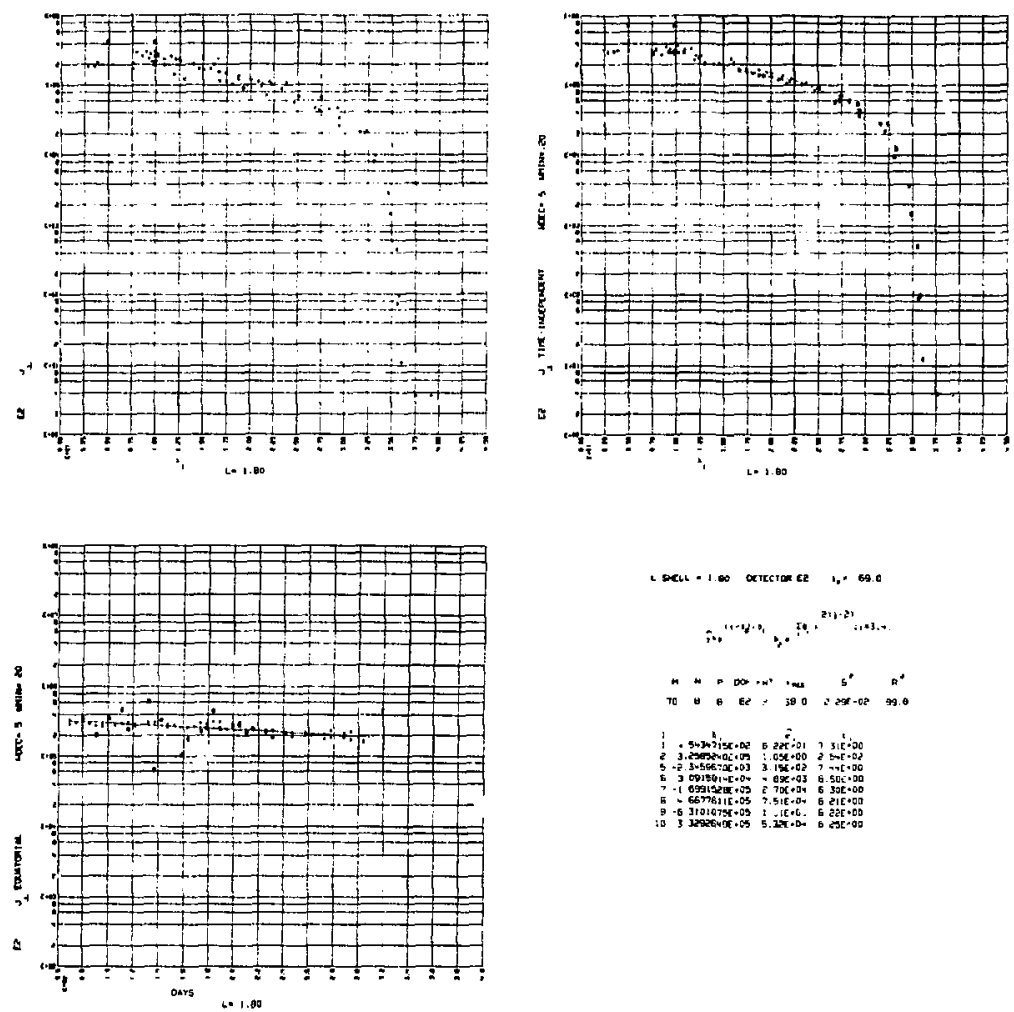

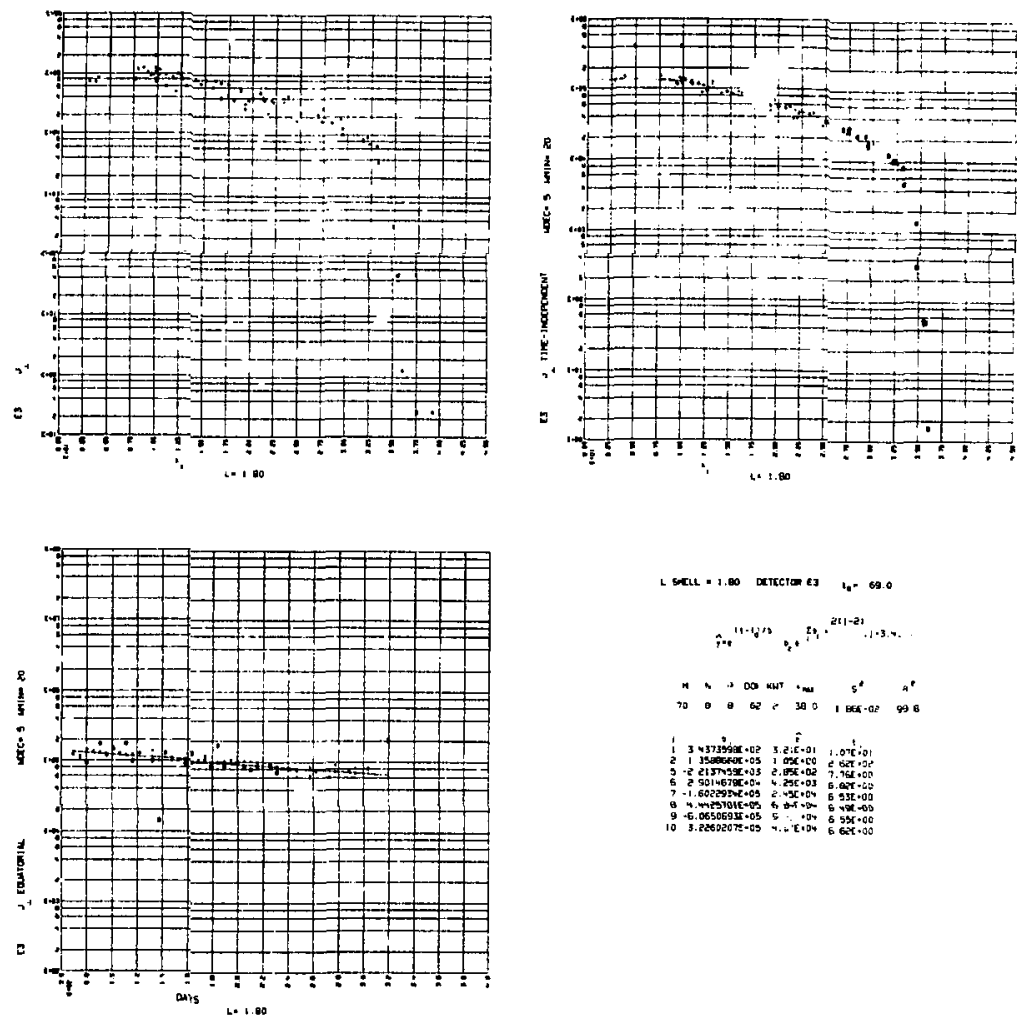

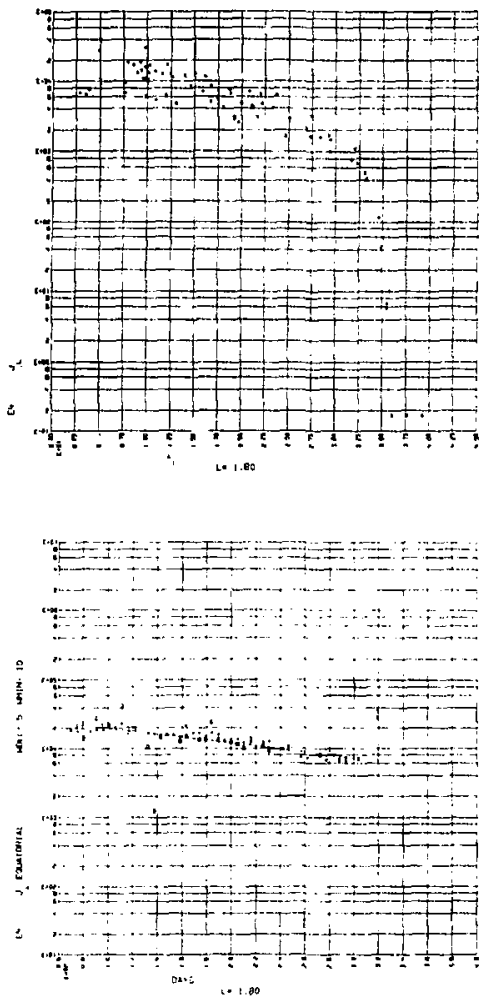
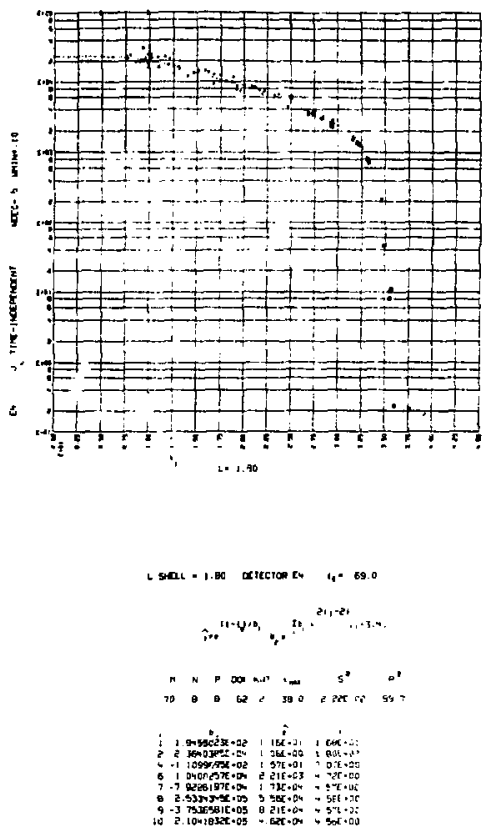

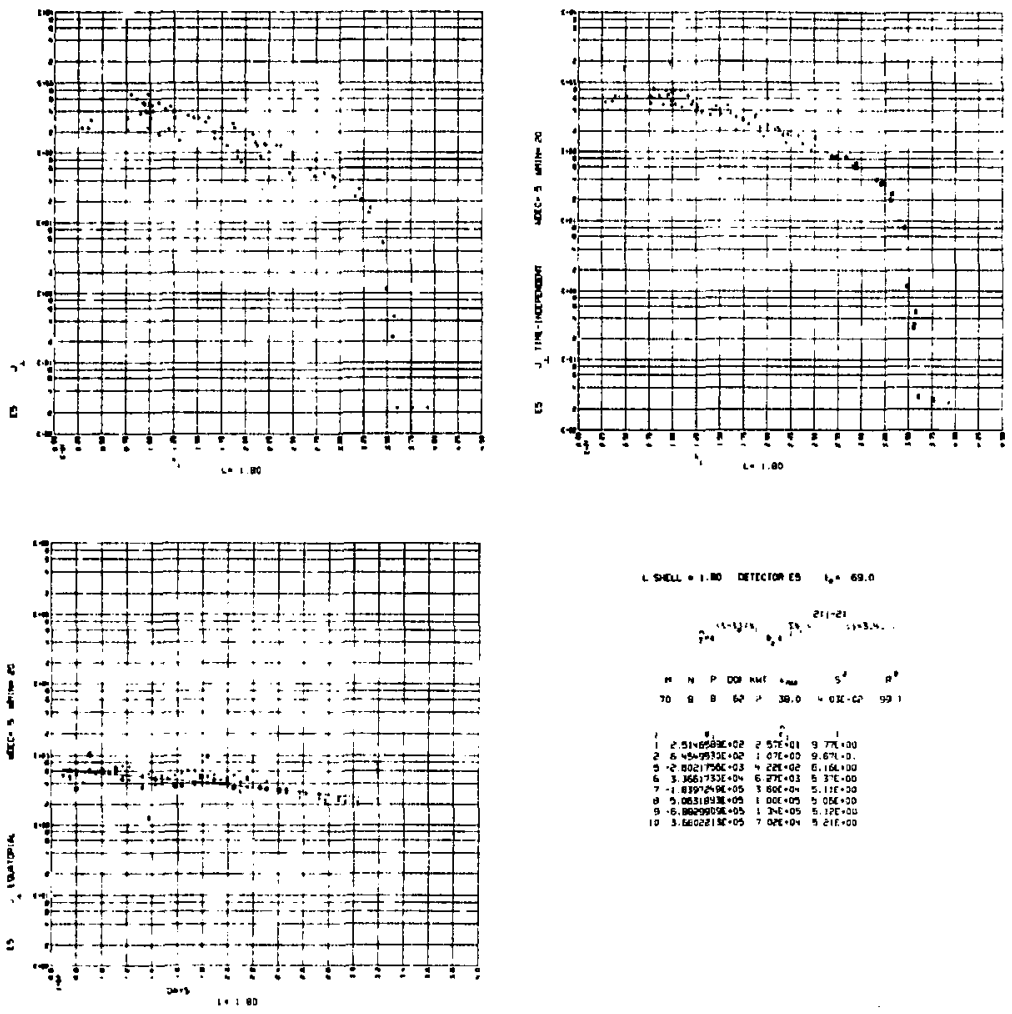

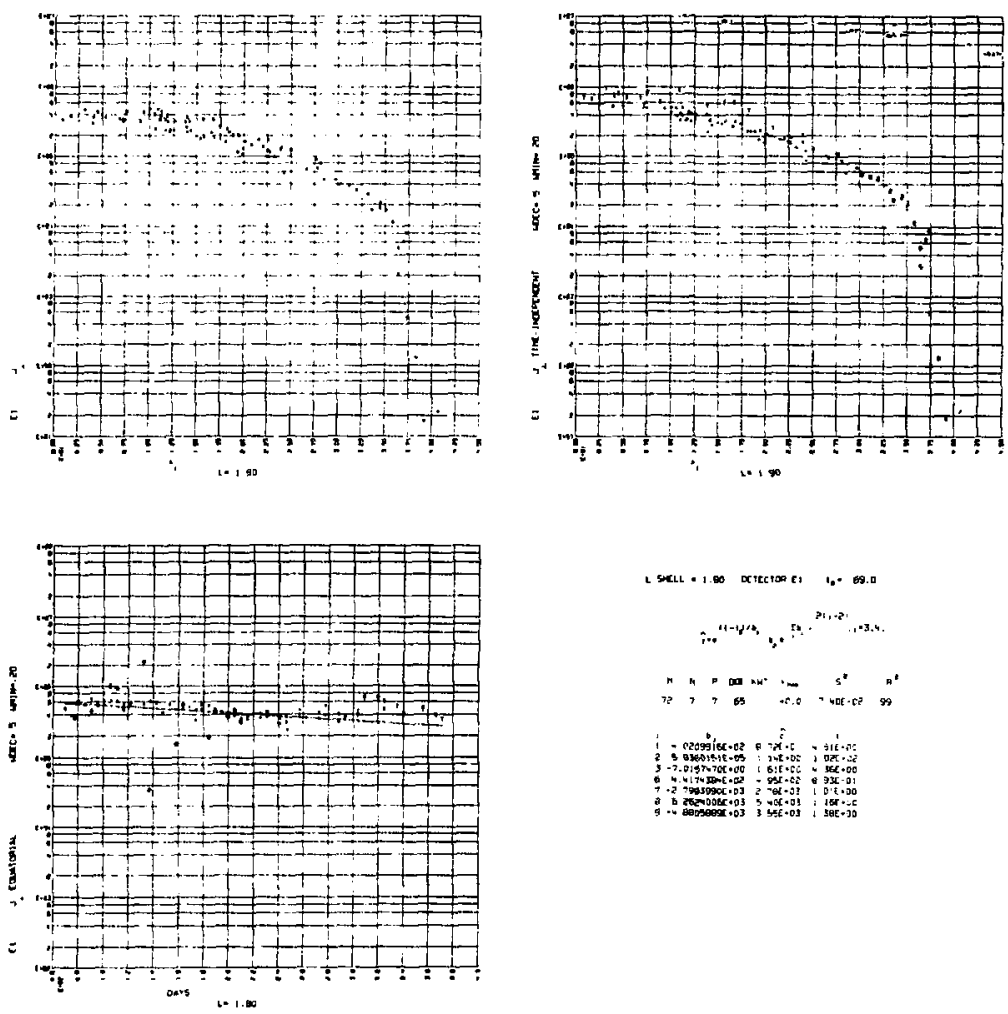

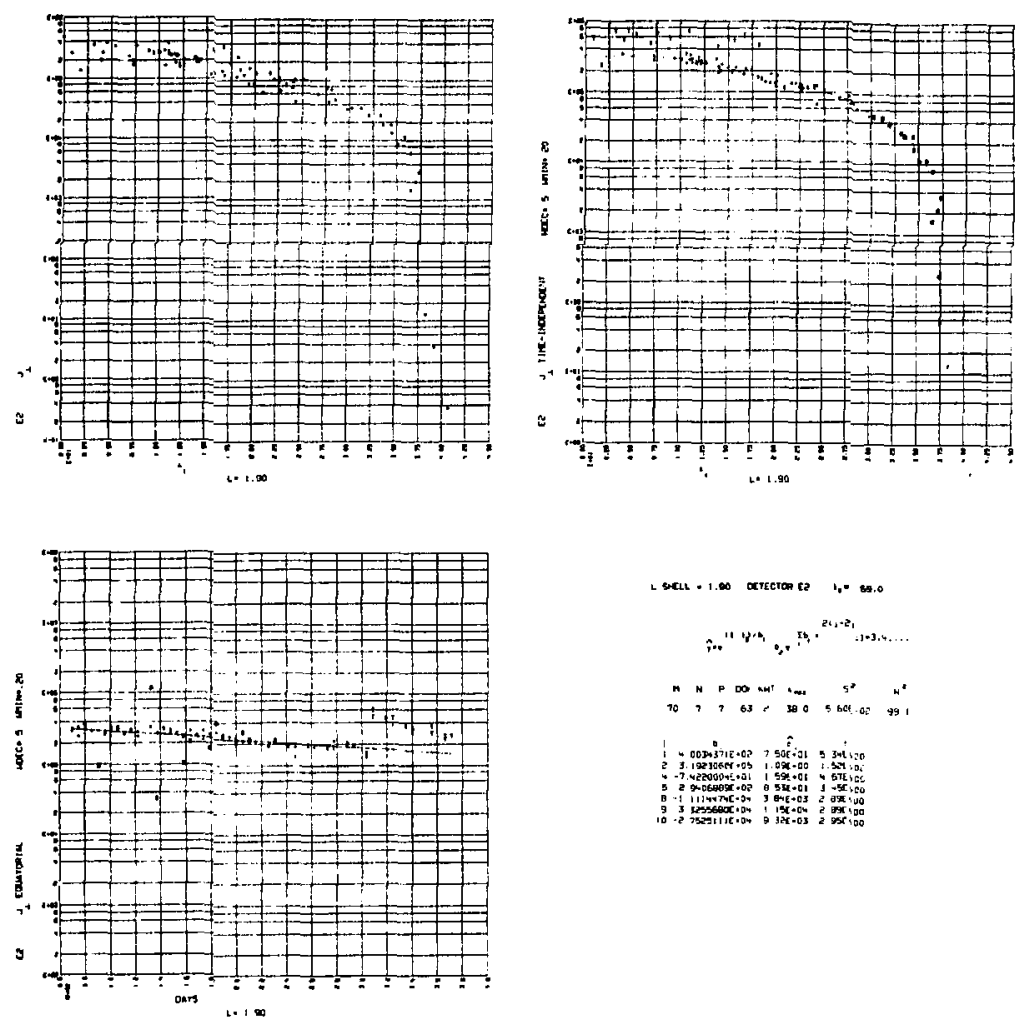

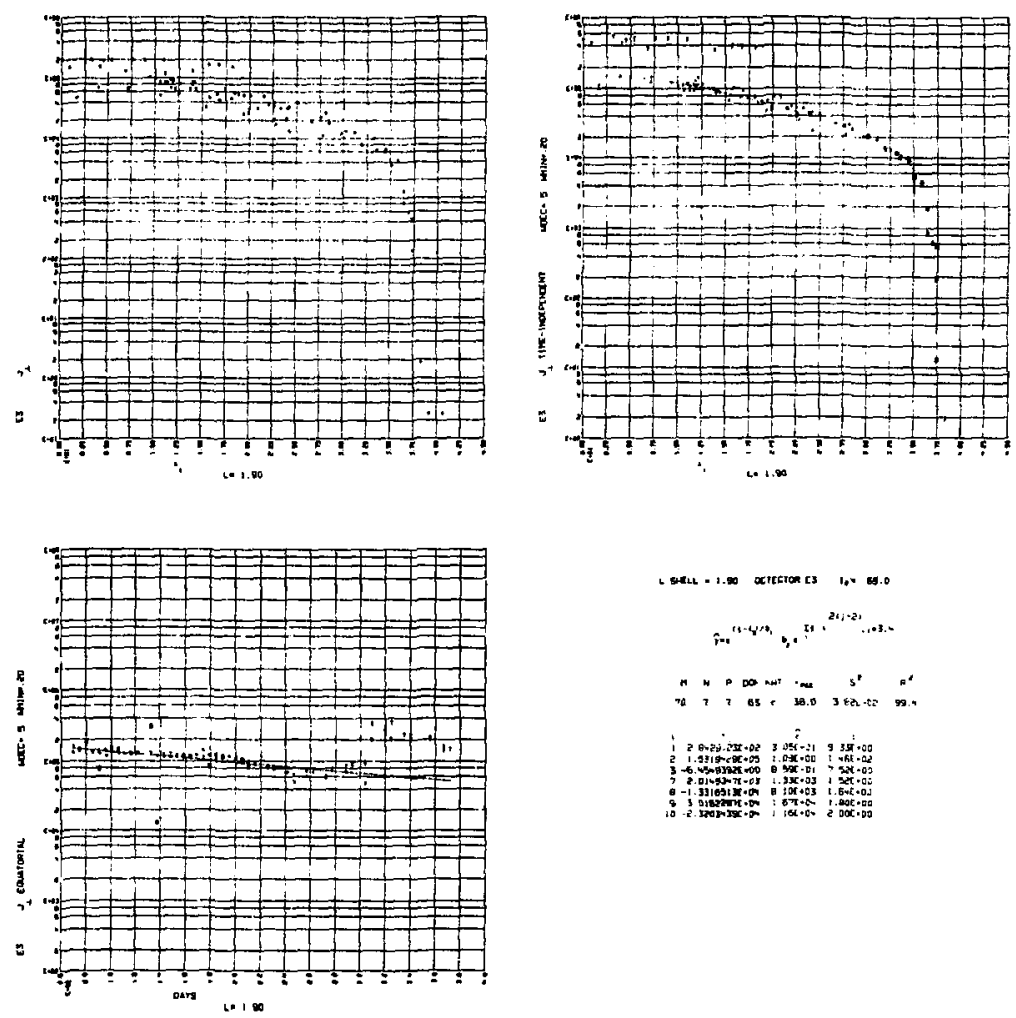

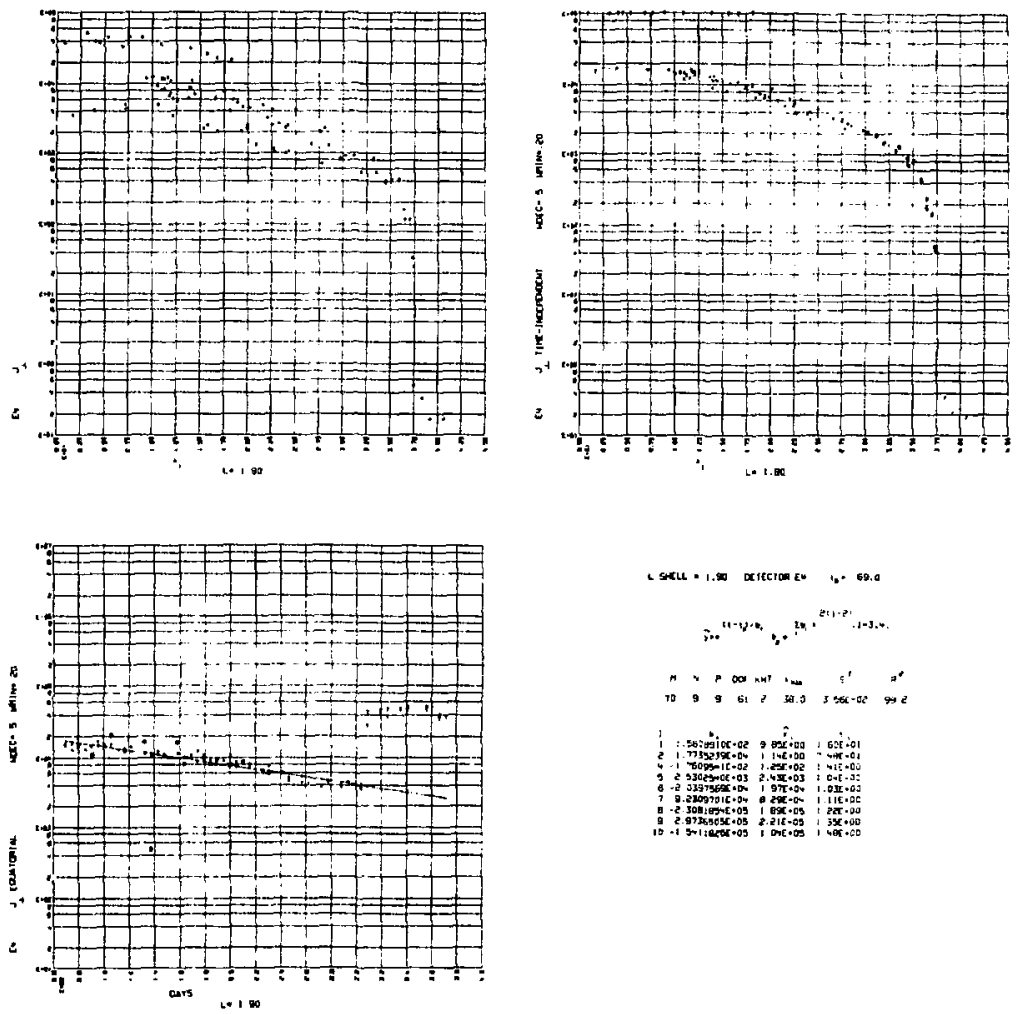

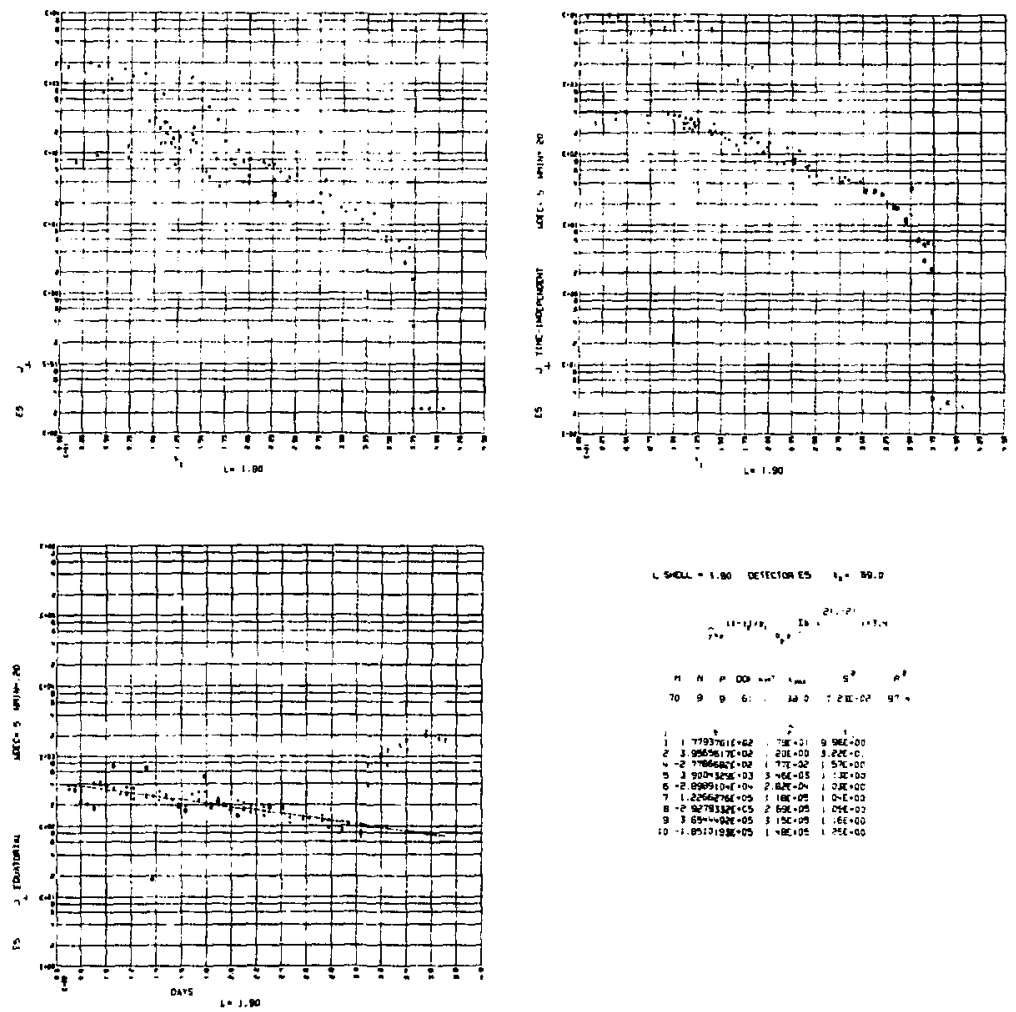

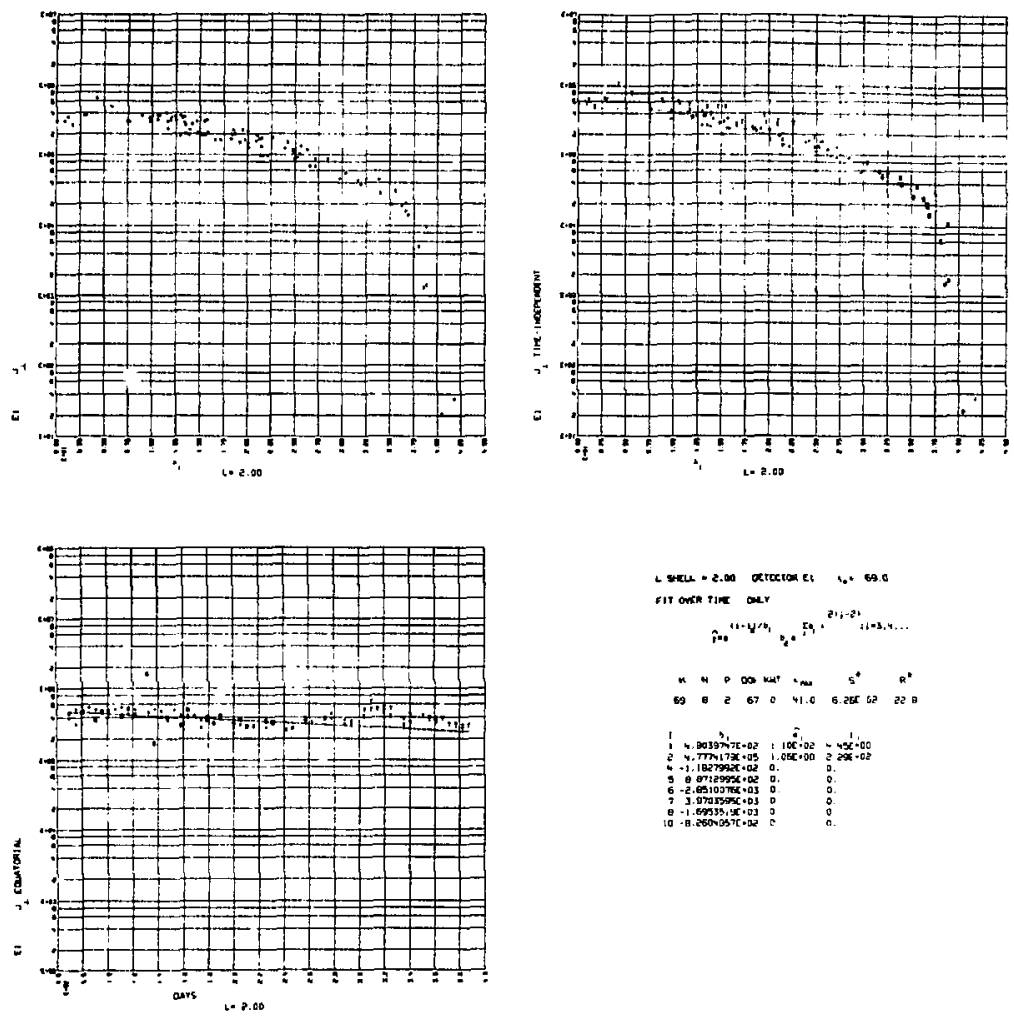

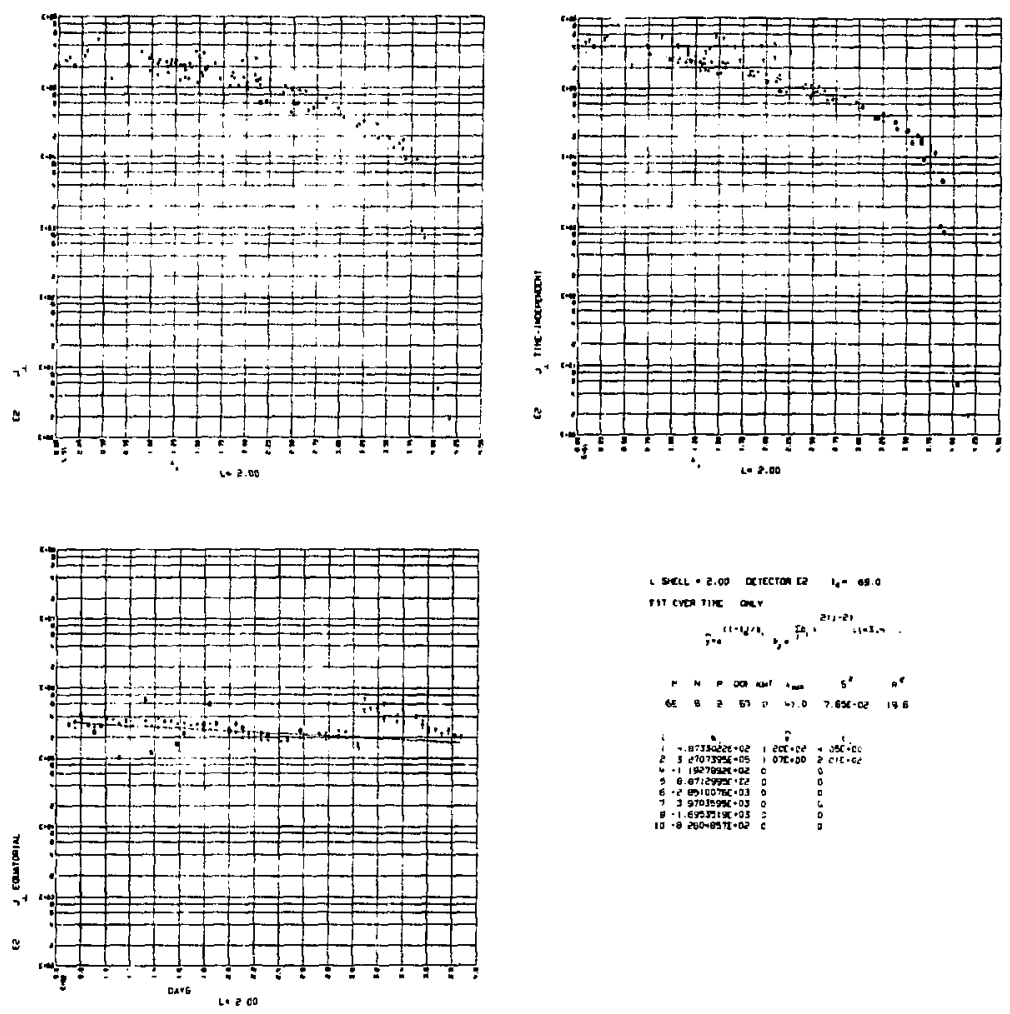

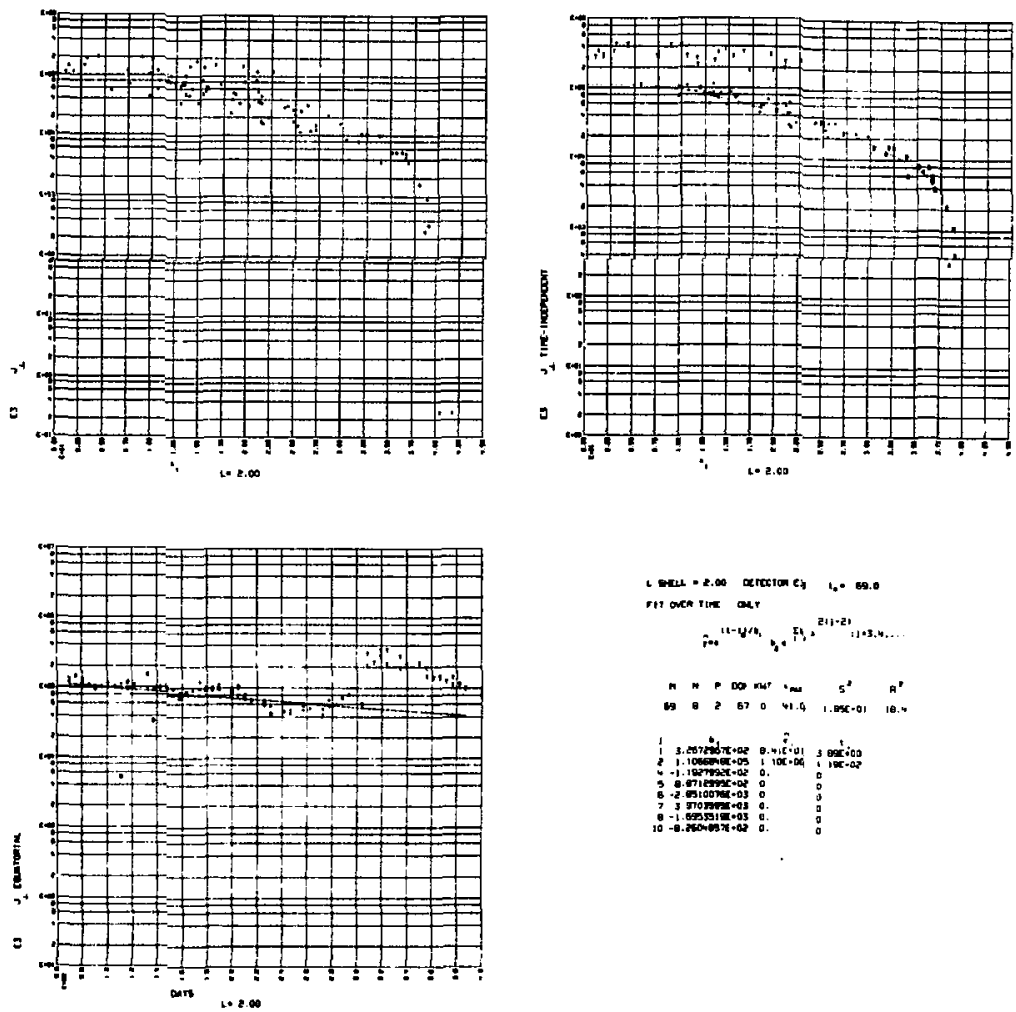

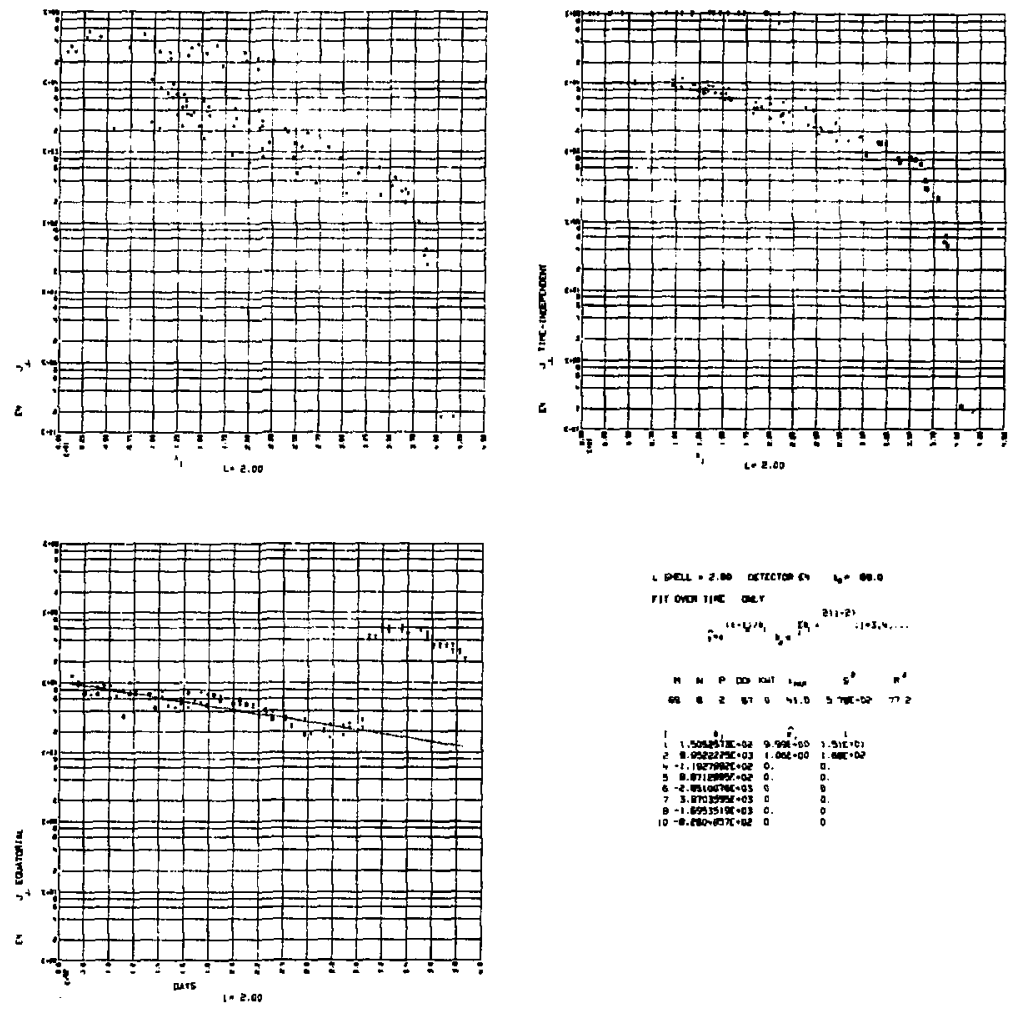

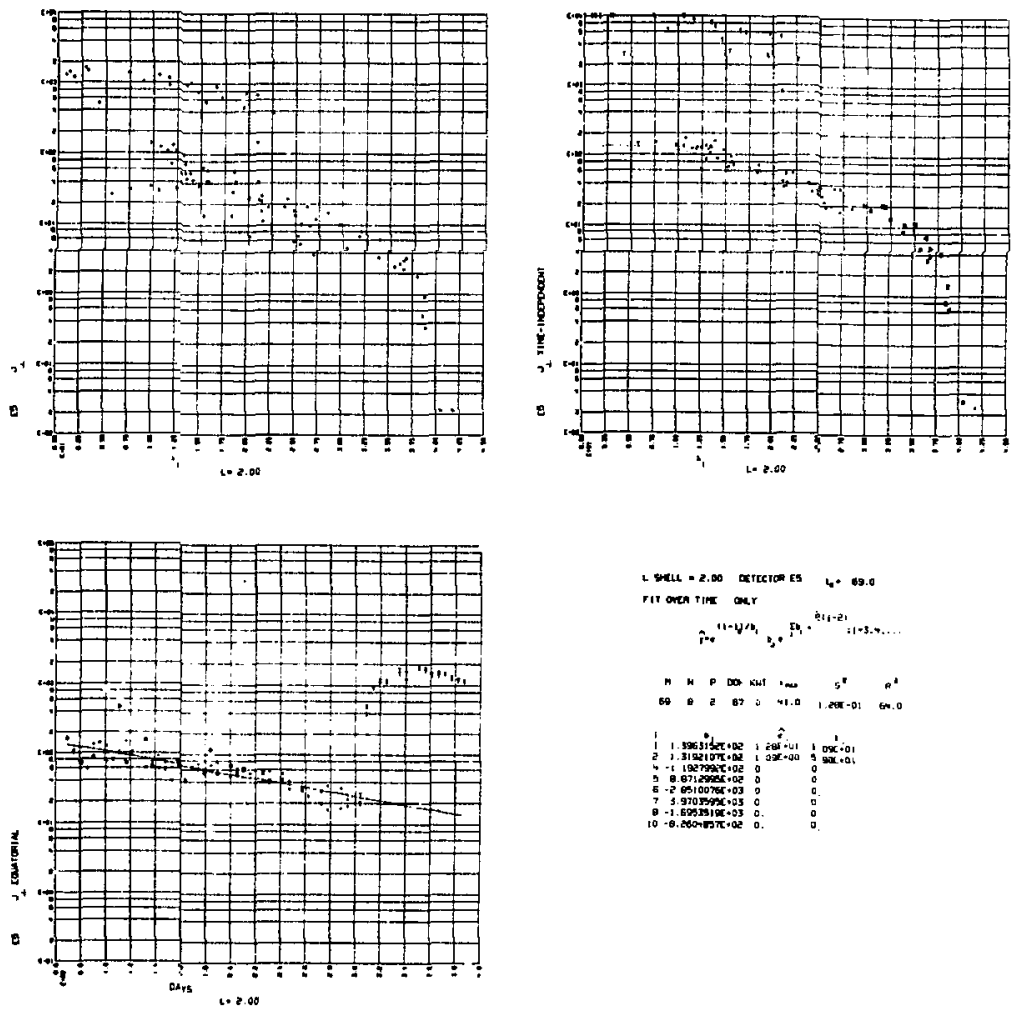

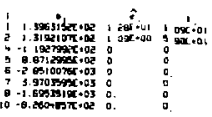



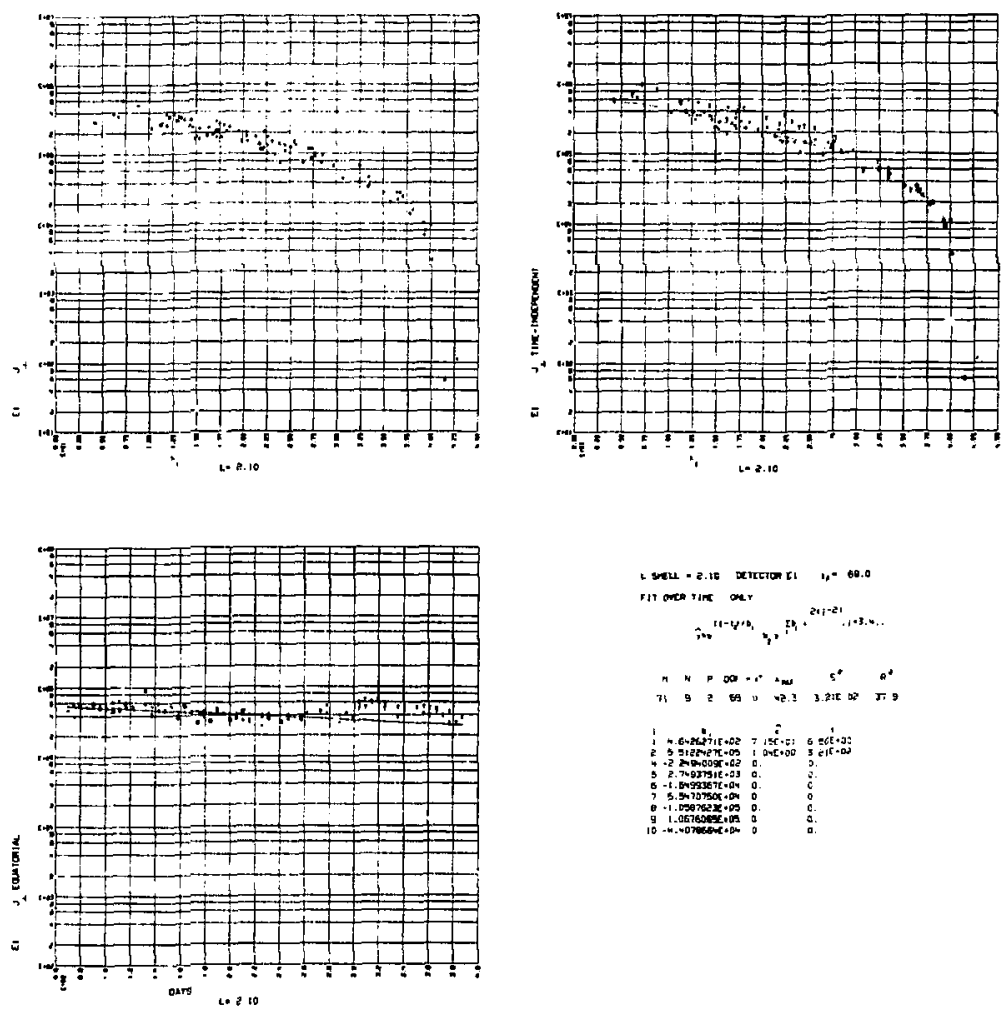

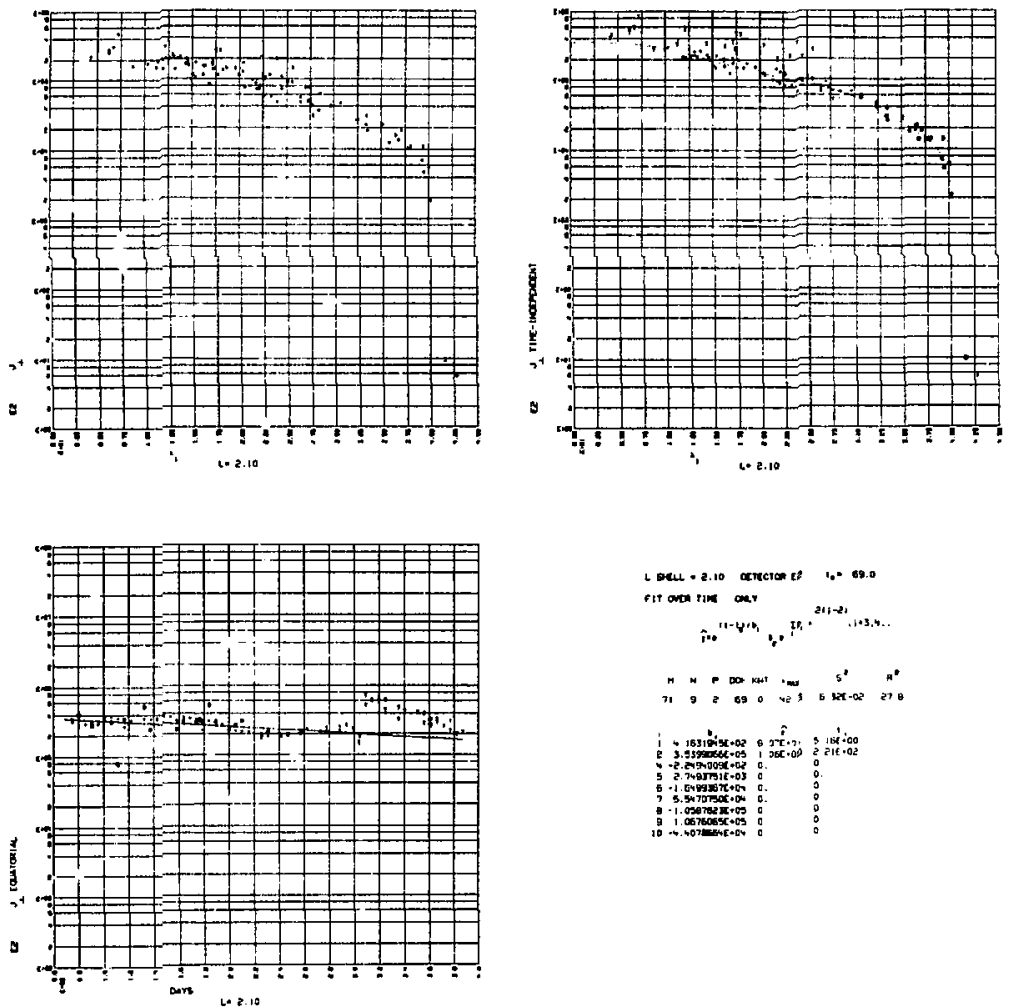

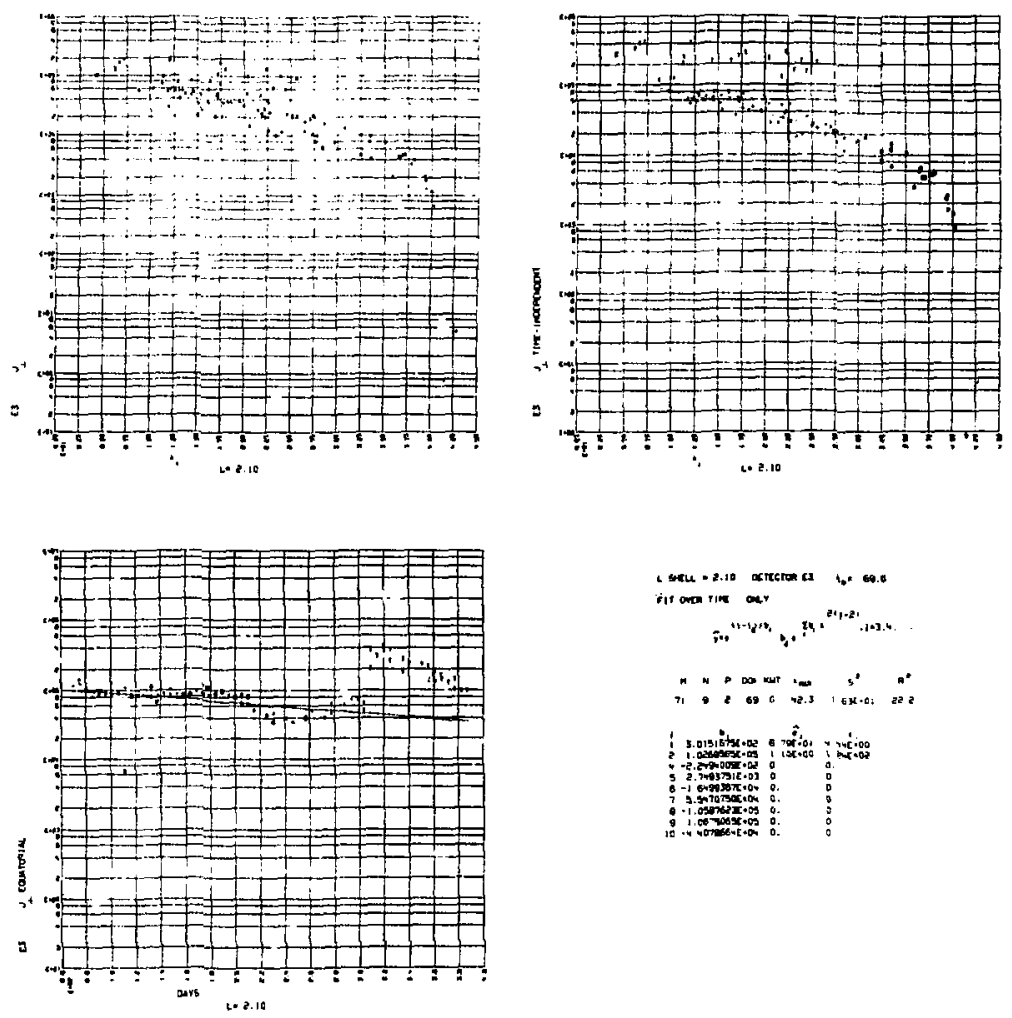


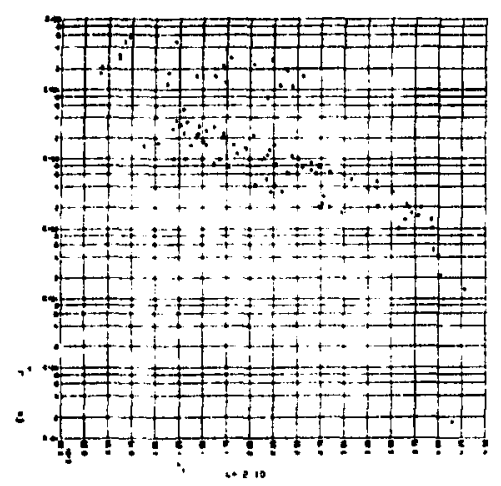

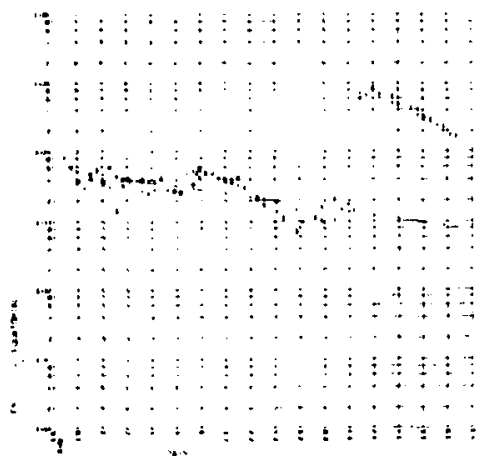
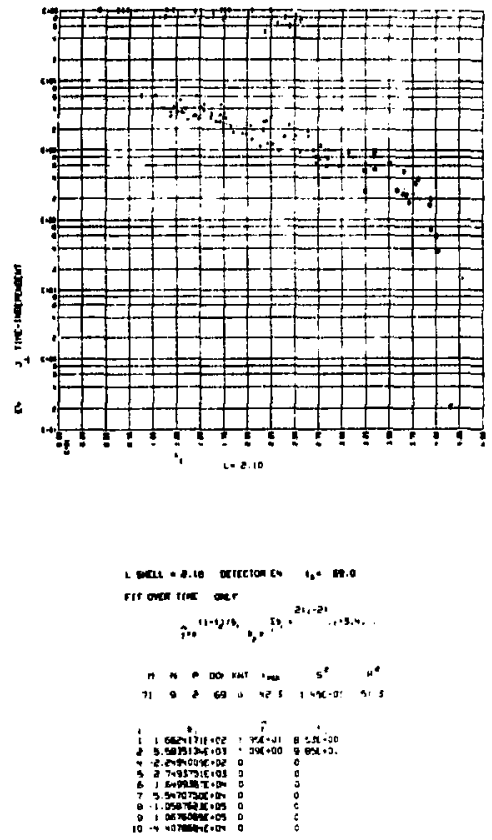

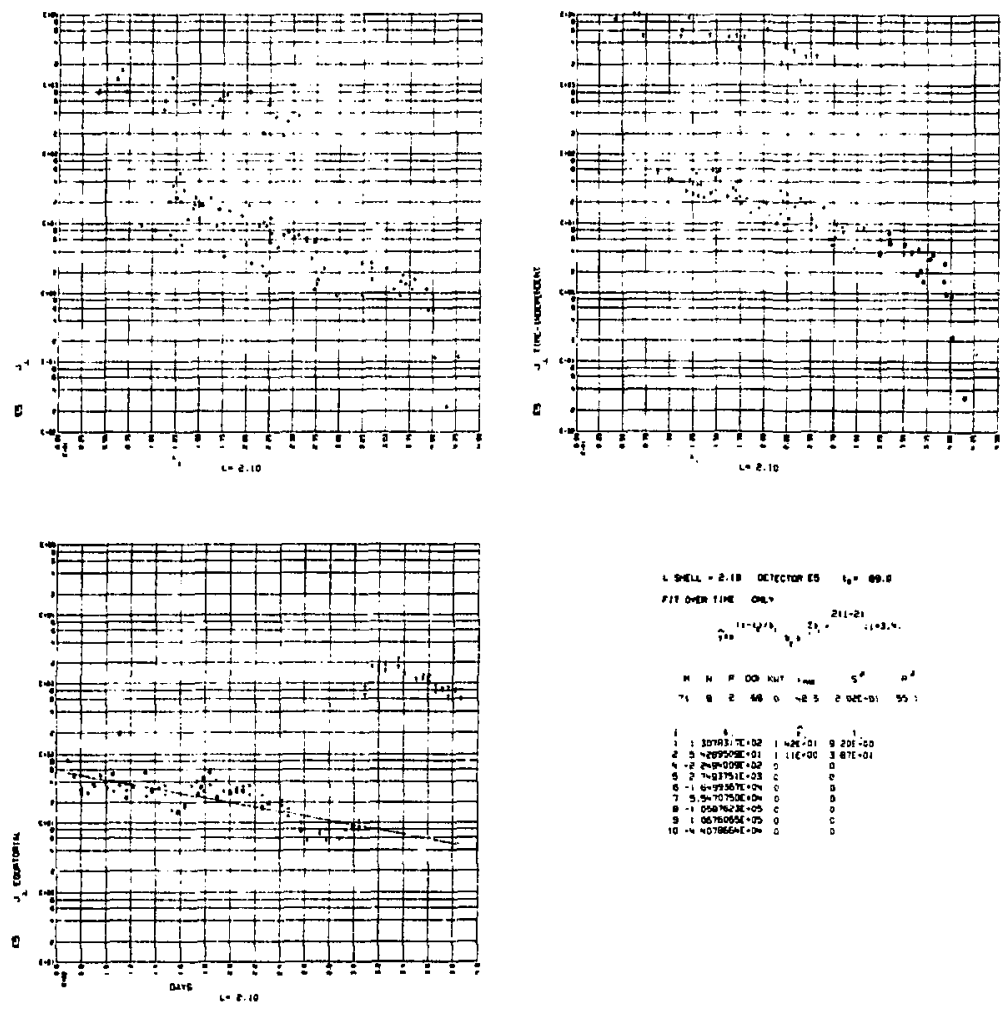

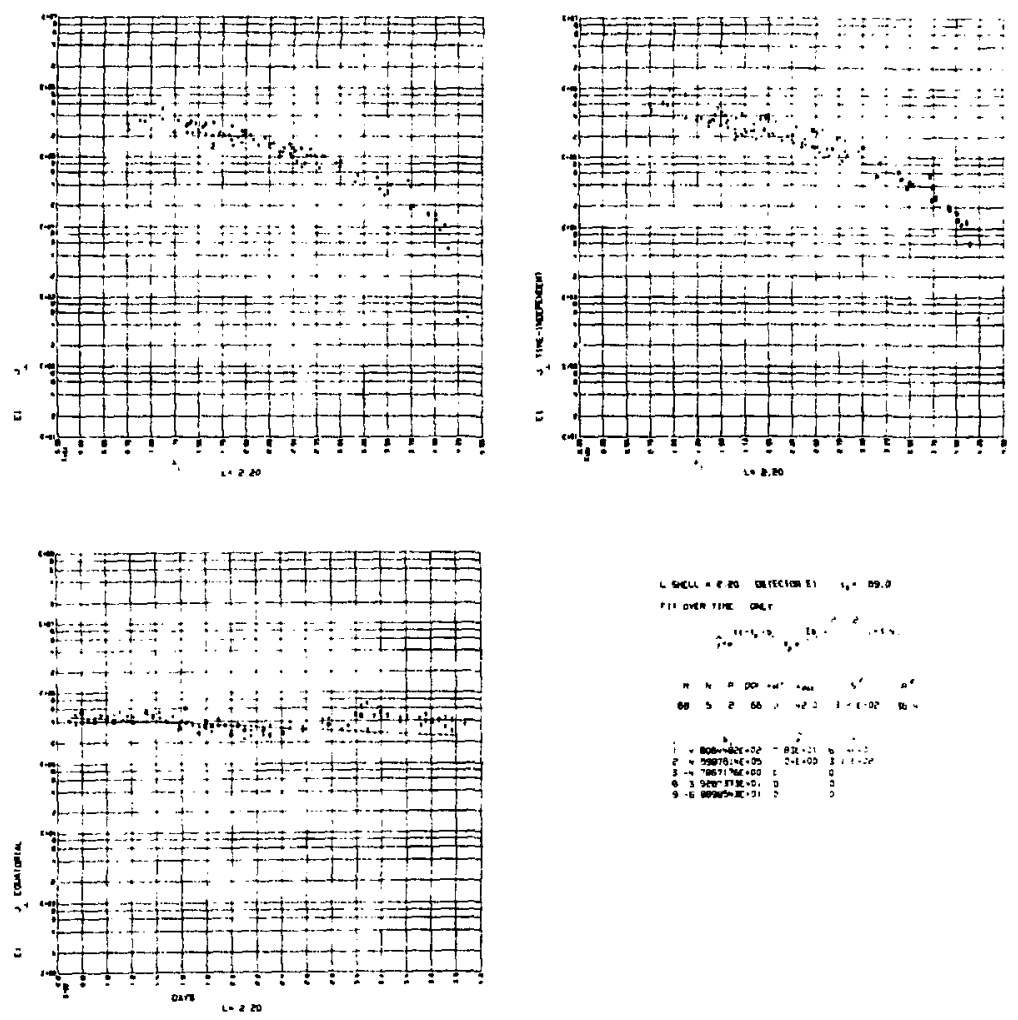

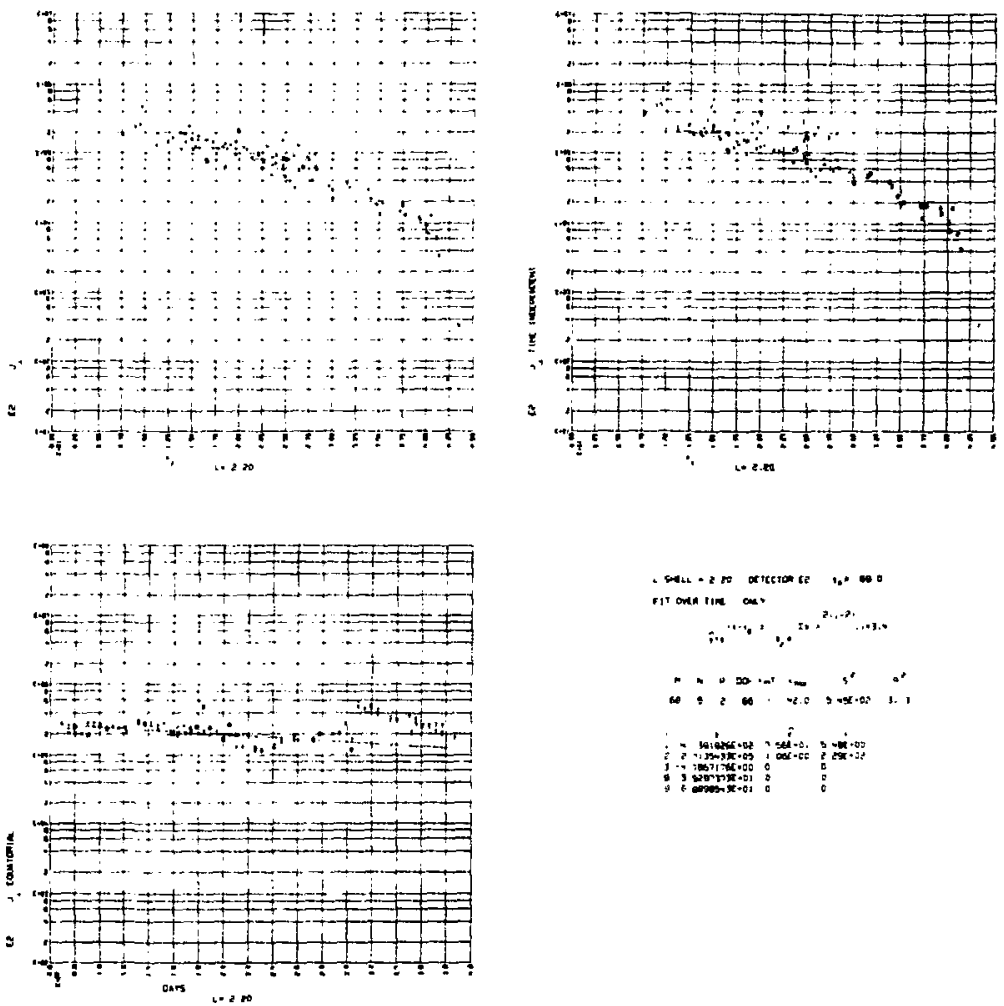

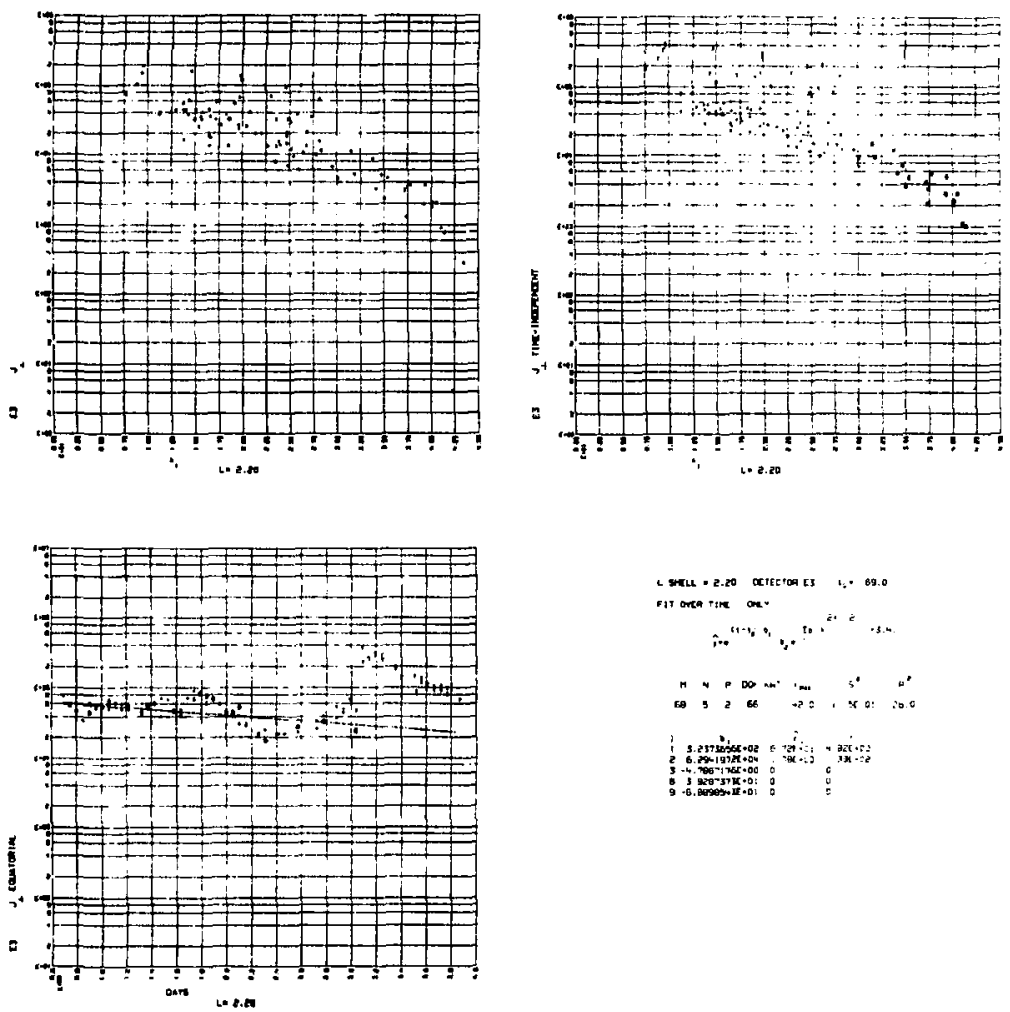

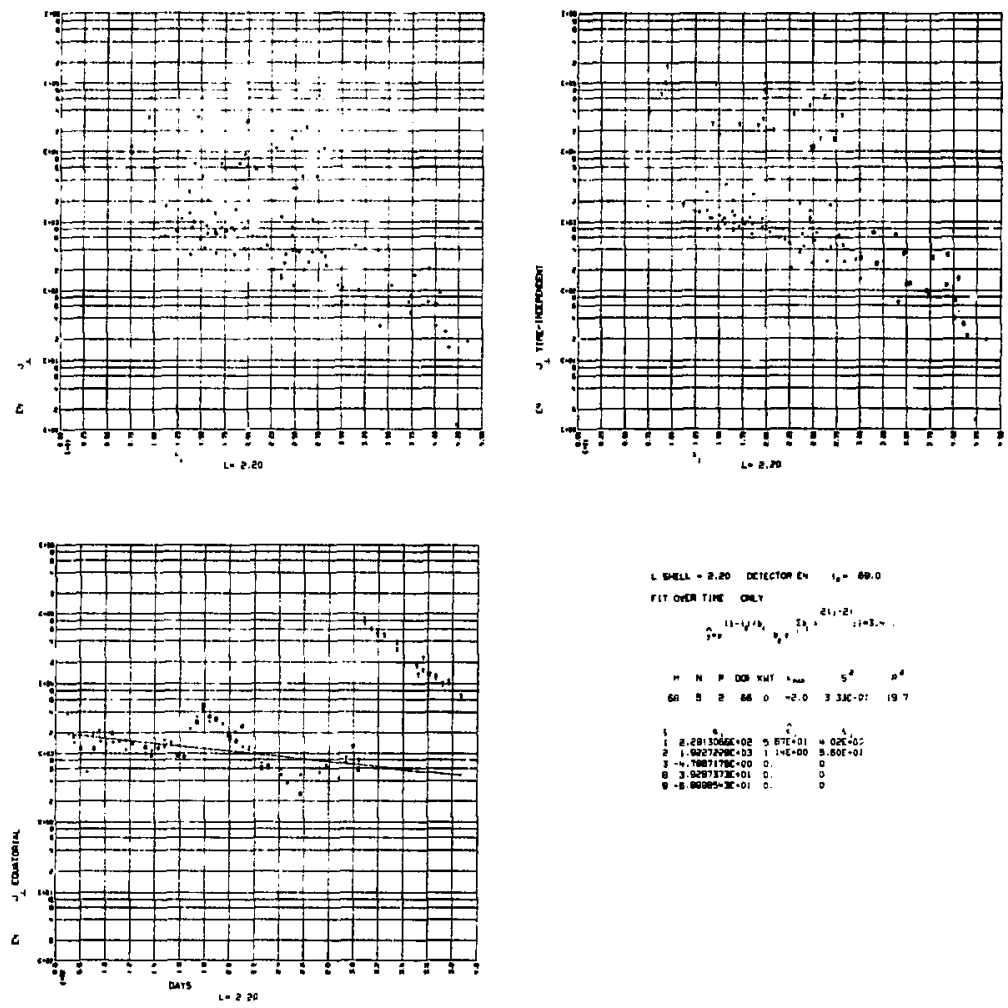

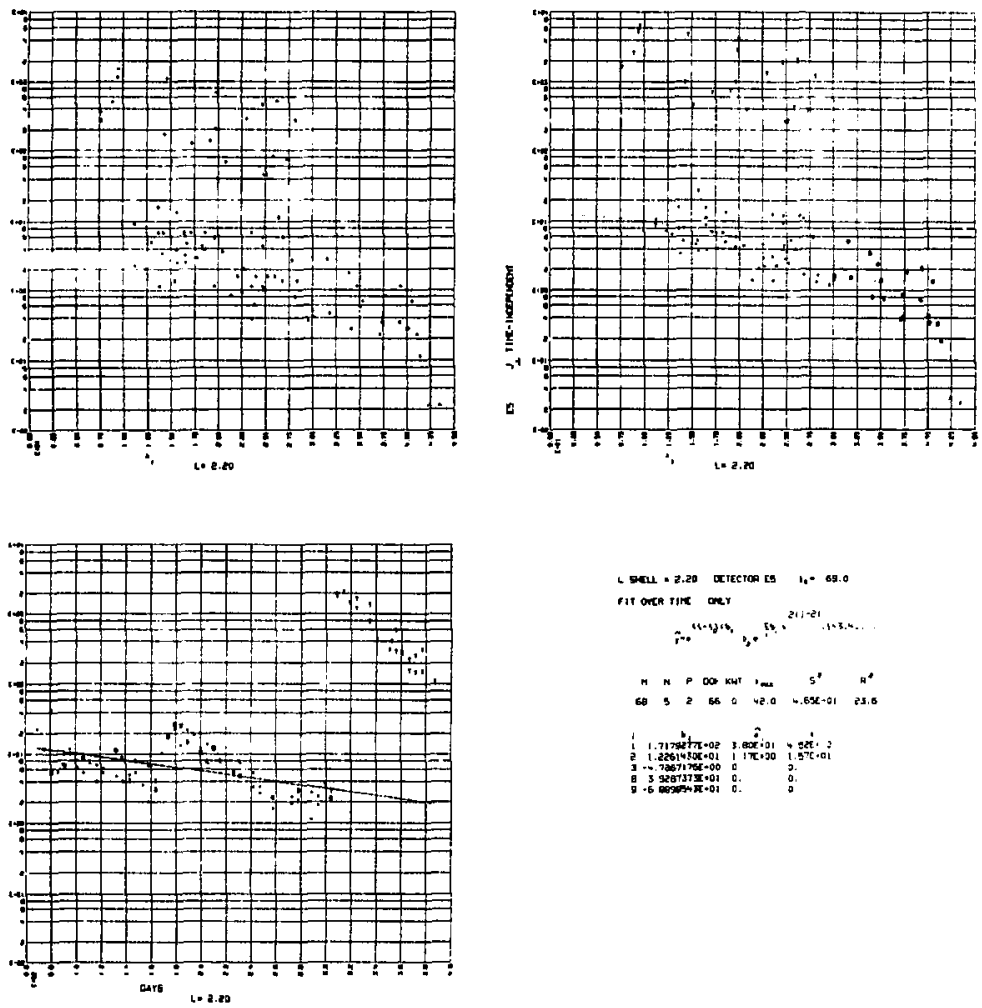

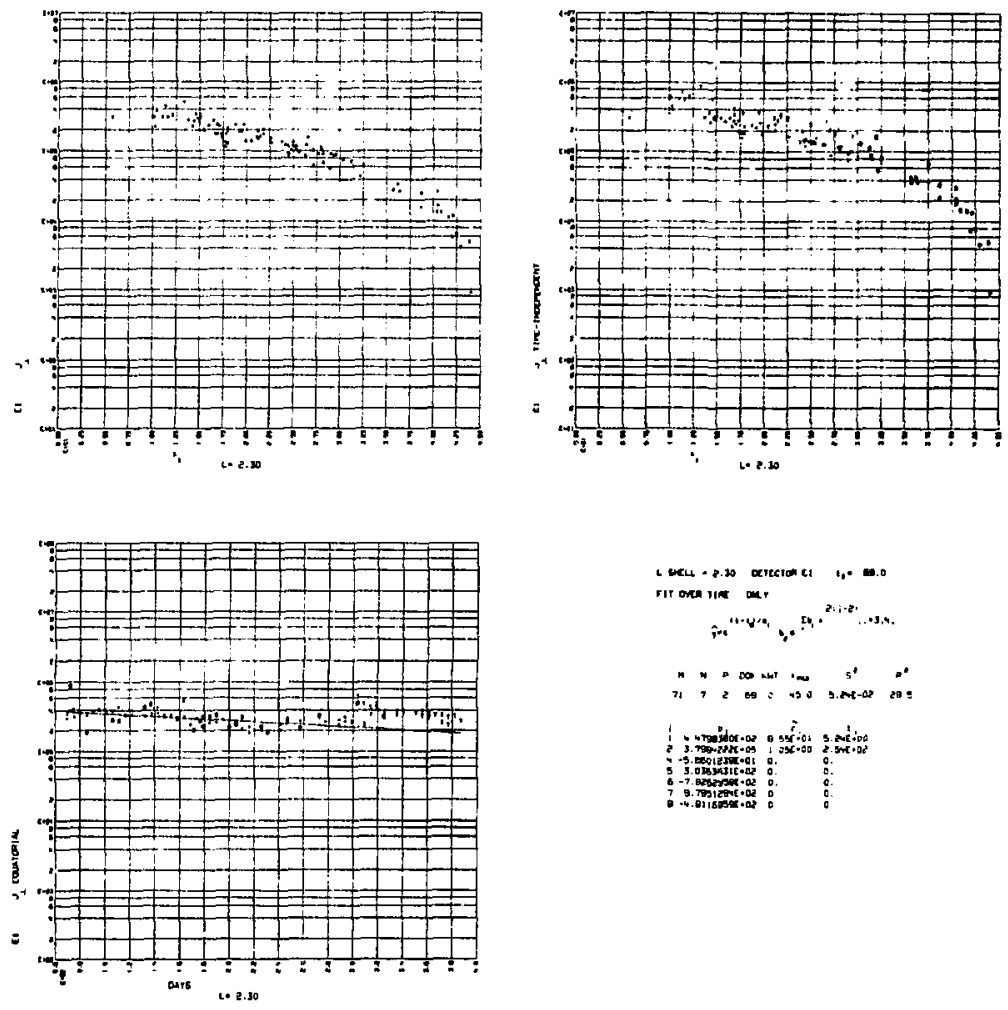

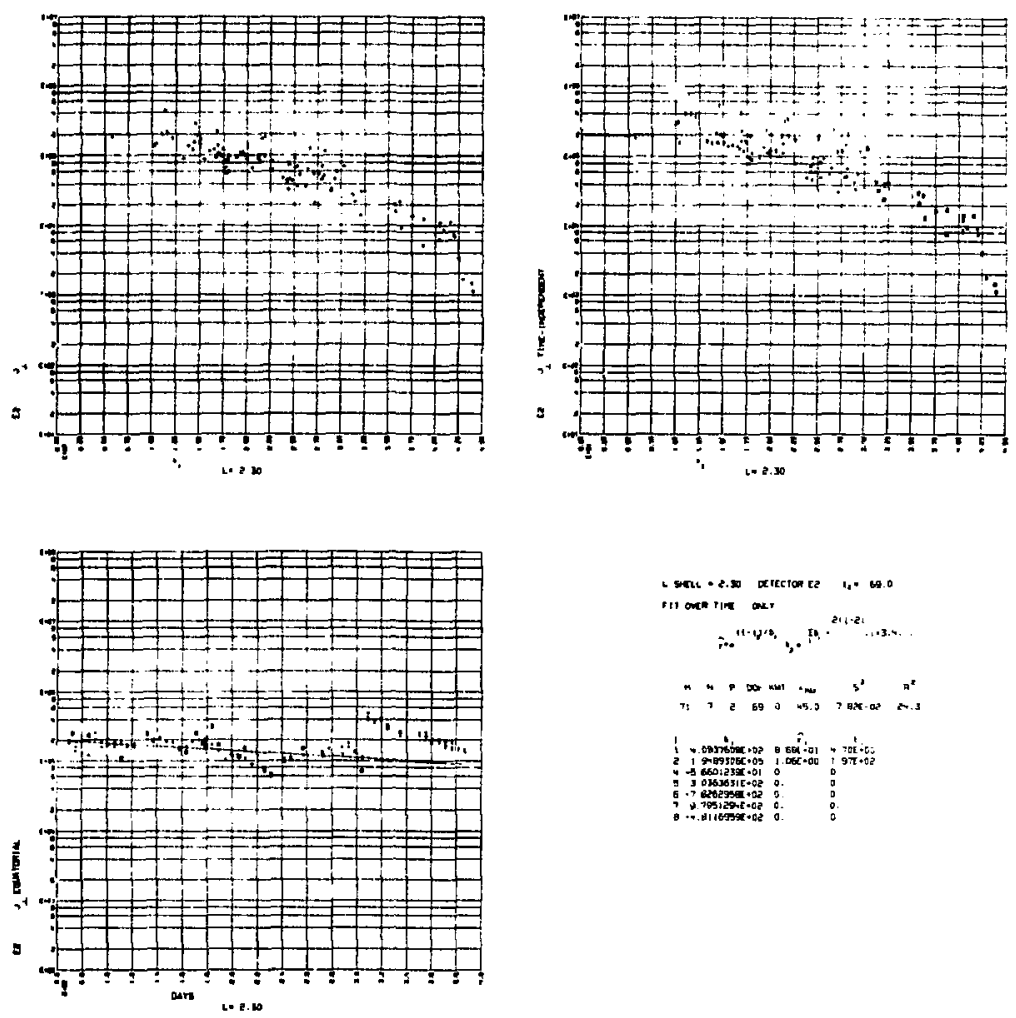

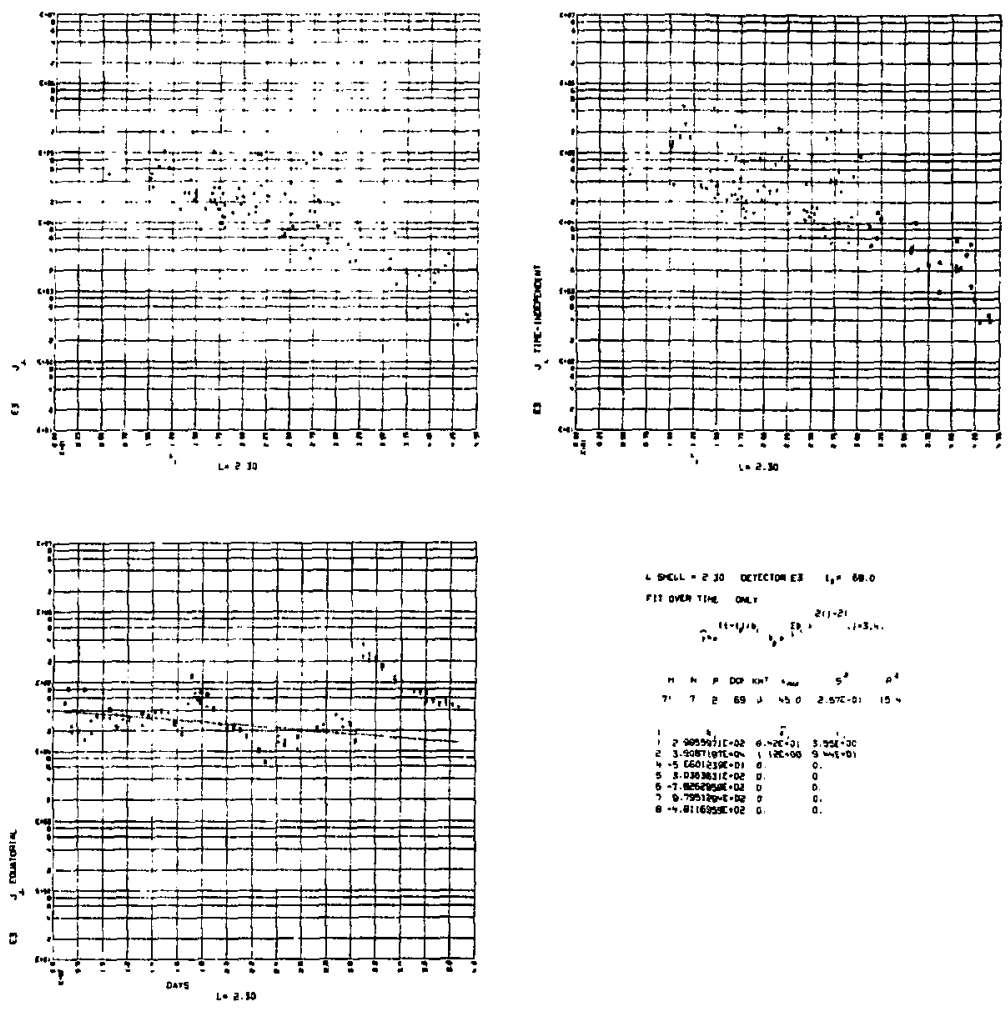

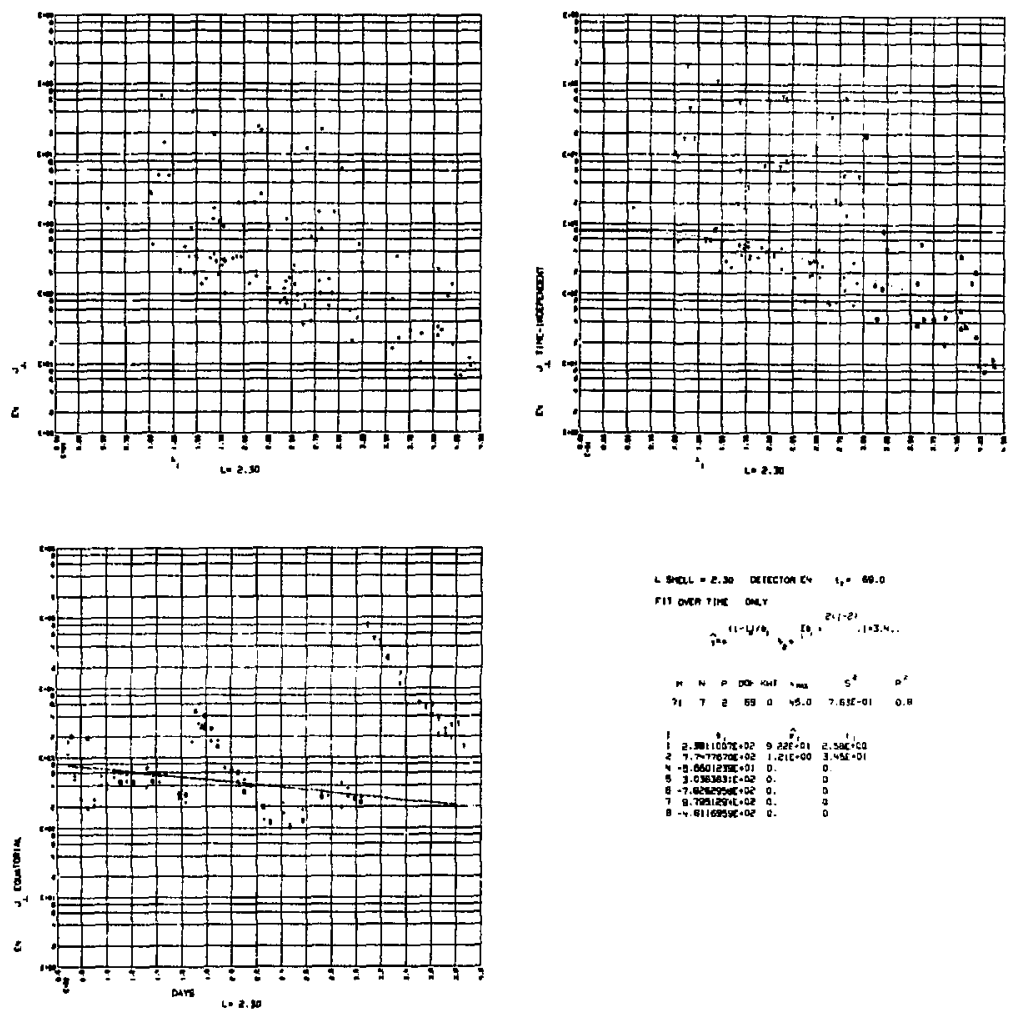

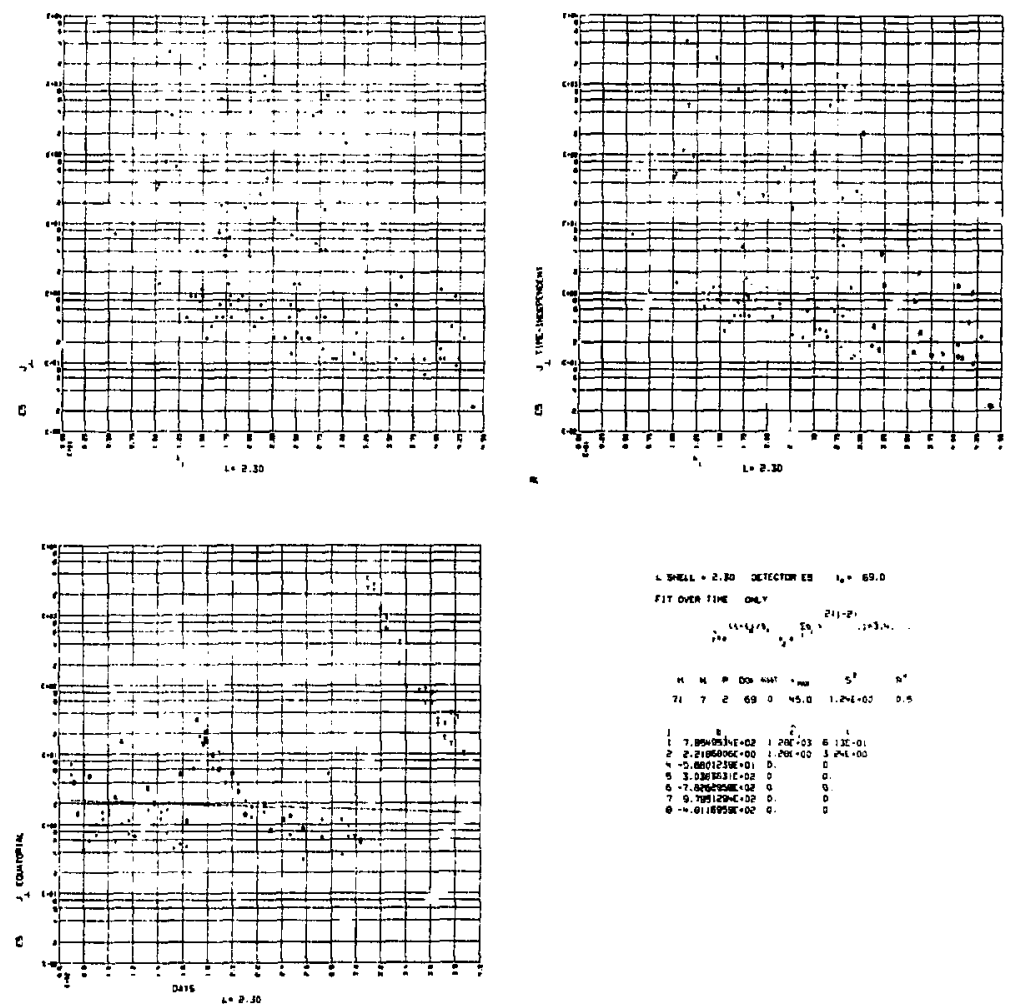

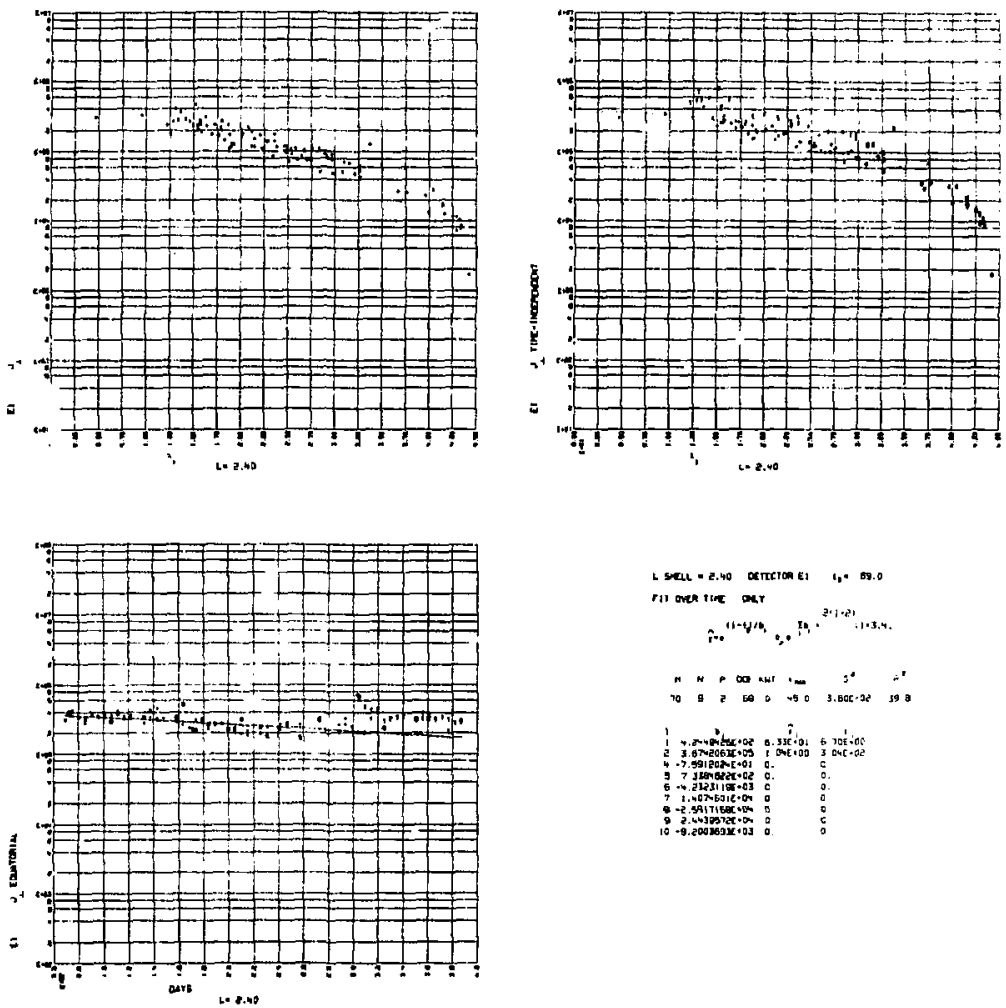

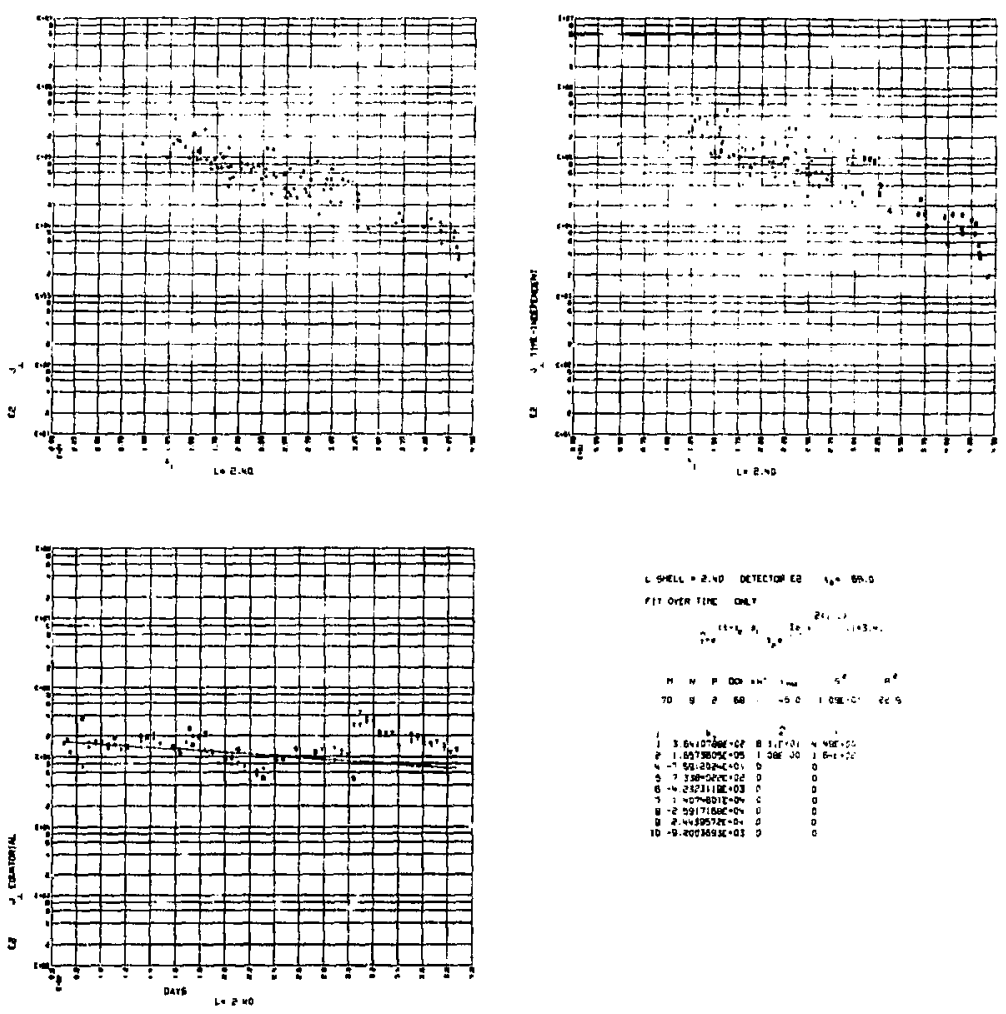

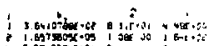

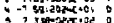

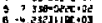

$8+4.23711[x+0]$

- $3917 \sec -4$

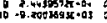



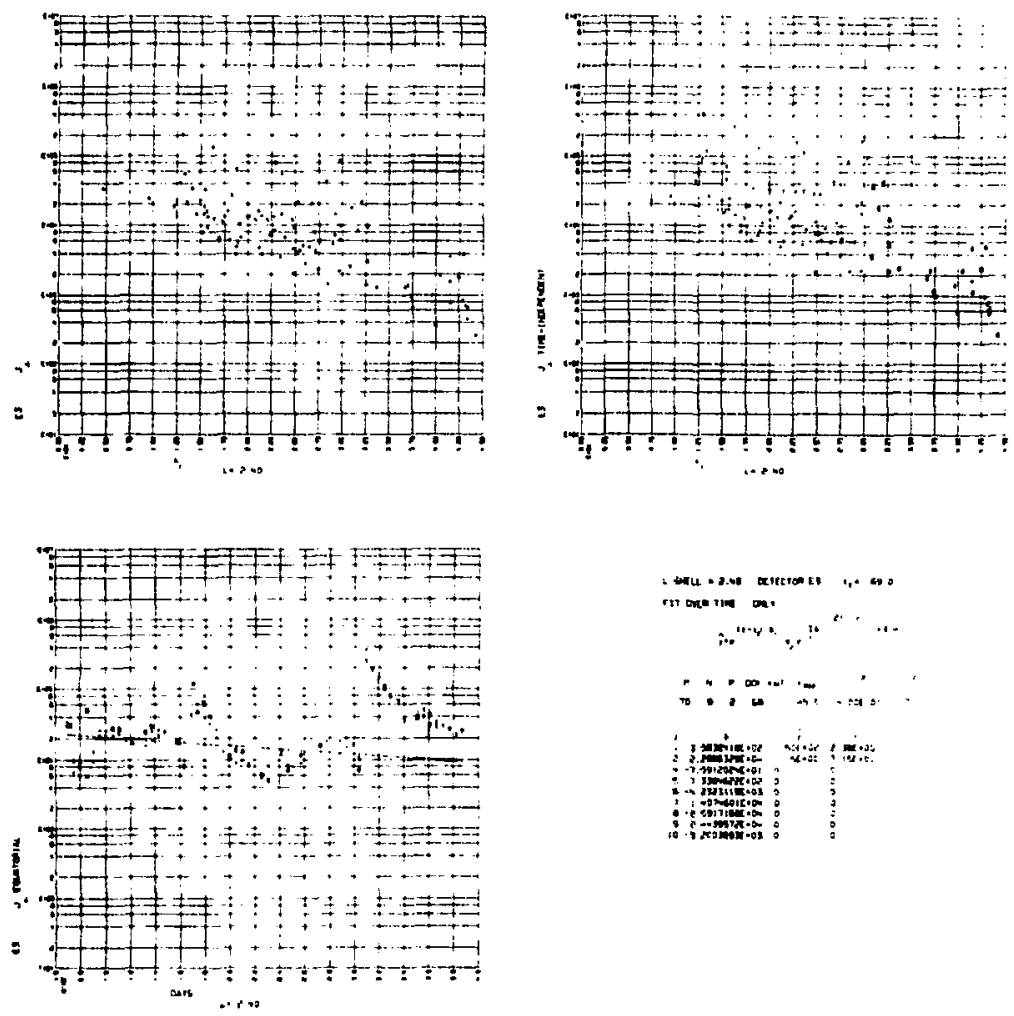

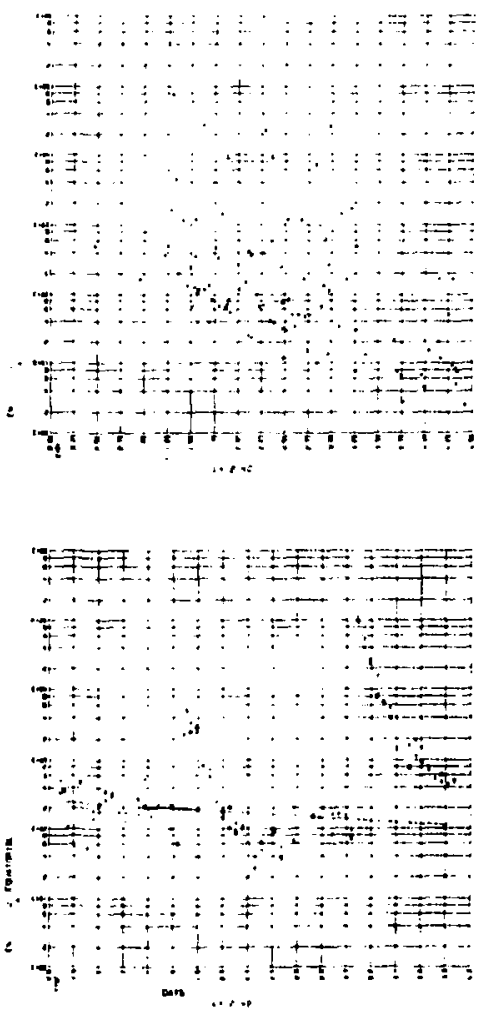
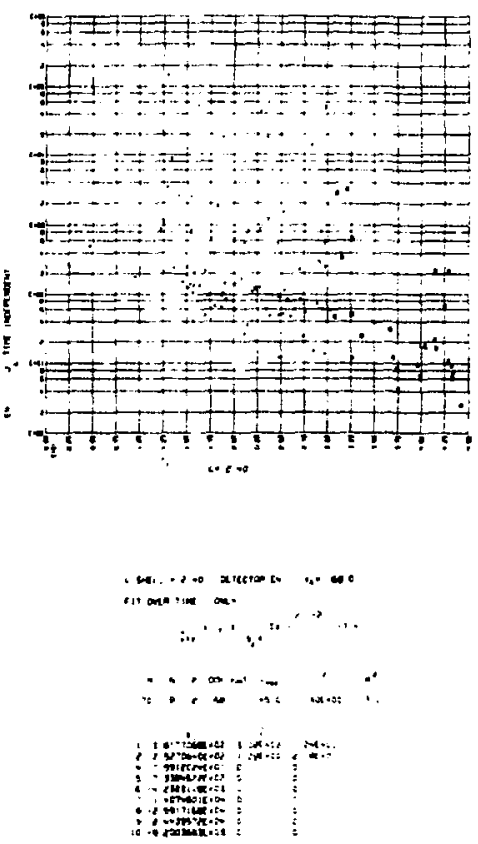

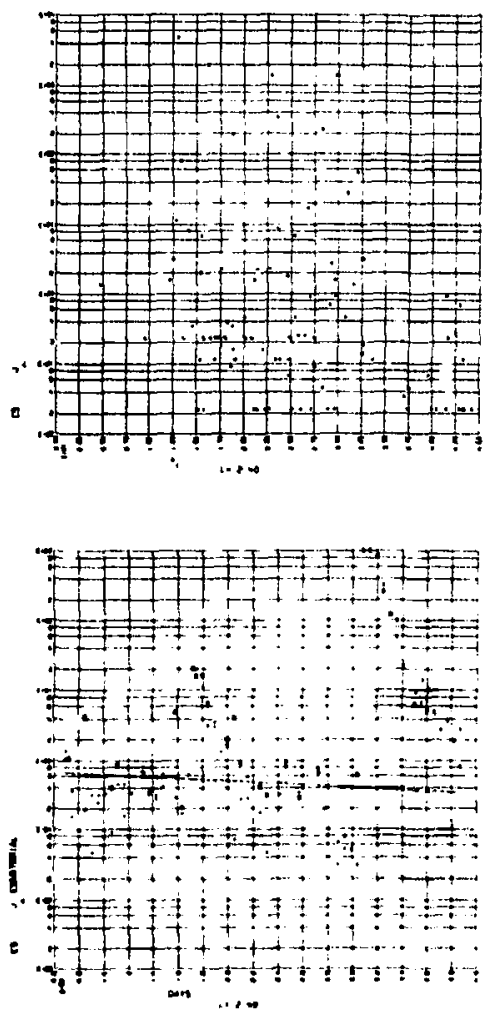
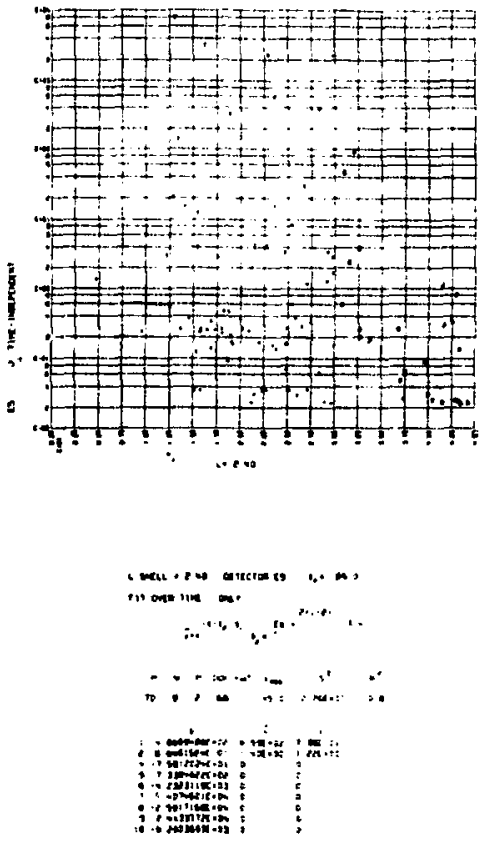


\section{References}

1. G. Pizzella, C. F. Me Iwain, and J. A. Van Allen, "Time Variationg of Intensity in the Earh's Radiation Zone, October 1959 through December 1960," J. Geopbys. Res. 67, 1235 (1962).

2. G. Pizzella, C, D. Laughlin, and B. J. Obrien, "Note on the Electron Energy Spectrum in the Inner Van Allen Belt," J. Geophys. Rev. 67, 3281 (1962).

3. C. Pizzella, "On the Inner Van Allen Zone of the Farth, "Nuovo Cimento 19, 867 (1963).

4. W. L. Brown, W. N. Hess, and J. A. Van Allen, "Collected Papers on the Arificial Radiation Belt from July 9. 1962, Nuclear Detonation," J. Geophys. Res. 68, 605 (1963).

5. D. S. Beall, C. O. Bostrom, and D. J. Williams. "Structure and Decay of the Starfish Hadiation Belt, October 1963 to December 1965," J. Geophys. Res. 72. $3403(1967)$.

6. C. O. Bostrom, 1), S. Beali, and J. C. Armstrong, "Time Higtory of the Inner Radiation Zone, Oetober 1863 to December 1968," J. Geophys. Res. 75. 1246 (1970).

7. K. A. Pfitzer, S. Kane, and J. R. Winkler, "The Spectra and Intensity of Electrons in the Radiation Belts," Space Res. 6. 702 (1966).

8. K. A. Pfitzer. An Experimental Study of Electron Fluxes from 50 ke V to 4 MeV in the Inner Radiation Belt. Univ. of Mlinnesota School of Phys. Astron. Tech. Rept. CK-123 (August 106B)

9. K. 1. Pfitzer and J. R. Winkler. "Expe rimental Observation of a Large Addition to the Electron Inner Radiation Belt atter a Solar Flare Event," J. Geophys. Res. ⒊ 5792 (1968).

10. 1. H. Winkler, The Origin and Distribution of Enerretic Electrons in the Van allen fiadlation Belts. Particles and Flelds in the Marnetosphere, B. M. McCormac, Ed. (D. Reidel Publishing Co., Boston, 1069) p. 332.

11. H. 1. West, ir. and It. M. Buck, Enerpetic Electrons in the Inner Belt in 106B. In preparation.

12. II. I, West, Ir., J, H, W'ujeck, J, II. McQuaid, N, C. Jensen, R. G. D'Arey, Jr.. H. W. HII and R. M. Bogdanowlcz, The LRL Electron and Proton Spectrometer on NASA's Orbitlar Ceophxical Observatory $V_{(E)}$, Lawrence Livermore Laboratory, Hept. VCRL-50572 (1469).

13. N. R. Draper and II. Smith, Applied Rerression Anulygis, IJohn Wiley and Sons, New York. 1906).

14. H. von Holdt, Minimize Linear Hegiduale, Law rence Livermore Laboratory. CIC Heport Fy-001 (1968). wint

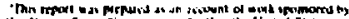

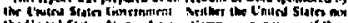

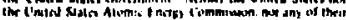

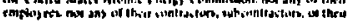

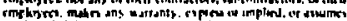

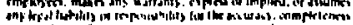

